\title{
SÉRGIO BASSI
}

\section{OTIMIZAÇÃO DO USO DE RECURSOS CRÍTICOS NO DESENVOLVIMENTO DE CAMPOS DE PETRÓLEO OFFSHORE}

\author{
(versão corrigida)
}

Dissertação apresentada à Escola Politécnica da Universidade de São Paulo para obtenção do título de Mestre em Ciências 


\title{
SÉRGIO BASSI
}

\section{OTIMIZAÇÃO DO USO DE RECURSOS CRÍTICOS NO DESENVOLVIMENTO DE CAMPOS DE PETRÓLEO OFFSHORE}

\author{
(versão corrigida)
}
Dissertação apresentada à Escola Politécnica da Universidade de São Paulo para obtenção do título de Mestre em Ciências
Área de Concentração: Engenharia de Produção.

Orientadora: Prof ${ }^{a}$ Dra. Débora Pretti Ronconi 
Este exemplar foi revisado e alterado em relação à versão original, sob responsabilidade única do autor e com a anuência de seu orientador.

São Paulo, de de 20

Assinatura do autor

Assinatura do orientador

Catalogação-na-publicação

Bassi, Sérgio

Otimização do uso de recursos críticos no desenvolvimento de campos de petróleo offshore / S. Bassi - versão corr. -- São Paulo, 2018. $117 \mathrm{p}$.

Dissertação (Mestrado) - Escola Politécnica da Universidade de São Paulo. Departamento de Engenharia de Produção.

1.Pesquisa operacional 2.Roteirização 3 .Indústria petrolífera I.Universidade de São Paulo. Escola Politécnica. Departamento de Engenharia de Produção II.t. 
Dedico esta dissertação a meus pais, amigos, colegas de trabalho, companheiros da pósgraduação e a todos aqueles que acreditaram no sucesso desta empreitada. 


\section{AGRADECIMENTOS}

Primeiramente, agradeço a Deus por ter me permitido chegar até este momento. Tenho convicção de que Ele me trouxe até aqui e me deu o potencial e a resiliência necessários.

Agradeço aos meus pais pelo suporte, compreensão e dedicação. Por terem me apoiado e, acima de tudo, por terem me contrariado. Cada passo, cada atitude, foi fundamental para o meu crescimento, minha contínua formação e pelo atingimento deste objetivo. Tudo que passamos moldou meu perfil e hoje eu entendo que este seja meu grande trunfo.

Agradeço o apoio de minha família e de meus amigos mais próximos, que entenderam meus momentos de ausência. Foi um período de muitas atividades - não somente acadêmicas - e de altos e baixos emocionais. Cito, especialmente, Amanda Lemos, João Elton, Carlos Silvestre, Joselma Oliveira, Sergio Shiroma, Julio Takeda, Bárbara Tarrataca, Bruno Franco, Fernanda Festucci, Carla Festucci, Luccas Ângelo e Melanie Ângelo por tanto me ouvirem e me acompanharem nestes desafios e mudanças que ocorreram nestes anos.

Registro também toda minha gratidão à professora Débora Pretti Ronconi, que além de ser a orientadora deste trabalho, teve especial atenção e respeito pelos momentos em que eu estava com maiores picos de atividades profissionais. Por ter me motivado nos momentos em que eu estava mais que exausto. Por ter compartilhado sua sabedoria, experiência e conhecimento de mundo. Por ter tido sensibilidade e zelo suficientes para comigo.

Relembro também meus companheiros de pós-graduação: Raquel Buzogany, João Manguino, Hanna Pamplona, Augusto Molke, Bruna Carvalho, Fernanda Barreto e Victoria Mutran. A dedicação de vocês é um exemplo para mim. Vocês são gigantes. E seres humanos muito bons. Obrigado por confiarem em mim quando eu achava que não ia dar conta.

Gosto das palavras, mas chega-se a um ponto em que não é possível mais traduzir tudo o que sentimos ou queremos nelas. Então, resumo-me ao meu "muito obrigado"! 
"As pessoas atualmente pensam que os cientistas existem para instruí-las, e os poetas, músicos, etc., para lhes dar prazer. A ideia de que estes últimos têm alguma coisa para ensinar-lhes isso não lhes ocorre."

(Ludwig Wittgenstein) 


\section{RESUMO}

O presente trabalho aborda a questão da interligação de poços de petróleo às plataformas de produção com a utilização de embarcações do tipo Pipe Laying Support Vessels (PLSVs). O objetivo do estudo é a maximização da curva de produção de óleo no período analisado, o que passa pelo melhor aproveitamento da frota de PLSVs contratada. São consideradas as especificidades da situação como, por exemplo, as restrições técnicas de cada embarcação para as atividades necessárias, a disponibilidade dos PLSVs, materiais para interligação e a já ocorrência da fase precedente, denominada completação. Considerando todo este conjunto de características do problema, desenvolveu-se uma formulação de Programação Linear Inteira Mista com pontos inovadores em relação à literatura, especialmente no que diz respeito ao incremento da curva de produção por conta da operação de poços injetores e ao declínio natural de poços produtores com o passar do tempo. Como os resultados obtidos nos testes da formulação matemática mostraramse satisfatórios para pequenas instâncias, mas de alta complexidade computacional para um número grande de atividades, foram elaboradas duas versões de uma heurística construtiva adequada para a resolução de problemas de maior porte. Levando em consideração as mesmas características do

problema que foram usadas na etapa de formulação matemática, puderam ser elaborados os algoritmos e suas devidas programações computacionais. A partir disso, foram realizados testes de pequeno porte para verificar a robustez dos algoritmos quanto aos seus comportamentos. Por fim, houve a comparação do caso completo, onde foram aplicadas as heurísticas, com o que ocorreu na situação real, tendo o resultado deste presente estudo apresentado um relevante ganho.

Palavras-chave: Pesquisa Operacional. Roteirização. Indústria Petrolífera. 


\begin{abstract}
This research presents a real case of connection of oil wells in subsea environment to the production platforms with the use of ships of the type PLSV - Pipe Laying Support Vessels. The objective of this study is to maximize the oil production curve in the horizon considered, which is due to the best exploitation of the outsourced fleet. Specificities of the situation are considered like, for example, technical constraints of each vessel for the required activities, the availability of the PLSVs, materials for connection and the end of the previous phase, called completion. Considering all this set of the problem characteristics, it was developed a Mixed-Integer Linear Programming (MILP) formulation with innovative aspects in relation to the literature, especially with respect to the increase of the production curve due to the operation of injector wells and to the natural decline of producer wells during their operation, in the course of time. As the results obtained in the tests of the mathematical formulation were satisfactory for small instances, but with a high computational time for a great number of activities, two suitable constructive heuristics were elaborated for the resolution of larger problems. Numerical experiments were conducted, in small scale, to verify the robustness of the algorithms. Next, the proposed methods were applied to a real case of an oil company and relevant gains were observed.
\end{abstract}

Keywords: Operations Research. Routing Problem. Oil industry. 


\section{ÍNDICE DE ILUSTRAÇÕES}

Figura 1 - Produção de petróleo no Brasil no horizonte 2004-2016 (ANP, 2017)........................ 16

Figura 2 - Etapas para obtenção da produção de petróleo ............................................................. 18

Figura 3 - Declínio natural e efeito da entrada de poço injetor no volume de produção de um poço

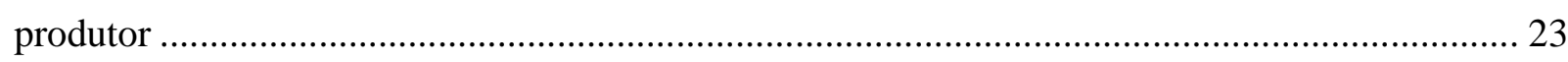

Figura 4 - Exemplo de gráfico de Gantt para o problema em questão .......................................... 25

Figura 5 - Esquema do problema piloto para teste da formulação matemática............................. 51

Figura 6 - Gráfico de Gantt com visão recursos e atividades para caso piloto............................... 55

Figura 7 - Gráfico de Gantt com visão recursos e atividades para caso piloto com acréscimo de

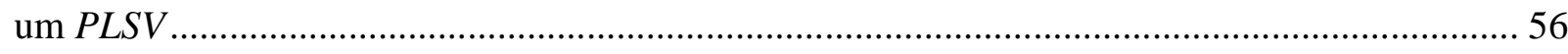

Figura 8 - Gráfico de Gantt com visão recursos para caso piloto com redução de um PLSV ...... 56 Figura 9 - Esquema de localização dos poços e UEPs para os testes computacionais ampliados 58 Figura 10 - Tempo de processamento versus o número de roteiros por embarcação, por cenário de PLSVS 61

Figura 11 - Tempo de processamento versus valor da função objetivo em cenários de igual quantidade total de roteiros.

Figura 12 - Número de nós restantes versus o número da iteração na resolução dos casos de multiplicação RB constante apresentados

Figura 13 - Detalhe do número de nós restantes versus o número da iteração para o caso de 6 PLSVS

Figura 14 - Pseudocódigo da heurística construtiva 1 70

Figura 15 - Recorte do gráfico de Gantt com o detalhe dos cenários de 4 PLSVs da instância I do

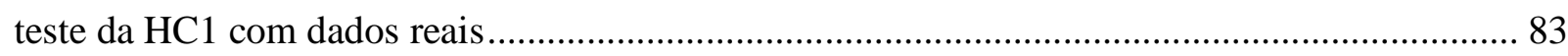

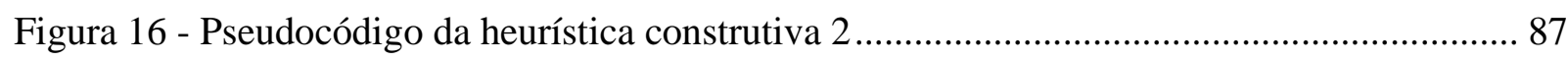

Figura 17 - Recorte do gráfico de Gantt com o detalhe dos cenários de 4 PLSVs da instância I do

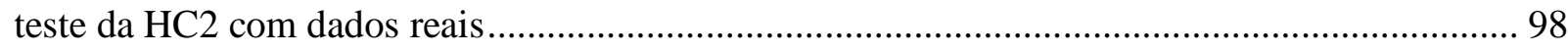

Figura 18 - Perfil de entrada em operação de poços produtores (Realizado x HC1) ................... 105

Figura 19 - Perfil de entrada em operação de poços injetores (Realizado x HC1)...................... 106 Figura 20 - Perfil acumulado de entrada em operação de poços produtores (Realizado x HC1 x $\mathrm{HC} 2)$ 108 
Figura 21 - Perfil acumulado de entrada em operação de poços injetores (Realizado x HC1 x $\mathrm{HC} 2)$

Figura 22 - Perfil acumulado de curva de produção, por período avaliado (Realizado x HC1 x $\mathrm{HC} 2)$ 


\section{ÍNDICE DE TABELAS}

Tabela 1 - Possíveis dimensões e características de problemas de roteirização de veículos

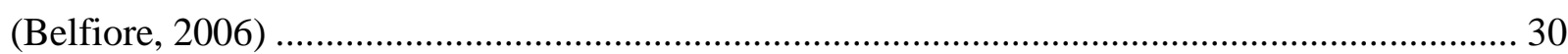

Tabela 2 - Tempos de translado entre as atividades (em dias) .................................................. 52

Tabela 3 - Parâmetros de entrada para caso piloto ..................................................................... 52

Tabela 4 - Índices das variáveis Xijrb positivas na solução ótima ............................................... 53

Tabela 5 - Dados de saída de tempo e ordem de atendimento, por roteiro-embarcação ................ 54

Tabela 6 - Quantidade de dutos e tempos de carregamento para caso piloto ................................. 55

Tabela 7 - Quadro resumo dos casos piloto para teste da formulação matemática....................... 57

Tabela 8 - Insumos para os testes computacionais ampliados.................................................... 57

Tabela 9 - Testes computacionais realizados utilizando o modelo proposto ................................. 59

Tabela 10 - Número total de iterações versus número de nós analisados .................................... 66

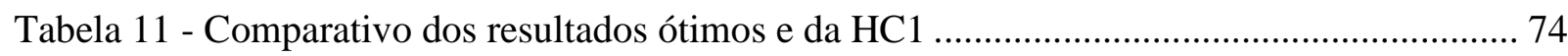

Tabela 12 - Resultados de potencial de produção nos testes da $\mathrm{HC} 1$ com dados reais................. 78

Tabela 13 - Resultados normalizados dos testes da $\mathrm{HC} 1$ com dados reais ................................. 80

Tabela 14 - Detalhe dos resultados dos cenários de 4 PLSVs da instância I dos testes da HC1 com

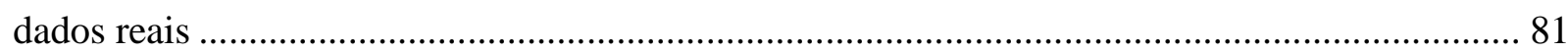

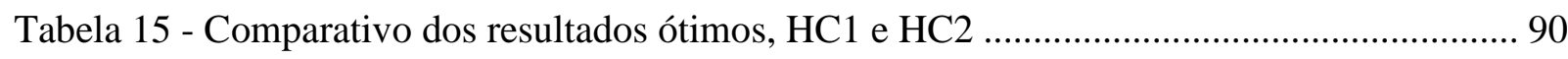

Tabela 16 - Resultados de potencial de produção nos testes da HC2 com dados reais................. 92

Tabela 17 - Resultados normalizados dos testes da HC2 com dados reais ................................. 94

Tabela 18 - Evolução percentual dos volumes de produção entre HC2 e HC1 nas instâncias com

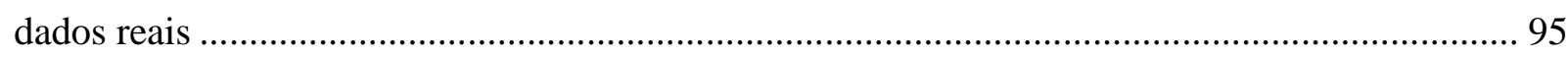

Tabela 19 - Detalhe dos resultados dos cenários de 4 PLSVs da instância I dos testes da HC2 com

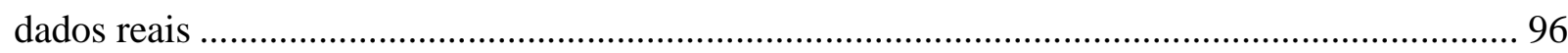

Tabela 20 - Modelo de dados de realização das atividades com PLSVs ................................... 101

Tabela 21 - Número de $P L S V s$, por categoria, a serem utilizados na heurística construtiva ...... 103

Tabela 22 - Tabela de diferenças de datas de entrada dos poços - HC1 X Caso real .................. 104

Tabela 23 - Tabela de diferenças de volume produzido - HC1 X Caso real .............................. 105

Tabela 24 - Tabela de diferenças de datas de entrada dos poços - HC2 X Caso real ................. 107

Tabela 25 - Tabela de diferenças de datas de volume produzido - HC2 X Caso real ................. 107 


\section{LISTA DE SIGLAS}

ANP - Agência Nacional do Petróleo, Gás Natural e Biocombustíveis

CVD - Conexão Vertical Direta

DP - Desenvolvimento da Produção

IBAMA - Instituto Brasileiro do Meio Ambiente e dos Recursos Naturais Renováveis FSMVRPMT - Fleet Size and Mix Vehicle Routing Problem with Multiple Trips FSMVRPTW - Fleet Size and Mix Vehicle Routing Problem with Time Windows

GRASP - Greedy Randomized Adaptive Search Procedure

HC1 - Heurística Construtiva 1

HC2 - Heurística Construtiva 2

MTVRP - Multiple Trip Vehicle Routing Problem

MTVRPTW - Multiple Trip Vehicle Routing Problem with Time Windows

PEM - Plano Exploratório Mínimo

PLIM - Programação Linear Inteira Mista

PLSV - Pipe Laying Support Vessels

PRV - Problema de Roteamento de Veículos

TSP - Traveling-Salesman Problem

UEH - Umbilical Eletro-Hidráulico

UEP - Unidade Estacionária de Produção

VPL - Valor Presente Líquido

VRP - Vehicle Routing Problem 


\section{SUMÁRIO}

1. Introdução..........................................................................................................................................13

2. Definição do objeto de estudo e caracterização do problema ............................................16

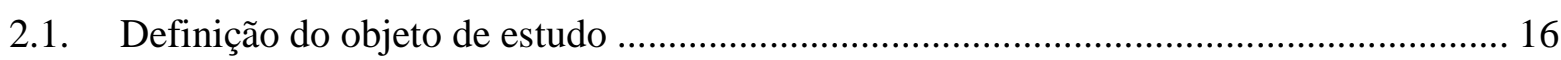

2.2. Conceitos fundamentais de projetos petrolíferos ........................................................ 18

2.3. Enunciado da problemática, relevância e metodologia............................................... 20

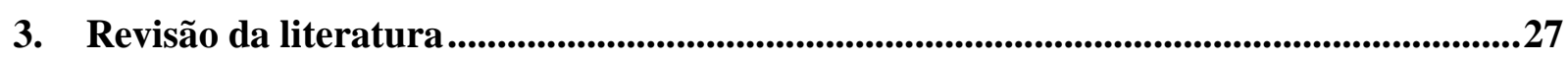

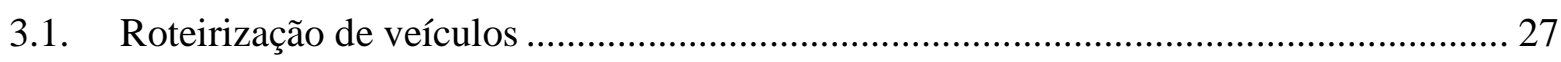

3.2. Roteirização de veículos com frota heterogênea .................................................... 31

3.3. Múltiplos roteiros por embarcação …................................................................... 32

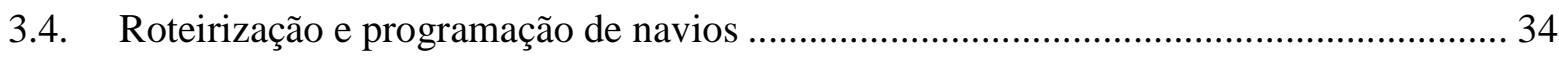

3.5. Programação de atividades em projetos petrolíferos .................................................. 36

4. Formulação matemática ....................................................................................................................41

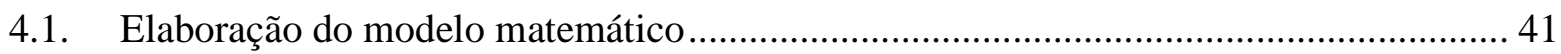

4.2. Caso-piloto para a formulação matemática ............................................................ 51

5. Elaboração das heurísticas construtivas ...................................................................67

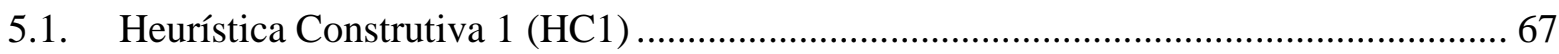

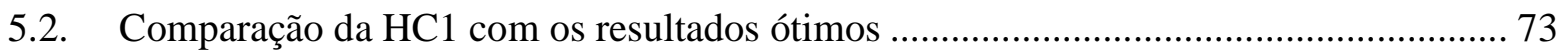

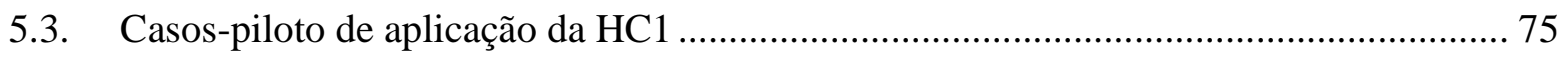

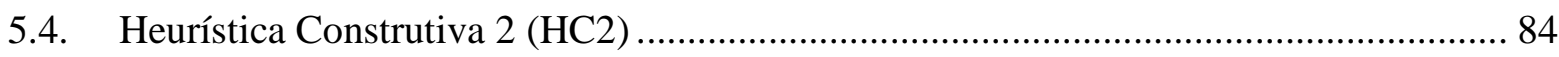

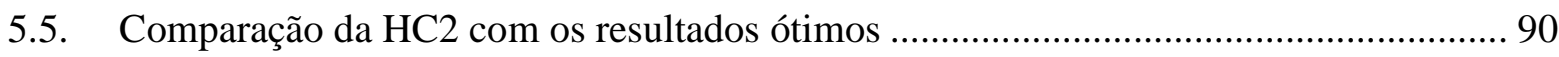

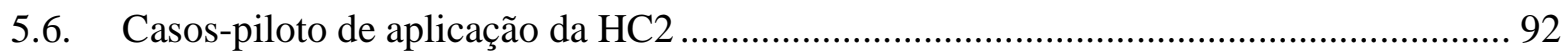

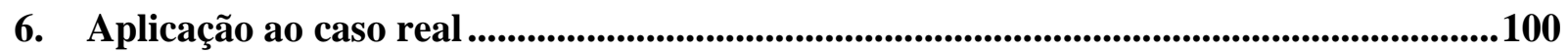

6.1. Aplicação das heurísticas construtivas ao conjunto completo de dados........................ 100 


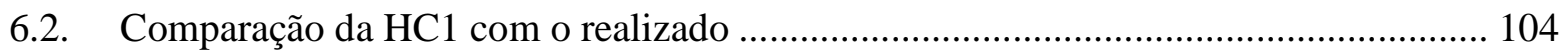

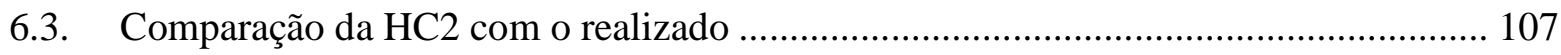

7. Conclusões e futuras pesquisas ......................................................................................................112

8. Referências Bibliográficas .................................................................................................114 


\section{Introdução}

Segundo o Anuário Estatístico Brasileiro do Petróleo, Gás Natural e Biocombustíveis de 2017, divulgado pela ANP (Agência Nacional do Petróleo, Gás Natural e Biocombustíveis), a indústria do petróleo brasileira tem, cada vez mais, ampliado suas operações em alto-mar (offshore) - com aumento de reservas de petróleo provadas e volume de produção de óleo e gás -, lançandose para descobertas e produção em águas cada vez mais profundas.

As atividades realizadas em ambiente marítimo são de alto risco e complexidade tecnológica, exigindo a utilização de embarcações específicas para as operações de construção de poços submarinos (as chamadas sondas, que são utilizadas para as atividades de perfuração e completação dos poços submarinos) e conexão destes poços às plataformas de produção (realizadas pelos barcos chamados PLSV - Pipe Laying Support Vessels), como aborda Bianco et al. (2014). Estas embarcações existem em número limitado, o que exige uma gestão eficiente destes recursos que são contratados de terceiros. Estes recursos são críticos para uma companhia deste ramo empresarial não somente pelo seu alto custo, mas também porque a priorização de um determinado poço implica na postergação de outros.

O crescimento da carteira de projetos de uma empresa deste setor e, consequentemente, do número de poços a serem perfurados e interligados às unidades de produção faz com que haja uma priorização dos mesmos e, assim, uma complexa programação de curto e longo prazo é necessária. Como as atividades também possuem alto grau de imprevisibilidade devido a condições de mar e datas de entrega de materiais ou equipamentos atrelados, é necessária uma revisão frequente nesta programação que, por ora, é feita sem o apoio de uma metodologia formal.

Há outros recursos - não somente estas embarcações - que também são considerados críticos pela companhia: ANM (árvore de natal molhada, que é um conjunto de válvulas de segurança para evitar derramamentos de fluido dos poços), linhas flexíveis (para interligação dos poços à unidade de produção, levando o fluido do fundo do mar para a superfície), a UEP (unidade estacionária de produção, conhecida normalmente como plataforma de produção), dentre outros itens que Neves et al. (2012) apresentam em seu trabalho. Será incluída a disponibilidade de alguns destes recursos nesta problemática como restrições, dado que eles afetam o momento em que os 
PLSVs podem começar a atuar, pois são ferramentas necessárias (pré-requisitos) para o acontecimento das operações em alto-mar.

A não-concomitância de embarcações para a realização de tarefas em um mesmo poço, a viabilidade técnica na realização de determinada atividade de interligação e o cuidado na formação dos roteiros - isto é, o conjunto de linhas que serão embarcadas nos PLSVs de uma só vez, na base de carregamento - são outros pontos de destaque no trabalho. As questões de declínio da produção dos poços em operação e influência dos poços injetores sobre a produção dos mesmos são diferenciais com relação ao que se pode verificar na literatura.

Tendo em vista todas estas questões levantadas, o objetivo deste trabalho é estabelecer um procedimento que visa maximizar a curva de produção de óleo da companhia durante determinado horizonte de tempo. E para que este objetivo seja alcançado atendendo às restrições do problema, é necessário que a utilização da frota de PLSVs seja a melhor possível. Como as diárias destas embarcações são de valor elevado, é importante que os navios sejam utilizados da melhor forma possível, reduzindo sua ociosidade e organizando-os de modo a aumentar o resultado de produção.

O trabalho está estruturado em 8 capítulos. O primeiro consiste nesta introdução, que contextualiza o cenário de atuação da empresa e traz as linhas gerais daquilo que se propõe estudar. Já o Capítulo 2 versa sobre a definição de objetivos e caracterização do problema, no qual se discorrerá sobre conceitos do ramo e de projetos petrolíferos e informações gerais sobre o fornecimento de matérias-primas levando, assim, à enunciação do problema, sua relevância, bem como são apresentados breve metodologia, características e restrições do problema.

O Capítulo 3 aborda a revisão da literatura, focando em cada um dos tópicos que compõem o problema. Com a observação detalhada daquilo que já foi estudado, pode-se obter melhor compreensão do que pode ser utilizado como ponto de partida para elaboração do modelo desejado e quais são os principais diferenciais e contribuições do atual trabalho.

O Capítulo 4 traz a formulação matemática do problema, abordando todas as características e restrições da situação real. Cada conjunto de restrições e função objetivo são explicadas, bem como os resultados dos testes realizados por meio da programação em software apropriado. Para maiores instâncias, foram elaboradas duas heurísticas construtivas, as quais são tema do Capítulo 5. Nele serão abordadas as lógicas de construção, os algoritmos, os testes para verificar o 
comportamento das mesmas, bem como os resultados obtidos em versões simplificadas. O Capítulo 6 traz os resultados quando efetuado o comparativo do resultado de ambas heurísticas com o cenário real.

O Capítulo 7 apresenta as conclusões do trabalho e sugestões de futuras pesquisas relacionadas. Finalizando, o Capítulo 8 trata das referências bibliográficas utilizadas neste trabalho. 


\section{Definição do objeto de estudo e caracterização do problema}

\subsection{Definição do objeto de estudo}

A indústria do petróleo tem apresentado crescimento expressivo no Brasil desde a última década, especialmente com importantes descobertas de acumulações de óleo na camada Pré-Sal, em águas ultra-profundas (em lâminas d'água acima de 2000 metros de profundidade). São 12,0 bilhões de barris de reservas provadas marítimas no país, sendo que a produção no mar em 2016 foi de cerca de 864 milhões de barris de petróleo (ANP, 2017). A Figura 1 apresenta a evolução da produção de petróleo no Brasil entre os anos de 2004 e 2016.

Figura 1 - Produção de petróleo no Brasil no horizonte 2004-2016 (ANP, 2017)

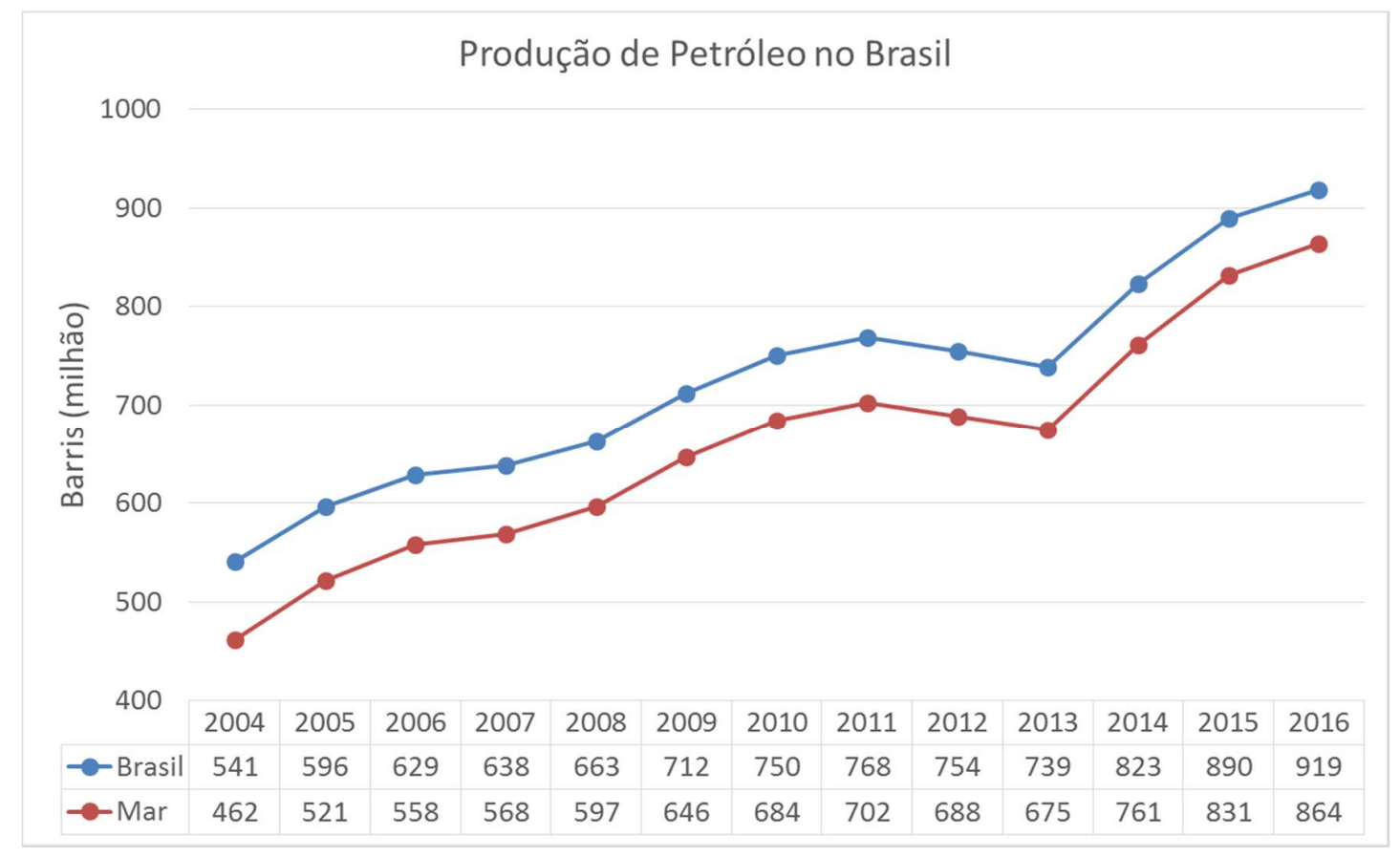

O ramo petrolífero, especialmente o submarino, é caracterizado por incertezas desde a análise do volume de óleo ou gás no campo, na fase exploratória, valendo-se de técnicas de geologia e geofísica, passando pela construção de poços marítimos - definições de trajetória, comprimento, diâmetro, localização - e condições de escoamento - características de pressão, 
permeabilidade, viscosidade - destes hidrocarbonetos até a superfície, chegando à plataforma de produção. Amostragens e informações destas jazidas são escassas e os resultados são sujeitos a variabilidades.

O desenvolvimento de tecnologias que propiciem a exploração destas novas acumulações tem sido um enorme desafio para a indústria brasileira, que tem se capacitado cada vez mais para atender prontamente as necessidades dos novos projetos destinados a cada uma das áreas a serem desenvolvidas (BNDES, 2012).

Por serem itens de alta complexidade e que operam em severas condições, os mesmos possuem elevados custos e alto lead time de fabricação (Neves et al., 2012) e, portanto, exigem uma alta dose de planejamento antecipado para contar com estes itens a tempo. E como, por ora, as indústrias nacional e internacional não possuem estrutura suficiente para entregar toda a demanda, isto configura uma forte restrição à elaboração antecipada dos projetos.

Sendo assim, por esta visão inicial, pode-se notar que é uma situação complexa e dependente de inúmeros atores, repleta de imprevisibilidades no qual decisões errôneas referentes à aplicação de recursos físicos levam a perdas consideráveis.

O objeto de estudo deste trabalho é o estabelecimento uma sistemática que otimize a utilização dos recursos físicos de uma companhia petrolífera, em vista da maximização da curva de produção de óleo, o que leva a um melhor resultado econômico para a empresa. Os principais recursos que serão considerados são as embarcações do tipo $P L S V$, responsáveis pelos lançamentos de dutos flexíveis e umbilicais eletro-hidráulicos (UEH) de controle entre as plataformas de produção e os poços produtores e injetores de fluidos em alto-mar. Através da roteirização destas embarcações, de frota heterogênea, sujeitas a restrições específicas, buscar-se-á a redução da ociosidade por questões de espera e alocação das atividades ao longo do tempo para cada barco. 


\subsection{Conceitos fundamentais de projetos petrolíferos}

Para melhor esclarecimento, faz-se necessário apresentar as principais fases de um projeto de produção de petróleo, com base no modelo de contrato de concessão (ANP, 2014). A Figura 2 apresenta as seguintes etapas:

a) Fase exploratória: caracterizada, principalmente, pelo Programa Exploratório Mínimo (PEM), no qual a ANP acorda com a empresa ganhadora da licitação quais são as atividades essenciais - sobretudo de geologia e geofísica - a serem realizadas naquele determinado bloco concedido;

b) Avaliação: caso durante o PEM, a companhia tenha indícios que a leve a se interessar por estudos mais profundos, ela deve gerar o Plano de Avaliação da Descoberta para áreas que devem ser retidas;

c) Declaração de comercialidade: realizada após a avaliação inicial, na qual concluiu-se que o campo é economicamente viável e que, a partir dali, será realizado um projeto abrangente para obtenção do petróleo acumulado, iniciando a fase de desenvolvimento da produção. Na prática, a declaração de comercialidade é um marco e não uma etapa;

d) Desenvolvimento da produção: nesta fase é traçada a estratégia de explotação (extração de recurso natural) do campo através da elaboração de um projeto atrelado a um Plano de Desenvolvimento entregue à ANP, que acompanha as ações do operador do campo;

e) Manutenção da Produção: fase que compreende a produção em si, a operação das plataformas de acordo com as medições e controles da ANP.

Figura 2 - Etapas para obtenção da produção de petróleo

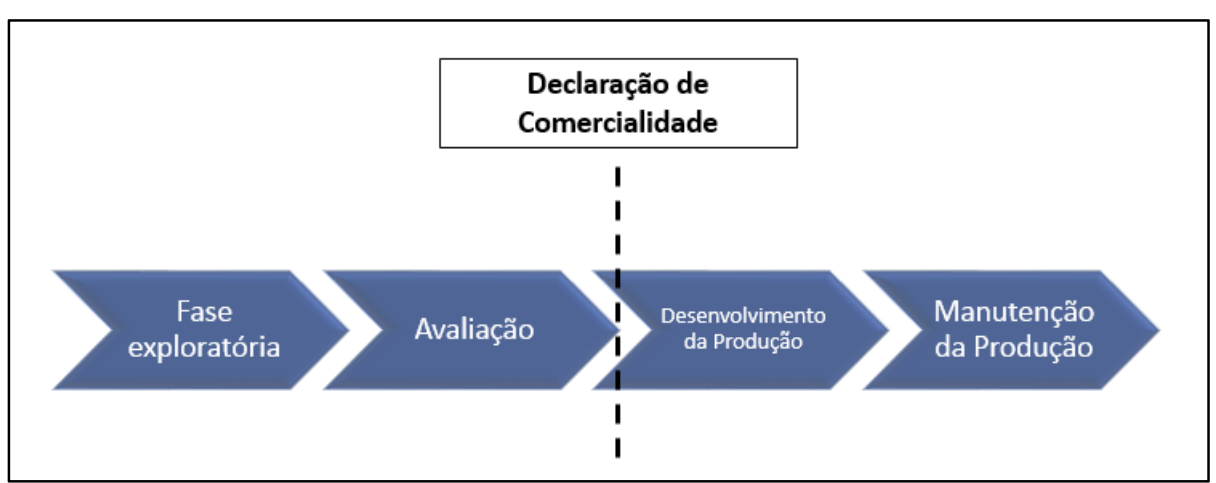


Ter-se-á como foco a fase que despende mais recursos da companhia e na qual verifica-se o maior número de atividades em alto-mar: a fase de desenvolvimento da produção (DP). Um sistema de produção marítimo de um típico projeto de DP de um campo de petróleo é composto por 3 itens: uma unidade estacionária de produção (UEP, conhecida também por plataforma de produção), uma série de poços (produtores ou injetores de fluidos) e equipamentos responsáveis utilizados para interligar estes dois primeiros itens (Neves et al., 2012).

Explicando sucintamente a estrutura de um projeto de desenvolvimento da produção, serão abordadas as equipes técnicas que compõem um projeto e será traçado um resumo das atividades físicas realizadas.

As equipes técnicas principais de um projeto de petróleo offshore são:

- Engenharia de Reservatórios: o principal motivo de um projeto de explotação de petróleo é obter o óleo que se encontra a quilômetros de distância da superfície marítima. A engenharia de reservatórios é a responsável por, a partir dos dados coletados pela geologia e geofísica nas sísmicas exploratórias e avaliações de poços, gerar um modelo de simulação que represente as condições físicas e contemple a localização daquele determinado volume de óleo a ser extraído. É responsável por definir onde, quantos e de que tipo serão os poços;

- Engenharia de Poço: a partir dos resultados de reservatório, a engenharia de poço estuda qual a melhor forma de se construir um poço de petróleo, isto é, qual o melhor caminho que ligue o leito marinho até o reservatório físico onde se encontra o óleo. Importante que a construção contemple o contato com a maior área possível do reservatório e que seja feita de modo seguro, com a quantidade de fases ideal. São duas as principais fases da construção de um poço: perfuração, na qual se fura e reveste cada uma das fases, cada vez mais profundas; e a completação, na qual se equipa o poço com válvulas e artefatos de segurança, deixando-o preparado para a produção;

- Engenharia Submarina/Elevação e Escoamento: responsável por estudar as melhores condições para trazer o petróleo do leito submarino até a plataforma de produção, através de dutos, no processo chamado interligação. Verificam qual é o posicionamento ideal de lançamento, diâmetro dos dutos, minimizando a perda de carga; 
- Engenharia de Construção e Montagem: responsável pelo projeto e fabricação da UEP, que receberá e realizará o processamento primário do petróleo recebido diretamente das camadas profundas.

\subsection{Enunciado da problemática, relevância e metodologia}

No caso em questão, a empresa encontra-se em um cenário na qual possui uma diversa gama de projetos de desenvolvimento da produção em elaboração, paralelamente.

Com base no discorrido no item de conceitos fundamentais, tendo como referência as atividades do poço, pode-se notar que as três etapas principais pelo qual o mesmo passa, em ordem, são: a perfuração, a completação e a interligação. Devido ao grande número de projetos e da quantidade de poços em cada um deles, ocorre que diversos poços encontram-se, simultaneamente, em alguma operação de confecção.

Neste trabalho, haverá foco, especialmente, na etapa de interligação dos poços, fase esta que precede imediatamente o início de operação dos poços, sendo realizada pelos PLSVs. Cabe, neste momento, esclarecer que a operação de interligação da linha à plataforma é denominada pullin e a interligação à ANM do poço é chamada CVD (conexão vertical direta).

De um modo geral, o processo completo de interligação consiste de três etapas:

a) carregamento do $P L S V$ com as linhas a serem lançadas posteriormente, etapa esta que ocorre em uma base de carregamento;

b) navegação até a locação do poço onde estas linhas serão efetivamente lançadas;

c) lançamento das linhas entre o poço e a UEP (ou entre UEP e poço).

Notar que o processo de carregamento pode ser realizado com linhas de mais de um poço e nem todas as linhas de um mesmo poço ficam em um mesmo lote carregado. Isto explica-se devido ao fato de a data de chegada das linhas (dutos e UEH) poder ser distinta e a capacidade de armazenamento do barco ser limitada. 
O intuito é estabelecer, mediante as premissas e restrições existentes, qual é o roteiro mais adequado a cada um dos navios, levando a um cenário otimizado da curva de produção da empresa.

Serão consideradas as seguintes premissas:

- os poços produtores têm 3 linhas a serem conectadas (dois dutos flexíveis - um de produção e outro de serviço - e mais um UEH) e os injetores podem ter 2 ou 3 linhas (a depender se injetam 1 ou 2 tipos de fluido, mais o UEH);

- a posição dos poços é fixada pela equipe de reservatórios do projeto;

- todas as linhas serão lançadas entre a cabeça do poço e a plataforma (não necessariamente neste sentido), ou seja, não havendo equipamento intermediário que funcione como hub de linhas;

- será também considerado como premissa o fato de já haver uma UEP instalada antes do efetivo lançamento das linhas;

- uma tarefa, após ser iniciada, não pode ser interrompida;

- não existe relação de precedência entre as atividades de um mesmo poço.

Os dados de entrada para o problema são:

- tempo de carregamento para cada uma das linhas a serem conectadas (em dias);

- tempo de lançamento para cada uma das linhas (em dias);

- tempo de navegação entre cada uma das locações - entre base e poço ou entre poços, no caso do roteiro ser direto entre dois poços, havendo carregamento prévio (em dias);

- produção e declínio esperados por poço, pois a produção de um poço de petróleo decai no decorrer do tempo (em barril/dia);

- comprimento das linhas a serem interligadas (em Km);

- o tipo de poço (se são injetores ou produtores) e seus potenciais de produção ou injeção;

- a relação de poços injetores e seus respectivos produtores, ou seja, a qual poço produtor cada injetor atende, aumentando o seu volume de produção.

Por sua vez, as restrições serão: 
- lâmina d'água (profundidade de atuação) e capacidade de lançamento (em toneladas), ou seja, viabilidade técnica dos PLSVs;

- capacidade de carregamento(estocagem) de cada $P L S V$;

- só pode ocorrer a interligação após o fim da completação;

- a data de chegada dos dutos e UEH à base deve preceder o carregamento para posterior lançamento das linhas;

- não poderá ocorrer concomitância de atividades em um mesmo poço, ou seja, não será possível a utilização de duas embarcações PLSV ao mesmo tempo para realização de atividades de interligação;

- tempo de comissionamento, que é o tempo necessário, após a interligação de todas as linhas de um poço, para testes antes da entrada dele em funcionamento.

Um dos pontos-chave e diferencial do estudo é a questão de declínio dos poços produtores no decorrer do tempo e o efeito da inclusão de poços injetores no passar do tempo. Um poço produtor começa a produzir com o máximo de seu volume, valor este que se chama de potencial inicial de produção e, no decorrer do tempo, tem este valor reduzido, devido ao declínio natural de produção que o reservatório possui, fato explicado pelo decréscimo de pressão das jazidas. Já os poços injetores, sejam de água ou de gás, repressurizam o reservatório, adicionando uma parcela de produção de óleo àquele campo nos próximos períodos.

Graficamente, é interessante apresentarmos, para melhor compreensão e entendimento do problema, o declínio natural de um poço produtor bem como o efeito de um poço injetor no volume de produção de seu poço produtor atrelado. Este comportamento inerente aos poços de petróleo é mostrado na Figura 3. 
Figura 3 - Declínio natural e efeito da entrada de poço injetor no volume de produção de um poço produtor

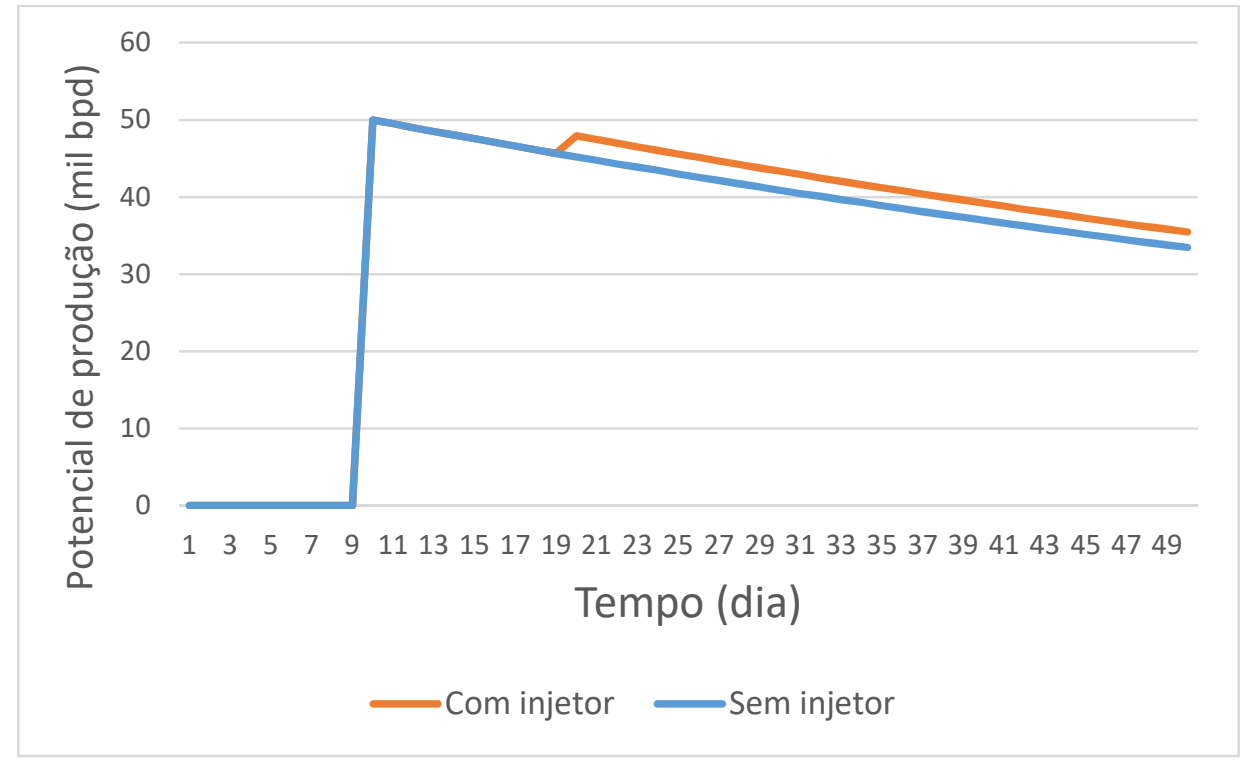

Pela Figura 3, é possível exemplificar numericamente esta questão. São considerados dois poços, um produtor e outro injetor. $\mathrm{O}$ poço produtor entra em operação no instante 10 e tem potencial de 50 mil bpd (barris por dia), o que explica a subida repentina neste instante. A partir deste instante, o poço produtor começa a declinar. O poço injetor que é atrelado a este produtor inicia sua operação no instante 20 e tem a capacidade de incrementar o atual potencial do produtor em 6\%. Sendo assim, se não houvesse poço injetor, a produção continuaria decaindo e seguiria a linha de cor azul.

Há casos em que há mais de um poço injetor atrelado a um produtor. Nestas situações, a produção é incrementada pela multiplicação cumulativa das frações adicionadas por cada poço injetor. Este aumento de produção expresso através de um percentual é uma simplificação extraída dos volumes previstos por curvas de produção geradas pelas áreas de reservatório.

Sendo assim, depara-se com uma questão altamente combinatória a qual se valerá de técnicas de pesquisa operacional para sua resolução com vistas à maximização do potencial de produção disponível. Inicialmente, será apresentada a formulação matemática do problema, com a aplicação a uma situação simplificada, com menor número de variáveis. Como é esperado que não se possa obter uma solução ótima para o problema completo, devido a sua complexidade combinatória, será utilizada, em seguida, uma heurística para obter uma solução de alta qualidade. 
Resumindo tudo que foi exposto até então, pode-se dizer que o problema em questão consiste na programação de atividades de interligação de dutos (também chamados de linhas) entre plataformas de produção e poços de petróleo situados em alto-mar, afastados até $300 \mathrm{Km}$ da costa brasileira. Existem dois tipos de poços: os produtores e os injetores. Os produtores são os responsáveis, efetivamente, pela produção de óleo e possuem a peculiaridade de ter a sua produção declinando no decorrer do tempo. O segundo tipo de poço, injetor, é responsável por repressurizar a jazida e, com isso, incrementar o volume produzido do poço produtor que esteja associado a ele.

Para que um poço entre em operação, é necessário que todos os três dutos referentes a este poço tenham sido interligados. Estes dutos, quando entregues pelos fornecedores de materiais à empresa em questão, ficam armazenados na base de carregamento, que é única, até a sua aplicação. Para que possam ser executadas tais tarefas, é necessário que já tenha sido executada uma etapa de construção do poço chamada de completação além dos materiais já terem sido entregues na base, como abordado anteriormente.

Há uma série de embarcações do tipo PLSV disponíveis para executar estas atividades. Contudo, nem todos PLSVs podem realizar todas as tarefas. Esta característica denomina-se viabilidade técnica. Denomina-se roteiro o conjunto de linhas que serão interligadas sucessivamente por um PLSV sem necessidade dele retornar à base para coletar outras linhas. Os dutos a serem carregados em cada roteiro não precisam ser de um mesmo poço nem de uma mesma plataforma. E este é um ponto interessante do problema pois a elaboração do roteiro é parte importante que definirá um pequeno percurso de interligação, caracterizando a roteirização desta embarcação. É relevante salientar que o carregamento deve ocorrer, portanto, integralmente antes de o barco navegar para as locações a serem atendidas. Outra restrição do problema é a nãoconcomitância, que vem a ser o fato de não ser possível a execução de duas ou mais atividades de um mesmo poço ao mesmo tempo.

Sendo assim, tendo em consideração os potenciais de produção e injeção, as datas de disponibilização do material e finalização da completação bem como as outras restrições (capacidade de cada barco, viabilidade técnica, não-concomitância etc.), busca-se um procedimento que resolva a situação-problema e apresente uma solução de boa qualidade em um tempo de processamento computacional adequado. Como resposta, o procedimento deve apresentar qual PLSV realizará qual atividade de interligação e apontar a partir de qual instante cada uma delas ocorrerá. 
Um exemplo de resultado esperado é aquilo que se apresenta no gráfico de Gantt da Figura 4. Os carregamentos ocorrem antes do barco saírem para realizar as interligações. Existem navegações entre a fase de carregamento e as atividades de interligação bem como entre estas atividades, exceto quando elas ocorrem no mesmo poço (ou em poços muito próximos).

Figura 4 - Exemplo de gráfico de Gantt para o problema em questão

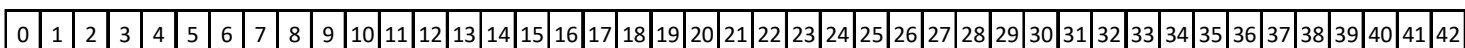

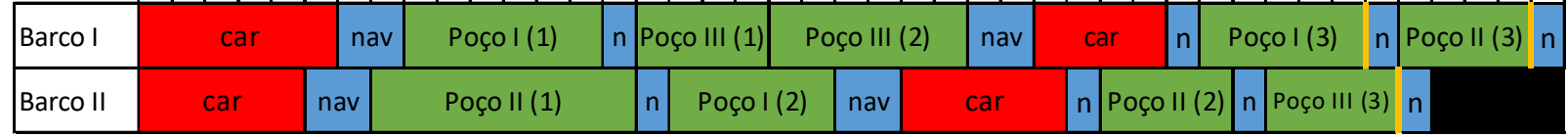

\footnotetext{
Atividade de interligação de poço

Atividade de navegação

Carregamento
}

As marcações em amarelo sinalizam o final da interligação das 3 linhas de um mesmo poço, o que indica que ele está pronto para ser comissionado (fase de testes operacionais) e entrar em operação. Pode-se observar também neste exemplo que não ocorre concomitância entre as atividades. Ou seja, não há intersecção em termos de tempo entre as atividades de um mesmo poço. Outro ponto o qual merece foco é que todo carregamento dá início a um novo roteiro.

Sendo assim, através deste resumo, espera-se realizar o esclarecimento a respeito do processo de interligação, o que colabora para melhor compreensão do conteúdo do trabalho.

\subsection{Justificativa do estudo}

$\mathrm{Na}$ indústria de exploração e produção de petróleo, os valores de investimento são muito elevados sendo, por exemplo, a diária das sondas de perfuração/completação da ordem de US\$ 500 mil (Soares e Leite, 2014) e a dos PLSVs, cerca de US\$ 350 mil (SINAVAL, 2017). Portanto, a correta programação dos barcos com a destinação às melhores locações onde se possa realizar as atividades é imprescindível para a otimização de recursos físicos e monetários.

Ainda, através do estudo, espera-se obter a ordem de interligação que maximize o resultado da empresa, gerando um procedimento computacional que aloque as atividades, automaticamente, 
segundo os critérios definidos, em um cronograma que atenda até o longo prazo pois, atualmente, este sequenciamento é feito sem uma metodologia formal.

Conforme contato com as gerências de programação de recursos críticos - a nível corporativo e das unidades de negócio (descentralizadas por região geográfica e campos produtores) - e equipes técnica e de planejamento de equipamentos submarinos, foram obtidas informações sobre a necessidade de geração de cronogramas de horizonte anual, mas também plurianual, periodicamente, para finalidade de planejamento de curto, médio e longo prazo. Isto ocorre, respectivamente, por questões predominantemente operacionais (alocação de ferramentas, detalhamento da atividade, elaboração de procedimento executivo, etc.) ou para planejamento das equipes de projeto e elaboração de plano de negócios corporativo, onde realiza-se previsão de verba de investimento e custo operacional, além da projeção de receita para os próximos anos.

Este cronograma, como é elaborado através de reuniões entre as equipes de planejamento e sem uma metodologia única, fica sujeito a não-otimizações das tarefas de interligação, podendo até possuir atividades alocadas em $P L S V s$ que não realizam as mesmas ou com durações não condizentes com a realidade, o que leva a um planejamento passível de falhas. Por não haver metodologia específica para esta previsão de interligações, a ordem do curto prazo definida em reuniões conforme expectativa que as áreas demandantes têm de que os poços fiquem prontos. Para o longo prazo, prevê-se apenas alocação ao decorrer de cada ano, sem especificar intervalos de início e fim de cada atividade separadamente.

Ademais, o processo como está onera as equipes de programação das embarcações quando há alguma decisão estratégica de portfolio que altera a ordem de entrada em operação das plataformas de produção e, com isso, modifica grande parte dos dados que alimentam o nivelamento do cronograma de PLSVs. Quando isto ocorre, são necessárias reuniões de alinhamento para que ocorra redistribuição das atividades aos barcos de acordo com as novas premissas.

Sendo assim, uma metodologia formal de análise, com base em técnicas de otimização, viria a agregar bastante no processo de planejamento destas embarcações. 


\section{Revisão da literatura}

O problema a ser tratado pode ser visto como um problema de roteirização de veículos (no caso, embarcações) com frota heterogênea, múltiplos roteiros por embarcação dentro da temática de desenvolvimento de campos petrolíferos. Roteirização, por definir o percurso de cada um dos barcos. Frota heterogênea, pois as embarcações diferem entre si em termos de capacidade de armazenamento e de lançamento de linhas. Múltiplos roteiros por conta de, no período de análise cada embarcação poder voltar à base de carregamento (depósito) para iniciar um novo roteiro, após ter abastecido com os materiais necessários para as atividades deste novo percurso. Isto caracteriza um problema do tipo MVRPMT (Mix Vehicle Routing Problem with Multiple Trips).

Segundo Brejon e Belfiore (2006), um dos complicadores de se modelar e resolver um problema de roteamento advém da grande quantidade de parâmetros que pode influenciar cada caso deste. Sendo assim, a adequada classificação dos problemas permite uma melhor compreensão dos aspectos relevantes, para os quais deve-se dar maior atenção, dado que o tipo de problema e seus parâmetros auxiliam no direcionamento da estratégia a ser adotada.

Nos próximos tópicos, serão apresentados alguns trabalhos que já trataram destas temáticas.

\subsection{Roteirização de veículos}

O problema de roteirização de veículos (ou problema de roteamento de veículos ou, simplesmente, PRV) é amplamente abordado na literatura sendo também um dos problemas de otimização combinatória mais estudados devido a sua relevância prática e também a sua considerável dificuldade (Toth e Vigo, 2002). Com o advento do comércio globalizado, os custos logísticos tornam-se cada vez mais importantes por conta de lidar-se com diversos modais e pelos custos de transporte serem cada vez mais representativos no custo total (Ballou, 2004). E, para esta finalidade, é interessante o investimento em modelos matemáticos que auxiliem as operações, através de otimizações, sejam elas de uso das capacidades dos veículos, das rotas utilizadas, ou de ambas. 
Em seu princípio, o PRV tem como preocupação a determinação de rotas ótimas a serem utilizadas por uma frota de veículos, baseada em um ou mais depósitos para servir uma série de clientes visando à minimização do trajeto. Outras restrições - e alterações na função objetivo do problema - são adicionadas conforme as aplicações práticas (Toth e Vigo, 2002).

O problema de programação de veículos é considerado uma generalização do TSP Traveling-Salesman Problem, apresentado por Flood (1956), onde consistia na apresentação de um método eficiente para minimização das distâncias percorridas, dentre todas as permutações possíveis dos clientes a serem atendidos. Com base nas ideias originais de Flood, o PRV foi formulado, originalmente, por Dantzig e Ramser (1959) e tem como principal fator de novidade a incorporação da capacidade dos veículos dado que, em uma situação onde o veículo comportasse toda a demanda dos clientes, este problema tornaria-se o TSP. Sendo assim, o fato capacidade limitada é o que obriga o veículo a retornar ao depósito para que seja efetuado o carregamento e iniciado um novo ciclo de viagens. Os autores apresentam, ainda, algoritmos para agregação dos pontos de demanda e cita, de forma bem embrionária, o caso de demanda de diferentes produtos e veículos de capacidades distintas.

Christofides e Eilon (1969) abordam que um PRV básico consiste na programação de veículos que partam obrigatoriamente de um depósito central e atendam a clientes dispersos em uma determinada e conhecida região, conforme a demanda de cada um e a capacidade de cada veículo - também conhecidos -, de maneira a minimizar os custos despendidos nesta operação ou minimizar o tempo de percurso. Ou seja, deve ser utilizada uma metodologia, para que sejam definidos os melhores percursos para que, dentro das restrições do problema real, tenha-se a otimização desejada. As condições ressaltadas por Christofides e Eilon são:

- toda demanda dos clientes deve ser atendida;

- as capacidades dos veículos não podem ser violadas;

- o tempo ou a distância total de cada veículo não deve exceder algum limite préestabelecido (como, por exemplo, questões contratuais existentes).

Com base nisto, deve-se minimizar os custos de translado, divididos em custos da frota custos fixos - e os aqueles necessários para completar as entregas - custos variáveis. Em seguida, aborda os tipos de problemas com os quais se depara com as combinações das restrições existentes, 
bem como as principais abordagens de solução para este caso (branch-and-bound approach, the savings approach e 3-optimal tour method).

Belfiore (2006) realiza em sua obra um extenso estudo sobre os tipos de roteirização de veículos, com base nas classificações feitas por diversos autores. Com isto, explora a diversidade dos problemas da área de roteirização, culminando na apresentação de uma tabela-resumo sobre a taxonomia dos problemas desta área. Em seguida, apresenta um capítulo sobre as estratégias de resolução e complexidade computacional, apresentando métodos exatos mas bastante focado nas heurísticas utilizadas em cada um dos casos, com um quadro-resumo sobre os tipos de problema, restrições, métodos de solução e função objetivo para cada uma das referências utilizadas. São abordados desde o caso de roteirização básica (VRP - Vehicle Routing Problem) até o caso FSMVRPTW (Fleet Size and Mix Vehicle Routing Problem with Time Windows), dentre outros.

A Tabela 1, elaborada a partir dos estudos realizados por Belfiore (2006), apresenta as principais dimensões e características que podem constar em problemas de roteirização de veículos esclarecendo, assim, o vasto leque de aplicação destes estudos. 
Tabela 1 - Possíveis dimensões e características de problemas de roteirização de veículos (Belfiore, 2006)

\begin{tabular}{|c|c|}
\hline Dimensão & Características \\
\hline \multirow{4}{*}{ Função objetivo } & Minizar custos de distribuição: fixos e variáveis \\
\hline & Minimizar a distância total percorrida \\
\hline & Minimizar o número de veículos \\
\hline & Minimizar a duração total das rotas \\
\hline \multirow{3}{*}{$\begin{array}{l}\text { Restrições dos } \\
\text { veículos }\end{array}$} & Limite de capacidade em peso e volume \\
\hline & Operação de carga e descarga dos veículos \\
\hline & Limitação do número de veículos disponível de cada tipo \\
\hline \multirow{3}{*}{$\begin{array}{l}\text { Restrições junto a } \\
\text { fornecedores }\end{array}$} & Janelas de tempo \\
\hline & Atendimento parcial ou total das demandas \\
\hline & Restrição de serviço em algum dia da semana \\
\hline \multirow{4}{*}{ Variáveis de decisão } & Roteiro que cada veículo deve percorrer \\
\hline & Qual veículo deve atender cada cliente em cada viagem \\
\hline & Quantidade transportada de cada fornecedor no veículo \\
\hline & Instante do início de atendimento de cada cliente da rota \\
\hline \multirow{3}{*}{ Tipos de operação } & Coleta \\
\hline & Entrega \\
\hline & Coleta e entrega simultaneamente \\
\hline \multirow{2}{*}{ Tipo de carga } & Fracionada \\
\hline & De lotação \\
\hline \multirow{2}{*}{ Tipo de demanda } & Determinística \\
\hline & Probabilística \\
\hline \multirow{3}{*}{$\begin{array}{l}\text { Localização da } \\
\text { demanda }\end{array}$} & Localizada nos nós \\
\hline & Localizada nos arcos \\
\hline & Localizada nos nós e nos arcos \\
\hline \multirow{2}{*}{ Tamanho da frota } & Limitada \\
\hline & Ilimitada \\
\hline \multirow{2}{*}{ Tipo de frota } & Homogênea \\
\hline & Heterogênea \\
\hline \multirow{2}{*}{ Depósito de veículos } & Um único depósito \\
\hline & Vários depósitos \\
\hline \multirow{3}{*}{ Jornada de trabalho } & Duração \\
\hline & Horário de almoço e demais interrupções \\
\hline & Permissão para viagens de mais de um dia \\
\hline \multirow{3}{*}{ Outras hipóteses } & Cada veículo pode visitar cada cliente uma vez na rota \\
\hline & Cada cliente pertence a uma única rota \\
\hline & Um cliente pode pertencer a mais de uma rota \\
\hline
\end{tabular}


Outra informação importante ao se lidar com problemas de roteirização de veículos é que os mesmos possuem um caráter combinatório muito forte, sendo classificados como NP-completos (Goldbarg e Luna, 2005). Com isso, o resultado ótimo pode ser inalcançável em termos práticos.

\subsection{Roteirização de veículos com frota heterogênea}

Clarke e Wright (1964) propõem a primeira heurística de economias, como uma evolução do estudo realizado por Dantzig e Ramser (1959), adicionando ao mesmo as questões de demandas variadas nos clientes e múltiplas capacidades dos veículos para que a mesma pudesse ser aplicada a um maior número de instâncias. Com base neste raciocínio, são desfeitos os links dos trajetos originais, de modo a incorporar-se novos clientes nas rotas já estabelecidas, não excedendo a capacidade do veículo ao adicionar a demanda deste novo cliente inserido na rota.

Golden et al. (1984) apresentam em seu trabalho o problema de determinar o dimensionamento da frota e seu correto mix, tanto com vistas aos custos de aquisição quanto aos incorridos nas rotas. O foco está no aluguel (e não na aquisição) de veículos durante determinado período de tempo para atender as necessidades da empresa, modelando-os como possuindo um custo fixo e outro variável, sendo este proporcional à distância percorrida (para combustível, manutenção e mão-de-obra). Embora a formulação matemática se mostre pronta sem maiores complicadores, não era conhecido, até então, método para obtenção de uma solução próxima à ótima. Sendo assim, em seguida, são utilizadas as heurísticas de economia (Savings, Combined Savings, Optimistic Opportunity Savings, Realistic Opportunity Savings), giant tour algorithms, the single partition GT algorithm, the multiple partition GT algorithm, dentre outras, comparando as eficiências de todas elas. É citado, em suas conclusões, que o trabalho de Fisher e Jaikumar (1981) pode ser utilizado para ampliação dos estudos nesta área. Fisher e Jaikumar apresentam uma formulação de programação inteira para minimização dos custos, considerando frota de veículos heterogênea. Por fim, apresentam uma heurística de inserção que supera os resultados obtidos quando da aplicação da heurística de Clarke e Wright (1964).

Dullaert et al. (2002) abordam que, ao serem utilizados veículos de diferentes capacidades, é permitida a maximização da utilização da capacidade dos mesmos, enviando veículos menores - 
e, em geral, mais baratos - para áreas com menor concentração de clientes. Além disso, é possível que os clientes exijam que apenas alguns tipos de veículo os atendam devido a restrições de acessibilidade. As diferenças em equipamento, capacidade de carregamento e outras demais técnicas podem causar uma diferente estrutura de custos para cada um deles. Analogamente, podese verificar similaridade com o caso de PLSVs que atendam a determinados poços. Nem todas embarcações estão aptas para atuarem em todas as profundidades marítimas e a capacidade de armazenamento de cada navio também é distinta. Os autores propõem novas heurísticas, adaptadas, para o problema de roteamento de veículos de frota heterogênea, com janelas de tempo e dimensionamento de frota, tendo por base a heurística de inserção de Solomon (1987), com o diferencial de ampliar o modelo de Solomon para uma frota heterogênea e utilizando ideias de inserção de Golden et al. (1984).

\subsection{Múltiplos roteiros por embarcação}

Esta característica ocorre quando um mesmo veículo ou embarcação efetua mais de um roteiro no horizonte de análise.

Drexl (2012) aborda este tópico em uma taxonomia sobre os tipos de VRP. A nomenclatura utilizada para esta questão é planejamento de múltiplas rotas fechadas para cada veículo, com aplicações em entregas, onde os veículos devem retornar ao depósito mais de uma vez por dia para reabastecimento (ou recarregamento).

Um caso onde existe apenas um veículo que atende uma série de consumidores levando produtos perecíveis, com janelas de tempo, é apresentado por Azi et al.(2007), caracterizando um MTVRPTW (Multi Trip Vehicle Routing Problem with Time Windows). Inicialmente, os autores propõem uma formulação PLIM para o problema em questão. Devido à especificidade do produto carregado e também ao limite de capacidade do veículo, o modelo matemático estabelece, no resultado, quais as rotas e a ordem na qual devem ser realizadas. O objetivo é reduzir a distância percorrida no decorrer de um dia de entregas. Interessante pontuar algumas caraterísticas da formulação: fazer a união entre os roteiros e estabelecer o tempo de carregamento necessário na base para cada um deles. Os autores também estabelecem um método exato de resolução que se dá 
em duas etapas de programação dinâmica: a primeira para criar rotas factíveis e, a segunda, para aglutinar os roteiros de modo a criar a programação do dia inteiro.

Nesta obra, Azi et al.(2007) retomaram este assunto, chamado também de múltiplos usos de um veículo, que havia sido levantado, anteriormente, nos trabalhos de Fleischmann (1990) e Taillard et al.(1995). Porém, é o primeiro trabalho a apresentar formulação matemática para a solução exata (Giroudeau et al., 2011). Azi et al.(2007) também cita em seu artigo que a motivação para o trabalho é o advento de serviços eletrônicos e entregas de mercadorias delivery que foram compradas pela internet, mostrando-se intrinsecamente atual com as tendências de mercado.

A partir do trabalho de Azi et al.(2007), novas instâncias do problema foram apresentadas. Cattaruzza et al. (2014) abordam o MTVRP (Multi Trip Vehicle Routing Problem) para uma situação onde, por condições legais, são favorecidas as viagens em veículos de pequeno porte. Com isso, durante um dia de trabalho, é necessário que os veículos retornem para o depósito e realizem carregamentos para outros roteiros. As seguintes condições devem ser satisfeitas no caso deste problema:

- cada rota inicia e é finalizada no depósito;

- cada cliente é visitado apenas uma vez;

- a soma das demandas dos clientes em cada rota não pode exceder a capacidade do veículo, todos de capacidade idêntica;

- a duração de todas as rotas direcionadas a um veículo não pode exceder um período de tempo limite, referente à duração de um dia de trabalho.

É desenvolvido um algoritmo chamado memético, com base em algoritmos genéticos, com analogias às permutações de cromossomos.

Azi et al. (2010) retomam os trabalhos de Azi et al. (2007), mas focando em um caso com múltiplos veículos e uma série de heurísticas de desconstrução e recriação, tendo como o primeiro passo o atendimento ao maior número possível de consumidores para que depois seja minimizada a distância total percorrida pelos veículos. 
Giroudeau et al. (2011) abordam que trabalhos na área de dimensionamento de frota e multi-viagem são escassos na literatura e a maioria dos mesmos preocupa-se em resolver, diretamente, estes problemas envolvendo meta-heurísticas, não passando pela parte da formulação exata. Os autores aprimoram a formulação matemática para a obtenção do resultado exato feita por Azi et al. (2007) incorporando variáveis que limitam a duração de cada viagem de cada veículo (e não apenas limite da jornada diária). Sendo assim, seu problema é do tipo MTVRPTW-LD (Multi Trip Vehicle Routing Problem with Time Windows - limited duration).

\subsection{Roteirização e programação de navios}

Dada a característica do problema, é essencial que sejam avaliados estudos realizados sobre o problema de programação e roteirização de navios (ship routing and scheduling problem). Estes tratarão especificamente de situações em ambiente marítimo que exigiram a utilização de embarcações, tal qual o problema em questão. Alguns deles abordam casos da indústria petrolífera embora não tratem especificamente do caso de roteirização de PLSVs.

Nishi e Izuno (2014) abordam um problema de roteirização e programação de navios de transporte de petróleo bruto de diversos tipos com entregas fracionadas, visando à minimização das distâncias e obedecendo à capacidade dos navios-tanque, que coletam petróleo em vários

pontos do mundo e o distribuem a alguns clientes. É citado pelos autores que este problema é um desafio para a indústria petroquímica em termos globais. Nota-se, na formulação matemática utilizada, restrições semelhantes àquelas utilizadas nas situações de roteirização em ambiente terrestre/rodoviário (capacidade das embarcações, restrições de eliminação de subtours, restrições de início e fim das rotas, por exemplo). A partir da relaxação deste problema original, utilizam uma heurística baseada no procedimento de geração de colunas de modo iterativo.

Outro trabalho que retrata o transporte de óleo bruto, com recolhimento e entrega de produtos é aquele elaborado por Hennig et al. (2012). Os autores abordam que este é um problema de conhecimento da literatura desde a década de 50 e relevante até hoje por conta do abastecimento das refinarias com determinados tipos de petróleo. Características deste problema são a frota heterogênea, a utilização de múltiplos produtos. Outras questões que o deixam ainda mais complexo são as capacidades de carregamento nos portos, cargas fracionadas e as janelas de tempo 
tanto para coleta quanto para entrega. Tem-se a preocupação de construir-se um modelo detalhado para esta situação, com bastantes características reais e forte direcionamento ao atendimento das demandas das refinarias por distintos tipos de óleo. É um problema de otimização no qual pequenas instâncias puderam ser resolvidas de modo ótimo quando se utiliza o procedimento da pré-geração de rotas dos navios. A função objetivo visa à minimização dos custos com combustível e de taxas portuárias. Hennig et al. (2015) é uma evolução do trabalho citado anteriormente, trazendo uma formulação mais simples e compacta do modelo além de um detalhamento do procedimento de pré-geração das rotas.

Christiansen et al. (2013) trazem, em seu trabalho, um levantamento bibliográfico das obras que trataram o tema de roteirização e programação de navios nos últimos anos (dentro do século XXI). Dentro desta revisão literária, estabelecem quais foram os 4 tipos básicos de modelos publicados, de acordo com suas características: modelos com uma única rota ou conjunto de rotas sem transbordo; modelos de transbordo e rotas de alimentação, nos quais cada porto alimentador é conectado a um porto de transbordo; modelos nos quais alguns portos são classificados como portos de transbordo sem nenhuma restrição no número de portos que uma rota pode visitar; e modelos de multi-rotas sem separação de portos de transbordo ou não. Tamanho e composição da frota também são tópicos elencados no trabalho. Abordam também a relevância deste tema para o desenvolvimento global, apresentando o aumento da frota e da carga a ser transportada, de 1980 a 2010.

Lee e Kim (2015) abordam o problema de roteirização com entregas fracionadas, janelas de tempo e frota heterogênea no contex to de uma empresa de manufatura de aço. O caso em questão lida também com dois tipos de navios: próprios, que podem realizar múltiplas coletas e múltiplas entregas em uma rota; e contratados, que realizam atividades de ponto a ponto. Um modelo PLIM é apresentado para o problema bem como o algoritmo de uma heurística, do tipo Adaptive Large Neighborhood Search (ALNS). Os testes computacionais são realizados com base em 30 instâncias categorizadas em grupos, de acordo com o número de navios utilizados e volume de carga a ser transportada. $\mathrm{O}$ percentual de gap da heurística com relação à formulação ótima para pequenas instâncias foi menor que $0,5 \%$.

Assis e Camponogara (2016) tratam do problema de navios aliviadores, que realizam o transporte entre as plataformas de petróleo, que se encontram em alto-mar e o terminal terrestre. A operação é caracterizada como um grafo, no qual os vértices representam justamente o terminal e 
as plataformas, bem como variáveis de tempo de viagem. As operações possíveis para o navio são a movimentação, o offloading, o uploading e a espera. A partir desta caracterização, é utilizado um modelo de programação inteira mista para a resolução do caso em questão. São estabelecidas restrições de factibilidade de rotas, número de navios a serem utilizados, balanço de estoque e de transferência de carga. Devido à complexidade do problema e dificuldade em achar-se uma solução factível, recorre-se a dois métodos heurísticos: rolling-horizon, no qual se foca em resolver um curto horizonte de tempo em cada iteração; e relax-and-fix, no qual o sub-problema a ser trabalhado é o horizonte de tempo inteiro que se possui dali em diante com relaxação de um período inicial destes sub-problemas.

Rodrigues et al. (2017) realizam um estudo sobre roteirização e programação de navios para cabotagem de petróleo. Conta com a questão de produtos diferentes a serem transportados, frota heterogênea de embarcações, plataformas dispersas ao longo do mar e terminais de recebimento ao longo da costa brasileira e janelas de tempo. A modelagem deste problema é do tipo PDPTW (pickup and delivery problem with time windows). O modelo matemático proposto pelos autores abrange uma série de detalhes e, portanto, possui certa extensão. Seu objetivo é a minimização dos custos variáveis com combustíveis e fixos, de atracação em plataformas. Foi utilizada a heurística relaxand-fix para a resolução de problemas reais que considerem um curto espaço de tempo (até 7 dias).

\subsection{Programação de atividades em projetos petrolíferos}

Há, na literatura, alguns estudos que versam sobre a mesma temática deste trabalho. Pereira (2005) realiza um trabalho sobre escalonamento de atividades de desenvolvimento de poços de petróleo, valendo-se da meta-heurística GRASP (Greedy Randomized Adaptive Search Procedure) como base para resolução. Para obter a solução final, foram incorporadas também outras técnicas. A meta-heurística GRASP é composta por duas fases: uma fase de construção, para que seja encontrada uma solução inicial; e uma fase de busca local, na qual busca-se que a solução inicial seja, gradativamente, melhorada. Para composição de sua dissertação, são apresentados dois artigos: um para o cenário sem tempo para deslocamento de recursos (Pereira et al., 2005b) e outro considerando o tempo de deslocamento de recursos (Pereira et al., 2005c). São apresentadas, 
também, algumas telas e funcionalidades do sistema desenvolvido, bem como seu algoritmo, função objetivo e técnicas de busca.

Há alguns anos, foi elaborado pela empresa considerada no trabalho de Pereira (2005), em parceria com universidades, um software que tinha por objetivo realizar o nivelamento e programação de curto, médio e longo prazo das embarcações sondas e $P L S V s$, conjuntamente. Na época de sua elaboração, esta ferramenta foi concebida para realização de simulações a nível macro, porém nunca foi utilizada como a oficial para o planejamento de curto e médio prazo que, costumeiramente, é o foco da companhia. Um horizonte muito grande de tempo serve apenas para análises de nível macro, pois o cenário econômico afeta por demais as atividades de uma empresa de petróleo, além de todas as estratégias que se utilizam para direcionar os investimentos dentro de uma empresa que mescla atividades de upstream (atividades de exploração e produção de petróleo, visando à retirada do óleo das camadas subterrâneas) e downstream (atividades relacionadas à refinação do petróleo e produção de derivados). Além disso, o principal complicador apontado pelos atuais engenheiros que integram a equipe de programação destes recursos críticos da companhia é que este sistema solicitava um número grande de informações como parâmetros de entrada. Isto implicava em uma limitação do sistema, o que fez com que o mesmo passasse a não ser tão utilizado devido à agilidade que se começou a exigir dentro da empresa. Como consequência, há cerca de cinco anos, tal sistema foi descontinuado dentro da companhia.

A proposta deste trabalho é utilizar, para análise, um horizonte de 12 meses, em uma versão mais simplificada - no que diz respeito a necessidades de informações - e que foque especialmente nos recursos $P L S V s$, dado que as imprevisibilidades nas atividades de sondas (cujas durações das atividades já são, por si só, maiores que as de interligação) são grandes e impõem alterações significativas em termos de frequência e duração das atividades. Ou seja, analisando apenas os $P L S V s$, acredita-se que este universo em estudo tenha uma incerteza menor, tornando-se um meio de análise e previsão mais confiável para curto e médio prazo.

Ainda abordando a área de programação de PLSVs, Moura (2012) realizou um trabalho utilizando a analogia de atividades de roteirização com as atividades de scheduling de máquinas em paralelo. O problema é representado através de um modelo de programação linear inteira mista e tem por função objetivo a minimização do custo de oportunidade. Ele é resolvido aplicando as seguintes técnicas: uma heurística construtiva que encontra um limitante superior; relaxação 
lagrangiana da restrição de capacidades das embarcações para estimar os limitantes inferiores e, por fim, um mecanismo de busca local, que investiga a vizinhança das soluções viáveis, realizando um refinamento visando a encontrar um limitante superior melhor. Este procedimento é repetido até que o critério de parada seja atingido. Seu trabalho não leva em consideração os tempos de deslocamento e considera que a frota de embarcações é homogênea, dentre outras diferenças com este presente estudo.

Bianco et al. (2014) realizaram um estudo que avalia se há crescimento de VPL com o aumento do número de PLSVs focando, especialmente, em dimensionamento da frota destes barcos. Como dados de entrada, foram utilizadas informações públicas e não detalhadas do planejamento estratégico de uma empresa de petróleo. A partir destes dados, foram estimadas datas de conexão dos poços de cada uma das plataformas a entrar em operação nos próximos anos, caracterizando um trabalho de horizonte plurianual. Com base nestas atividades estimadas, utilizou-se uma heurística para definição da data de mobilização de novas embarcações. O Método de Monte Carlo foi também utilizado para incorporar uma análise probabilística de risco ao problema.

Pereira (2005) e Silva (2012) são trabalhos focados na área de implementação computacional e possuem uma linguagem dedicada a esta área do conhecimento, não ressaltando tanto os aspectos de engenharia e processo presentes no problema em questão. $\mathrm{O}$ escopo de ambos os trabalhos é mais abrangente e de olhar menos detalhado do que o deste trabalho, dado que lidam não somente com os recursos $P L S V$ mas também com os recursos sonda.

Neste momento, cabe salientar os motivos pelos quais foca-se apenas nas embarcações PLSVs, desconsiderando as atividades de sondas que precedem a fase de interligação, de modo detalhado (ou seja, não considerando os intervalos necessários de perfuração e completação mas sim apenas a data de finalização do poço).

As atividades de sonda, além de estarem sujeitas à disponibilidade de materiais e condições de mar, possuem várias fases em sua composição dadas as grandes profundidades com as quais se está trabalhando. Devido ao formato dos poços confeccionados (que podem ser verticais, direcionais ou horizontais), não são raras as vezes que ocorrem travamento das ferramentas utilizadas nestas operações. Com isto, há uma série de tempos perdidos por conta do destravamento 
destas ferramentas. Ou, ainda, quando há ruptura ou desconexão das ferramentas pode haver perda de tempo para as atividades chamadas de "pescaria", na qual há a tentativa de se pinçar com ferramentas específicas aquelas que caíram no fundo deste poço em perfuração. Ademais, a camada de sal que deve ser atravessada na perfuração dos poços de camada "Pré-Sal" é um grande complicador técnico, devido às características plásticas daquele material, o que leva a ter uma imprevisibilidade e grande desvio padrão nos tempos das atividades.

Portanto, dadas as maiores imprevisibilidades a que estão sujeitas as atividades de sondas, ou seja, nas fases de perfuração e completação, este trabalho foca apenas nas atividades de PLSV, para interligação dos dutos entre os poços e as plataformas. Um cronograma que unisse todas as atividades de embarcações mostra-se muito útil para efeito de planejamento macro (sem muitos detalhes no resultado), de dimensionamento de recursos a longo prazo. Porém, operacionalmente, ele não se apresenta realista.

Bremenkamp et al. (2016) tratam do problema de roteirização de PLSVs porém partem de um procedimento de pré-criação de blocos de atividades, compostos por carregamento, navegação até o local das atividades, as atividades a serem realizadas e a navegação de retorno ao porto (base de carregamento). Este procedimento já retira toda a parte combinatória do problema de definição de quais atividades fazem parte de cada roteiro de cada embarcação. Este trabalho não considera os eventuais tempos de deslocamento entre as atividades e nem faz menção à questão de declínio de poços ou acréscimo de produção por conta dos poços injetores. Devido à menor característica combinatória, conseguem solução ótima para alocação destes blocos de atividades nos PLSVs e utilizam-se de contagem de tempo discreta, e não contínua.

Como se vê nesta revisão bibliográfica, há trabalhos que abordam a alocação de atividades com PLSVs como uma analogia ao problema de scheduling em máquinas, considerando cada atividade a ser alocada a um barco como uma tarefa a ser processada em determinada máquina. Assim, por exemplo, as navegações entre locações poderiam ser consideradas como os tempos de setup entre atividades a serem processadas em uma mesma máquina; a não-concomitância entre 3 atividades poderia ser tratada como um produto que precisa de 3 processamentos distintos, que não podem ser realizados com simultaneidade, sem ordem.

Todavia, optou-se pela estratégia de resolução baseada em formulações específicas de roteirização por conta de algumas questões peculiares do problema: carregamento conjunto dos 
materiais que serão utilizados em atividades de um mesmo roteiro de uma mesma embarcação; por conta de precisar ser controlada a capacidade de estocagem das embarcações, que são heterogêneas; não existe, no problema em questão, uma data de necessidade de entrega, mas sim um desejo de antecipação de todas as atividades para que se aumente o volume de produção; além de guardar um melhor sentido físico com a operação que ocorre, a qual é efetivamente uma roteirização de embarcações. 


\section{Formulação matemática}

Nesta seção, será realizada a modelagem matemática do problema em questão, com o detalhamento de índices, parâmetros e variáveis, bem como das restrições e seu funcionamento. Por fim, serão efetuados testes para verificação da robustez da formulação proposta.

\subsection{Elaboração do modelo matemático}

O intuito deste modelo matemático é traduzir a situação na qual barcos de interligação $(P L S V S)$ realizem a conexão de poços de petróleo às plataformas de produção. Visando à maximização da produção de óleo nestes campos petrolíferos, o modelo dará como resposta, através dos valores assumidos por suas variáveis na solução ótima, a ordem na qual os poços de petróleo devem ser interligados e em qual barco e tempo estas interligações devem acontecer. Ou seja, com isto tem-se a roteirização que otimiza a curva de óleo dos campos em questão. A cada roteiro a ser efetuado, há a necessidade de o barco ir até a base de carregamento e armazenar as linhas a serem utilizadas nas atividades deste próximo roteiro.

O modelo proposto é de programação linear inteira mista (PLIM), no qual há uma intrínseca relação entre os índices $i$ e $p$. Para cada poço $p$, há 3 atividades $i$ atreladas a ele, sempre em ordem. Ou seja, para o poço 1, tem-se as atividades 1, 2 e 3 . Para o poço 2, tem-se as atividades sequenciais, ou seja, as de número 4, 5 e 6 . O conjunto $N$ representa o conjunto das atividades a serem realizadas e o conjunto $N^{+}$representa o conjunto $N$ adicionado das atividades 0 e $I+1$ representativas da base de carregamento (saída e chegada à base).

\section{Índices}

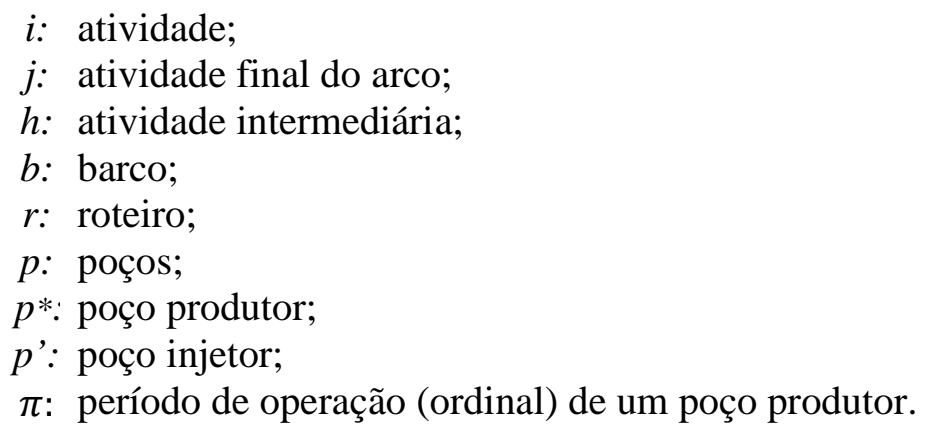




\section{Parâmetros}

$P: \quad$ número total de poços;

I: $\quad$ número total de atividades;

B: $\quad$ número total de barcos PLSVs;

T: $\quad$ número total de dias na análise;

$R$ : $\quad$ número de roteiros que cada barco está apto a realizar no horizonte de tempo;

$d_{i j}$ : $\quad$ duração do translado entre as atividades $i$ e $j$ (em dias);

$s_{i}$ : $\quad$ duração da atividade $i$ (em dias);

$m_{i}^{b}$ : $\quad 1$, caso o barco $b$ seja capaz de realizar a atividade $i$ no poço $p ; 0$, c.c.;

$W_{p^{*}}^{\pi}$ : $\quad$ potencial de produção, por período de operação $\pi$, do poço produtor $p^{*}$ (barril/dia);

$\operatorname{Inj} j_{p^{\prime}}^{\pi}$ : acréscimo de produção, por período de operação do produtor atrelado $\pi$, devido ao poço injetor $p^{\prime}(\%)$;

$D C_{i}: \quad$ instante a partir do qual a completação, prévia à atividade $i$, está finalizada;

$D M_{i}: \quad$ instante a partir do qual o material da atividade $i$ está disponível para carregamento;

$q_{i}: \quad$ quantidade de duto para a atividade $i$ (em $\mathrm{Km}$ de duto);

$Q_{b}$ : $\quad$ capacidade de armazenamento do barco $b$ (em Km de duto);

comis: tempo para comissionamento da linha após sua instalação (em dias);

$\beta: \quad$ taxa de carregamento, em dias/Km de duto.

\section{Variáveis}

$X_{i j}^{r b}$ : 1 , se o barco $b$, na rota $r$, realiza a atividade $j$ logo após a atividade $i$; 0 , c. c. ;

$Y_{i}^{r b}: \quad 1$, se a atividade $i$ está na rota $r$ do barco $b ; 0$, c. c.;

$t_{i}^{r b}$ : instante de início da atividade $i$, no roteiro $r$ do barco $b$; especialmente para a atividade 0 , é o instante no qual o barco deixa o centro de carregamento em cada roteiro $r$ de cada barco $b$;

$g_{i}^{r b}$ : instante de início da atividade $i$, no roteiro $r$ do barco $b$; contabiliza somente os instantes utilizados nos roteiros e não os cálculos intermediários, como o $t_{i}^{r b}$;

$\alpha_{i}$ : variável auxiliar para definição da data de realização da atividade $i$ de cada poço

$a_{i 1, i 2}$ : 1 , caso a atividade $i 1$ ocorra antes da atividade $i 2$, sendo $i 1$ e $i 2$ atividades de um mesmo poço; 0 , c.c.;

$\sigma^{r b}$ : duração do carregamento dos dutos das atividades que compõem o roteiro $r$ do barco $b$;

$k_{p}$ : instante a partir do qual o poço $p$ pode entrar em operação.

$\mu_{p^{*}}^{\pi}: \quad 1$, se o poço produtor $\mathrm{p}^{*}$ tem seu $\pi$-ésimo período de operação dentro do intervalo de análise; 0 , c.c.;

$\gamma_{p^{\prime}}^{\pi}: \quad 1$, se o poço injetor p' atua no $\pi$-ésimo período de operação de seu respectivo produtor de dentro do intervalo de análise; 0 , c.c.; 


\section{Modelo}

$M A X \sum_{\pi=1}^{T} \sum_{p^{*} / p^{\prime}} W_{p^{*}}^{\pi}\left(\mu_{p^{*}}^{\pi}+I n j_{p^{\prime}}^{\pi} \gamma_{p^{\prime}}^{\pi}\right)$

$\sum_{j \in N^{+} \backslash 0} X_{i j}^{r b}=Y_{i}^{r b}$

$i \in N, \forall r, \forall b$

$\sum_{b=1}^{B} \sum_{r=1}^{R} Y_{i}^{r b}=1$

$i \in N$

$\sum_{i \in N^{+}} X_{i h}^{r b}-\sum_{j \in N^{+}} X_{h j}^{r b}=0$

$h \in N, \forall r, \forall b$

$\sum_{i \in N^{+}} X_{0 i}^{r b}=1$

$\forall r, \forall b$

$\sum_{i \in N^{+}} X_{i(I+1)}^{r b}=1$

$\forall r, \forall b$

$\sum_{i \in N} q_{i} Y_{i}^{r b} \leq Q_{b}$

$\forall r, \forall b$

$t_{i}^{r b}+s_{i}+d_{i j}-M\left(1-X_{i j}^{r b}\right) \leq t_{j}^{r b}$

$i \in N^{+}, j \in N^{+}, \forall r, \forall b$

$t_{0}^{r b} \geq D M_{i} Y_{i}^{r b}+\sigma^{r b}$

$i \in N, \forall r, \forall b$

$\sigma^{r b}=\beta \sum_{i \in N} q_{i} Y_{i}^{r b}$

$\forall r, \forall b$

$t_{I+1}^{r b}+\sigma^{(r+1) b} \leq t_{0}^{(r+1) b}$

$r=1, \ldots, R-1 ; \forall b$

$Y_{i}^{r b} \leq m_{i}^{b}$

$i \in N, \forall r, \forall b$

$t_{i}^{r b} \geq D C_{i}$

$i \in N, \forall r, \forall b$

$g_{i}^{r b} \geq t_{i}^{r b}-M\left(1-Y_{i}^{r b}\right)$

$i \in N, \forall r, \forall b$ 


$$
\begin{aligned}
& g_{i}^{r b} \leq t_{i}^{r b}+M\left(1-Y_{i}^{r b}\right) \\
& g_{i}^{r b} \leq M Y_{i}^{r b}
\end{aligned}
$$

$k_{p} \geq \sum_{r=1}^{R} \sum_{b=1}^{B} g_{(3 p-2)}^{r b}+s_{3 p-2}+$ comis

$k_{p} \geq \sum_{r=1}^{R} \sum_{b=1}^{B} g_{3 p-1}^{r b}+s_{3 p-1}+$ comis

$k_{p} \geq \sum_{r=1}^{R} \sum_{b=1}^{B} g_{3 p}^{r b}+s_{3 p}+$ comis

$$
\begin{array}{ll}
\sum_{b=1}^{B} \sum_{r=1}^{R} g_{3 p-2}^{r b}-\sum_{b=1}^{B} \sum_{r=1}^{R} g_{3 p-1}^{r b}+s_{3 p-2} \leq M\left(1-a_{3 p-2,3 p-1}\right) & \\
\sum_{b=1}^{B} \sum_{r=1}^{R} g_{3 p-1}^{r b}-\sum_{b=1}^{B} \sum_{r=1}^{R} g_{3 p-2}^{r b}+s_{3 p-1} \leq M a_{3 p-2,3 p-1} & \\
\sum_{b=1}^{B} \sum_{r=1}^{R} g_{3 p-1}^{r b}-\sum_{b=1}^{B} \sum_{r=1}^{R} g_{3 p}^{r b}+s_{3 p-1} \leq M\left(1-a_{3 p-1,3 p}\right) & \\
\sum_{b=1}^{B} \sum_{r=1}^{R} g_{3 p}^{r b}-\sum_{b=1}^{B} \sum_{r=1}^{R} g_{3 p-1}^{r b}+s_{3 p} \leq M a_{3 p-1,3 p} & \\
\sum_{b=1}^{B} \sum_{r=1}^{R} g_{3 p-2}^{r b}-\sum_{b=1}^{B} \sum_{r=1}^{R} g_{3 p}^{r b}+s_{3 p-2} \leq M\left(1-a_{3 p-2,3 p}\right) & \\
\sum_{b=1}^{B} \sum_{r=1}^{R} g_{3 p}^{r b}-\sum_{b=1}^{B} \sum_{r=1}^{R} g_{3 p-2}^{r b}+s_{3 p} \leq M a_{3 p-2,3 p} & \\
\alpha_{i} \geq D C_{i} & \\
\alpha_{i} \geq D M_{i} & \\
t_{i}^{r b} \leq \alpha_{i}+120 & \\
X_{i i}^{r b}=0 & \\
\mu_{p^{*}}^{\pi} \leq \frac{T-k_{p^{*}}}{\pi} & \\
\pi \gamma_{p^{\prime}}^{\pi}+M\left(1-\gamma_{p^{\prime}}^{\pi}\right) \geq k_{p^{\prime}}-k_{p^{*}}+1 & \\
\mu_{p^{*}}^{\pi} \geq \gamma_{p^{\prime}}^{\pi} & i \in N, \forall p^{*} \\
& \\
& \\
&
\end{array}
$$


$t_{i}^{r b} \geq 0$

$$
\begin{gathered}
i \in N^{+}, \forall r, \forall b \\
i \in N^{+}, \forall r, \forall b \\
\forall p \\
i \in N \\
\forall r, \forall b \\
i \in N^{+}, j \in N^{+}, \forall r, \forall b \\
i \in N^{+}, \forall r, \forall b \\
i 1, i 2 \in N \\
\forall \pi, \forall p^{*} \\
\forall \pi, \forall p^{\prime}
\end{gathered}
$$$$
k_{p} \geq 0
$$$$
\sigma^{r b} \geq 0
$$

A função objetivo (1) visa ao maior volume de produção dentro do horizonte de tempo considerado. Neste ponto, vale a pena esclarecer melhor a diferença entre o tempo $t$ e o tempo $\pi: t$ é o tempo do cronograma, que vai de 0 até o horizonte de análise $T$, podendo um poço entrar em operação em qualquer ponto deste intervalo; já $\pi$ é o período de operação do poço produtor, e inicia necessariamente do período 1 . Sendo assim, a função objetivo considera a multiplicação, em cada período de operação, do potencial de produção (do poço produtor), $\left(W_{p^{*}}^{\pi}\right)$, pelas variáveis que indicam em quais períodos o poço estará produzindo $\left(\mu_{p^{*}}^{\pi}\right)$ e, em quais destes momentos haverá operação do(s) poço(s) injetor(es) atrelado(s), resultando em um fator de aumento de produção dado por $I n j_{p^{\prime}}^{\pi} \gamma_{P^{\prime}}^{\pi}$. Esta função objetivo poderia ser reescrita como a minimização das perdas de produção de óleo devido aos poços ainda não estarem produzindo. Porém, por motivo de melhor compreensão do modelo optou-se pela maximização da produção no período de interesse. Importante salientar que $\pi$ é o tempo de operação do poço produtor mesmo quando está se tratando de poços injetores. Neste caso, o $\pi$ começa a contar a partir da entrada em operação de seu respectivo produtor.

O conjunto de restrições (2) exprime que, se alguma atividade é atendida em determinado roteiro de algum barco $\left(Y_{i}^{r b}=1\right)$, é necessário que haja um arco de saída com destino a uma atividade $j$ (que pode ser uma atividade na base $I+1$ ou para a execução de uma atividade em qualquer outra locação), ou seja, um, e apenas um $X_{i j}^{r b}=1$. 
As restrições (3) implicam que todas as atividades devem ser atendidas. Importante notar que atividades de partida e de chegada à base de carregamento não são consideradas nesta restrição, pois devem ocorrer uma vez em cada roteiro de cada barco, como será visto adiante.

As restrições (4) são as responsáveis pela existência de fluxo nas rotas de cada embarcação. Dado que uma atividade $h$ está sendo atendida, garante-se que, antes dela houve uma atividade $i$ atendida e, após ela, haverá uma atividade $j$ a ser atendida. As atividades $i$ e $j$ podem ser atividades efetuadas na partida e na chegada à base $(0$ e $I+1$, respectivamente).

Os conjuntos de restrições (5) e (6) são responsáveis pela exigência de partida e chegada à base em cada roteiro de cada PLSV, respectivamente. Em cada rota de cada barco, ele deve sair do nó 0 e deve chegar ao nó $I+1$, ambas atividades representativas da base, sendo que as mesmas não possuem duração, apenas existem para que seja fechado o ciclo. Tempo de carregamento das linhas na base será tratado em outra restrição, apresentada adiante.

A garantia de que a quantidade de dutos a serem carregados em cada roteiro de cada embarcação não ultrapassa a capacidade $Q_{b}$ do $P L S V$ é assegurada pelas restrições (7). A multiplicação do comprimento de cada duto carregado pela variável binária $Y_{i}^{r b}$ implica que, quando $Y_{i}^{r b}=1$ naquele roteiro daquele barco, as linhas daquela determinada atividade deverão ser carregadas naquele barco. A somatória dos quilômetros das linhas carregadas naquele roteiro não pode ultrapassar a capacidade de armazenamento do PLSV.

As restrições (8) explicam como, dentro de um mesmo roteiro de um mesmo barco, há a continuidade do tempo. Sendo $j$ a atividade imediatamente seguinte à atividade $i$ em um roteiro $r$ de um barco $b$, o valor de $X_{i j}^{r b}$ é 1 e o valor de $-M\left(1-X_{i j}^{r b}\right)$ é zero. $M$ é um número grande, tendo, para esta formulação, o seu valor atribuído como 10000. Com isto, tem-se que $t_{i}^{r b}+s_{i}+d_{i j} \leq$ $t_{j}^{r b}$, ou seja, o instante de início da atividade seguinte, $j$, é maior ou igual ao instante de início da atividade anterior, $i$, adicionada do tempo de execução da atividade $i-s_{i}$ - e do tempo de translado entre o local onde é executada a atividade $i$ e onde será feita a atividade $j-d_{i j}$. Como, na formulação como um todo, o intuito é que as atividades sejam realizadas o quanto antes para que os poços entrem em produção e isso favoreça a função objetivo, a tendência é que esta desigualdade $(\leq)$ atue como uma igualdade. No caso de $j$ não ser a atividade seguinte de $i$ neste roteiro e embarcação, o valor de $-M\left(1-X_{i j}^{r b}\right)$ é $-M$. Com isso, $t_{j}^{r b}$ não fica limitado para esta rota e embarcação por conta desta atividade predecessora, não havendo interferência. 
O conjunto de restrições (9) expressa que um PLSV só possa sair da base carregado a partir do instante em que todas as linhas estejam disponíveis. Sendo assim, a partir do momento em que a linha da atividade $i$ está disponível $\left(D M_{i}\right)$, pode-se somar o valor da duração daquele determinado carregamento $\sigma^{r b}$. Este dá o instante mínimo de partida daquele roteiro considerando apenas uma das linhas do roteiro. Para a formulação como um todo, é considerado para o limite $t_{0}^{r b} \mathrm{o}$ instante mais tarde dentre todas as linhas daquele carregamento. É assumido, também, que o carregamento de todas as linhas só poderá ser realizado com todas as linhas do mesmo disponível. Não poderá ser realizado carregamento parcial com, por exemplo, espera da embarcação por apenas uma linha restante para que ela seja carregada sozinha.

O conjunto de restrições (10) traduz o cálculo do tempo a ser gasto no carregamento das linhas de um roteiro $\left(\sigma^{r b}\right)$. Os componentes deste cálculo são: a quantidade (comprimento) de linhas de cada atividade $i\left(q_{i}\right)$, que são ativadas na multiplicação caso o $Y_{i}^{r b}$ tenha valor 1 , o que representa que a atividade $i$ compõe o roteiro $r$ da embarcação $b$; e um parâmetro $\beta$ que representa o tempo, em dias, gasto para o carregamento de cada Km de linha.

As restrições (11) referem-se à transição entre roteiros dentro de mesma embarcação. Ou seja, a continuidade de tempo quando o primeiro roteiro encerra-se (ocorrendo, assim, o retorno para a base de carregamento) e há a preparação para o início do próximo roteiro do mesmo PLSV. Expressam que o instante inicial do próximo roteiro é, no mínimo, o instante final do roteiro anterior acrescido do tempo de carregamento do próximo carregamento. No mínimo, pois pode haver ainda alguma restrição de chegada de material na base que pode impactar mais alguns dias. Num cenário no qual já estão disponíveis os recursos necessários, esta desigualdade deve atuar como uma igualdade.

As restrições (12) avaliam se determinada atividade pode ser realizada pelos barcos da frota. Para tanto, $Y_{i}^{r b}$ somente poderá ter seu valor maior do que 0 caso o parâmetro $m_{i}^{b}$ tenha valor 1 . O valor 1 para $m_{i}^{b}$ significa que a atividade é viável tecnicamente para este PLSV. Será fornecida uma matriz de parâmetros $m_{i}^{b}$ com a finalidade de verificação dos PLSVs que podem ser utilizados para cada uma das tarefas a serem executadas.

O conjunto de restrições (13) impede que atividades de interligação sejam realizadas antes que a atividade de completação referente tenha sido finalizada. Serão fornecidos, como parâmetros de entrada, os instantes de finalização da completação. 
As restrições (14) são utilizadas para cálculo dos instantes que são, de fato, utilizados em cada um dos roteiros. Como as variáveis $t_{i}^{r b}$ são, por vezes, utilizadas para cálculos, aqui são estabelecidas as variáveis $g_{i}^{r b}$, que serão variáveis que assumem valores apenas quando a atividade é atendida. Estas variáveis serão importantes nas restrições que vinculam o instante de início de determinada atividade com o instante $k_{p}$ de finalização das mesmas. Serão igualmente importantes nas restrições que evitam a concomitância de duas embarcações em um mesmo poço, como será visto adiante. Caso $Y_{i}^{r b}$ tenha valor $1, g_{i}^{r b} \geq t_{i}^{r b}$. Conjuntamente com as restrições (15), que resultam em $g_{i}^{r b} \leq t_{i}^{r b}$ para $Y_{i}^{r b}=1$, tem-se que $g_{i}^{r b}$ só pode assumir valor igual a $t_{i}^{r b}$. As restrições (16) obrigam que $g_{i}^{r b}$ tenha valor nulo caso $Y_{i}^{r b}$ seja zero.

O conjunto de restrições (17) indica o valor do instante mais cedo de início de produção de cada um dos poços. Sabendo que cada poço é composto de 3 atividades de interligação, estas restrições calculam a data mais cedo de finalização de cada uma como se ela fosse a atividade crítica do poço. Estas 3 equações referem-se, respectivamente, à primeira, segunda e terceira atividade de um mesmo poço. Por exemplo, o termo $\sum_{r=1}^{R} \sum_{b=1}^{B} g_{(3 p-2)}^{r b}$ indica, no somatório de todos roteiros e barcos, qual foi o instante de início da atividade $i$ (no caso, representada por $3 p-2$ ). Dado que somente existe um $g_{(3 p-2)}^{r b}$ positivo, garante-se que este somatório expressa exatamente o instante de início da atividade. A este somatório, adiciona-se a duração da atividade $s_{3 p-2}$, de modo a ter o instante de término da atividade. Acresce-se, ainda, o tempo de comissionamento (comis) de modo a ter este tempo computado no caso de cada uma destas atividades daquele poço ser a crítica. Analogamente, para estes termos nas equações 2 e 3 expressas no conjunto (17). A data mais cedo $k_{p}$ é definida, portanto, como o maior valor destas 3 equações, para cada $p$.

As restrições (18) impedem que mais de uma embarcação atuem ao mesmo tempo em um mesmo poço. Dado que cada poço possui 3 atividades, estas restrições permitem que uma atividade de interligação ou deva ser finalizada antes do início de outra atividade ou que a atividade seja iniciada após o término de uma outra atividade no mesmo poço. São utilizadas as variáveis $g_{i}^{r b}$ porque as mesmas não são influenciadas por cálculos intermediários, tal qual ocorre com as variáveis $t_{i}^{r b}$. As variáveis $a_{i 1, i 2}$ indicam a ordem na qual as atividades ocorrem. Se ela assume valor 1 , significa que a atividade i1 acontece antes da atividade $\mathrm{i} 2$.

As restrições (19) possuem intrínseca relação com o conjunto de restrições (20) e utilizamse da variável auxiliar $\alpha_{i}$ para cálculo do prazo limite no qual deve ocorrer o início da interligação 
da linha de cada atividade e foi inserida na formulação, especialmente, por conta dos poços injetores. O prazo máximo, assumido como 120 dias após o término da completação e da disponibilidade de materiais (o que ocorrer mais tarde) é chamado de $\alpha_{i}+120$, prazo este que, por sua vez, limita o valor de $t_{i}^{r b}$, efetivando o que a restrição se propõe a fazer. Vale ressaltar, mais uma vez, que estas restrições são aplicáveis preferencialmente, mas não somente, aos poços injetores dado que os mesmos tendem a ser despriorizados por não contribuírem tanto para o aumento da curva de produção de óleo quanto os poços produtores.

O conjunto de restrições (21) impede os subtours de uma atividade para ela própria, ou seja, impede a criação de arcos do tipo $i-i$.

O conjunto de restrições (22) discretiza o período no qual cada poço produtor irá produzir dentro do horizonte de análise $T$. Dado que o potencial $W_{p^{*}}$ de cada poço é dado pelo período $\pi$ de produção do poço e considera o declínio de produção, é necessário que se saiba durante quantos períodos o poços irá produzir. Importante ressaltar, novamente, a diferença entre o tempo $t$ e o tempo $\pi$ : $t$ é o tempo do cronograma, que vai de 0 até o horizonte de análise $T$, podendo um poço entrar em operação em qualquer ponto deste intervalo; já $\pi$ é o tempo de operação do poço produtor, e inicia necessariamente do período 1. Sendo assim, se um poço produzir por 30 períodos, as variáveis $\mu_{p^{*}}^{1}, \ldots, \mu_{p^{*}}^{30}$ devem valer $1 \mathrm{e}$, as demais, devem valer $0 . \mathrm{O}$ valor de $\frac{T-k_{p}}{\pi}$ vai se tornando cada vez menor com o aumento do valor de $\pi$, dado que $T-k_{p}$ é um valor constante, oriundo da parcela da formulação que define a data de partida dos poços, trabalhando com variáveis contínuas. Assim, o valor do segundo membro vai limitando, pouco a pouco, o valor de $\mu_{p^{*}}^{\pi}$. Dado que o problema é de maximização, $\mu_{p^{*}}^{\pi}$ tende a ser sempre 1, a não ser que o valor do segundo membro o limite a um valor menor do que 1. Com estas restrições, garante-se que todos $\mu_{p^{*}}^{\pi}$ serão positivos até o momento de inversão, no qual $\frac{T-k_{p}}{\pi}$ torna-se menor que 1 , o que força $\mu_{p^{*}}^{\pi}$ assumir valor 0 . Esta inversão ocorre exatamente na restrição na qual $\pi$ converge ao valor de $T-k_{p}$, assegurando o comportamento desejado.

As restrições (23) são aplicáveis aos poços injetores, tendo por base o instante de entrada de seu respectivo poço produtor $\left(k_{p^{*}}\right)$. Importante relembrar que $\pi$ é o período de operação do poço produtor mesmo quando está se tratando de seu respectivo poço injetor. Dado que o valor de $k_{p^{\prime}}-$ $k_{p^{*}}$, a diferença entre o instante de entrada do poço injetor e de seu respectivo produtor, é oriundo 
da parte da formulação que trabalha com tempo contínuo, e sabendo que $\gamma_{p^{\prime}}^{\pi}$ são variáveis binárias que contabilizam para a maximização da função objetivo, o intuito é que $\gamma_{p^{\prime}}^{\pi}$ assuma o valor 1 o quanto antes. Enquanto $k_{p^{\prime}}-k_{p^{*}}+1$ (o segundo membro da restrição 23) possuir um valor maior que o coeficiente $\pi$ que acompanha $\gamma_{p^{\prime}}^{\pi}$, a expressão $1-\gamma_{p^{\prime}}^{\pi}$, obrigatoriamente, assumirá valor 1 para que o primeiro membro seja maior ou igual ao segundo membro. Garante-se que, neste caso, $\gamma_{p^{\prime}}^{\pi}$ assumirá valor 0 e não adicione valor à função objetivo. Do contrário, quando a expressão $k_{p^{\prime}}-$ $k_{p^{*}}+1$ tiver um valor menor ou igual ao coeficiente $\pi$ que acompanha $\gamma_{p^{\prime}}^{\pi}$, tem-se que o valor de $\gamma_{p^{\prime}}^{\pi}$ poderá ser 0 ou 1 para obedecer a esta restrição. Nesta condição, o modelo escolhe que o valor de $\gamma_{p^{\prime}}^{\pi}$ deve ser 1 pois esta decisão incrementa a função objetivo.

Por exemplo, em uma situação na qual o poço produtor entre no instante 5 (ou seja, este é o $k_{p^{*}}$ ) e seu respectivo injetor entre no instante 9(sendo este o valor de $k_{p^{\prime}}$ ), haveria o seguinte cenário: os quatro primeiros períodos de produção do poço produtor não possuiria injetor em operação. Sendo assim, $\gamma_{p^{\prime}}^{1}, \gamma_{p^{\prime}}^{2}, \gamma_{p^{\prime}}^{3}$ e $\gamma_{p^{\prime}}^{4}$ devem possuir valor zero. Os termos de $\gamma_{p^{\prime}}^{5}$ em diante devem ser positivos (até o limite $T$ de análise, garantido pelas restrições 22 e 24), demonstrando que o injetor já está operando e pode adicionar valor à função objetivo. Este raciocínio explica a necessidade de adicionar uma unidade à expressão $k_{p^{\prime}}-k_{p^{*}}$ pois, de outra forma, o termo $\gamma_{p^{\prime}}^{4}$ já poderia ter valor 1, o que não é desejável. Isto se explica pois a inequação é do tipo maior ou igual $(\geq)$ e permitiria que $4 \gamma_{p^{\prime}}^{4}\left(\pi \gamma_{p^{\prime}}^{\pi}\right.$, do primeiro membro da restrição 23) fosse maior que 4 (valor de $\left.k_{p^{\prime}}-k_{p^{*}}\right)$. Adicionando-se uma unidade, garante-se que apenas do quinto elemento $\left(\gamma_{p^{\prime}}^{5}\right)$ em diante possa assumir valor 1 .

O conjunto de restrições (24) possui a finalidade de impedir que um injetor acrescente valor à função objetivo antes da entrada do produtor associado ou após a finalização do horizonte de análise. Assim como nas restrições (23), elas são aplicáveis para cada par de poço - um produtor com seu respectivo injetor.

As restrições (25), (26), (27), (28) e (29) são os domínios das variáveis que, por se relacionarem a tempo, podem assumir valores reais e maiores ou iguais a zero. As restrições (30), (31) e (32), (33) e (34) também versam sobre o domínio das variáveis que, no caso, são binárias. 


\subsection{Caso-piloto para a formulação matemática}

Para que pudesse ser verificada a eficácia da formulação proposta, foi realizado um estudo piloto de um pequeno caso, programado no software CPLEX em um computador Dell Studio XPS 8100, de processador Intel Core i7 de 2,93 GHz e memória RAM de 16Gb. O problema contempla todos os fatores abordados na formulação porém, é composto de apenas 2 poços - 1 produtor e 1 injetor e, portanto, constam 6 atividades de interligação - e 2 PLSVs. Veja na Figura 5 a configuração deste problema piloto.

Figura 5 - Esquema do problema piloto para teste da formulação matemática

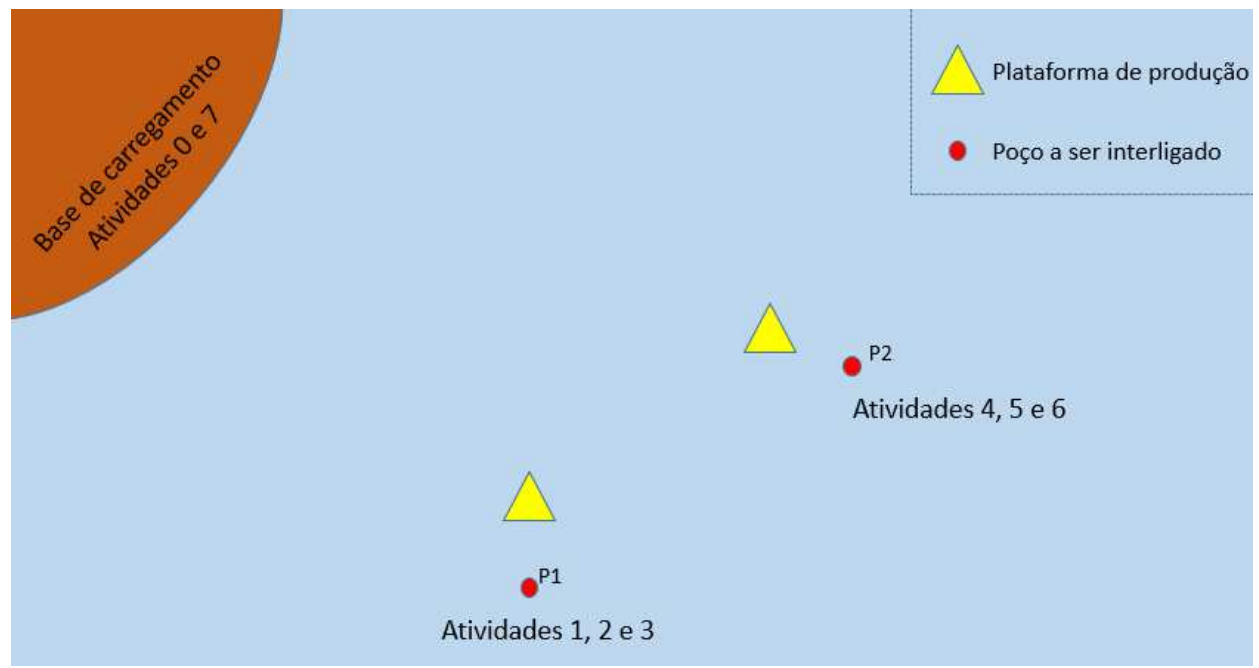

Como dados de entrada do problema, precisa-se dos tempos de translado $d_{i j}$, que podem ser vistos na Tabela 2. 
Tabela 2 - Tempos de translado entre as atividades (em dias)

\begin{tabular}{|c|c|c|c|c|c|c|c|c|c|}
\cline { 2 - 10 } \multicolumn{2}{c|}{} & \multicolumn{7}{c|}{ Para } \\
\cline { 2 - 11 } \multicolumn{2}{c|}{} & At. 0 & At. 1 & At. 2 & At. 3 & At. 4 & At. 5 & At. 6 & At. 7 \\
\hline At. 0 & 0 & 2 & 2 & 2 & 3 & 3 & 3 & 0 \\
\hline At. 1 & 2 & 0 & 0 & 0 & 1 & 1 & 1 & 2 \\
\hline At. 2 & 2 & 0 & 0 & 0 & 1 & 1 & 1 & 2 \\
\hline At. 3 & 2 & 0 & 0 & 0 & 1 & 1 & 1 & 2 \\
\hline At. 4 & 3 & 1 & 1 & 1 & 0 & 0 & 0 & 3 \\
\hline At. 5 & 3 & 1 & 1 & 1 & 0 & 0 & 0 & 3 \\
\hline At. 6 & 3 & 1 & 1 & 1 & 0 & 0 & 0 & 3 \\
\hline At. 7 & 0 & 2 & 2 & 2 & 3 & 3 & 3 & 0 \\
\hline
\end{tabular}

Os valores utilizados como parâmetros de entrada para o caso piloto serão todos fictícios, apenas utilizados para validação da formulação. Pode ser visto na Tabela 2 que, para atividades a serem efetuadas no mesmo poço, o tempo de translado é nulo. Da base, para o poço 1 , o tempo é 2 e vice-versa. Da base para o poço 2, o tempo é 3 e vice-versa. Para percursos entre os poços, o tempo de translado é 1 . As atividades 0 e 7 representam a base de carregamento.

Os outros parâmetros de entrada podem ser verificados na Tabela 3.

Tabela 3 - Parâmetros de entrada para caso piloto

\begin{tabular}{ccccccc}
\hline $\boldsymbol{p}$ & Tipo & $\boldsymbol{i}$ & $\boldsymbol{s}_{\boldsymbol{i}}$ & $\boldsymbol{q}_{\boldsymbol{i}}$ & $\boldsymbol{D} \boldsymbol{C}_{\boldsymbol{i}}$ & $\boldsymbol{D M}_{\boldsymbol{i}}$ \\
\hline \multirow{3}{*}{$\mathbf{1}$} & \multirow{3}{*}{ Produtor } & $\mathbf{1}$ & 3 & 5 & 4 & 3 \\
& & $\mathbf{2}$ & 4 & 4 & 4 & 8 \\
& & $\mathbf{3}$ & 5 & 6 & 4 & 7 \\
\multirow{2}{*}{$\mathbf{2}$} & \multirow{2}{*}{ Injetor } & $\mathbf{4}$ & 5 & 6 & 6 & 2 \\
& & $\mathbf{5}$ & 6 & 4 & 6 & 10 \\
& & $\mathbf{6}$ & 7 & 5 & 6 & 12 \\
\hline
\end{tabular}

Na Tabela 3, há os dados para os dois poços. Em ordem: o tipo do poço, o número de cada uma das atividades atreladas $(i)$, a duração prevista para execução da mesma $\left(s_{i}\right)$, o tamanho do duto de cada atividade $\left(q_{i}\right)$, o instante fim da completação do poço $\left(D C_{i}\right)$ e o instante a partir do qual o material está disponibilizado na base para carregamento $\left(D M_{i}\right)$.

Para este caso, assume-se que as duas embarcações são idênticas e ambas são capazes, tecnicamente, de realizar todas as atividades. Ou seja, $m_{i}^{b}$ possui valor 1 para todos os casos, 
independente da atividade e do $P L S V$ em questão. O limite de armazenamento das embarcações, em cada roteiro, também é igual e assumido como $12 \mathrm{Km}$ de duto. Trabalha-se também com um tempo de 180 dias para análise do volume de produção a ser obtido na configuração ótima que se deseja alcançar. Para cada embarcação foi possibilitado que realizasse até 3 roteiros sequenciais.

A curva de potencial de produção para este teste é assumida com seu valor inicial em 180 (primeiro dia em que ele produzir) e vai decrescendo uma unidade a cada dia de produção. Quanto ao poço injetor (poço 2), assume-se que, quando o mesmo entrar em operação, irá adicionar 3\% ao volume produzido no momento pelo poço 1 .

Realizando a programação, obtém-se na saída do CPLEX as seguintes variáveis $X_{i j}^{r b}$ com valor positivo, conforme a Tabela 4 .

Tabela 4 - Índices das variáveis $X_{i j}^{r b}$ positivas na solução ótima

\begin{tabular}{cccc}
\hline \multicolumn{4}{c}{ Índice da variável $\boldsymbol{X}_{\boldsymbol{i} \boldsymbol{j}}^{\boldsymbol{r b}}$} \\
\hline $\boldsymbol{i}$ & $\boldsymbol{j}$ & $\boldsymbol{r}$ & $\boldsymbol{b}$ \\
0 & 1 & 1 & 1 \\
1 & 7 & 1 & 1 \\
0 & 2 & 2 & 1 \\
2 & 7 & 2 & 1 \\
0 & 5 & 3 & 1 \\
5 & 4 & 3 & 1 \\
4 & 7 & 3 & 1 \\
0 & 3 & 1 & 2 \\
3 & 7 & 1 & 2 \\
0 & 7 & 2 & 2 \\
0 & 6 & 3 & 2 \\
6 & 7 & 3 & 2 \\
\hline
\end{tabular}

Analisando o conjunto roteiro e embarcação, pode-se traçar os roteiros definidos no caminho ótimo bem como cruzar os dados com o início do atendimento em cada um destes instantes, como apresenta a Tabela 5. 
Tabela 5 - Dados de saída de tempo e ordem de atendimento, por roteiro-embarcação

\begin{tabular}{|c|c|c|c|c|c|c|}
\hline \multicolumn{2}{|c|}{ Embarcação/Roteiro } & \multicolumn{5}{|c|}{ Percurso/Instantes de início } \\
\hline \multirow{6}{*}{$\mathrm{b}=1$} & \multirow[b]{2}{*}{$\mathrm{r}=1$} & Trajeto & At. 0 & \multirow{2}{*}{\multicolumn{2}{|c|}{ At. 1}} & At. 7 \\
\hline & & $g_{i}^{11}$ & 5,5 & & & 12,5 \\
\hline & \multirow[b]{2}{*}{$r=2$} & Trajeto & At. 0 & \multicolumn{2}{|c|}{ At. 2} & At. 7 \\
\hline & & $g_{i}^{21}$ & 14,5 & \multicolumn{2}{|c|}{17} & 23 \\
\hline & \multirow{2}{*}{$\mathrm{r}=3$} & Trajeto & At. 0 & At. 5 & At. & At. 7 \\
\hline & & $g_{i}^{31}$ & 28 & 31,5 & 38 & 46 \\
\hline \multirow{4}{*}{$\mathrm{b}=2$} & \multirow{2}{*}{$\mathrm{r}=1$} & Trajeto & At. 0 & \multicolumn{2}{|c|}{ At. 3} & At. 7 \\
\hline & & $g_{i}^{12}$ & 10 & \multicolumn{2}{|c|}{12} & 19 \\
\hline & \multirow[b]{2}{*}{$r=3$} & Trajeto & At. 0 & \multicolumn{2}{|c|}{ At. 6} & At. 7 \\
\hline & & $g_{i}^{32}$ & 21,5 & \multicolumn{2}{|c|}{24,5} & 34,5 \\
\hline
\end{tabular}

Quando se analisa cada um dos roteiros, dentro de cada embarcação, nota-se que os mesmos guardam sentido. Alguns fatos que merecem ser destacados:

- embora a sequência rigorosa de numeração dos roteiros não seja respeitada (por exemplo, na embarcação 2, não há roteiro 2 apenas os roteiros 1 e 3), a resposta guarda sentido. Isto deve-se ao fato de existir múltiplas respostas ótimas. Sendo utilizados dois roteiros de uma mesma embarcação, poderiam ser escolhidos pelo software os roteiros 1 e 2, ou 2 e 3, ou 1 e 3. Em termos de resposta, o que se espera é que os instantes de início do roteiro posterior fossem maiores e sequenciais aos do roteiro anterior;

- analisando os instantes resultantes nas variáveis $g_{i}^{r b}$, verifica-se que eles são totalmente condizentes com aquilo que é esperado, de acordo com os dados de entrada. Isto pode ser melhor verificado através de um gráfico de Gantt, com visão de recurso PLSV e visão de atividades de poço, conforme apresentado na Figura 6. Pode-se verificar que são obedecidos, os tempos de espera de materiais (no início do percurso de cada barco), carregamentos (de acordo com a quantidade de $\mathrm{Km}$ de linhas de dutos em cada roteiro), navegações e período de execução das atividades; 
Figura 6 - Gráfico de Gantt com visão recursos e atividades para caso piloto

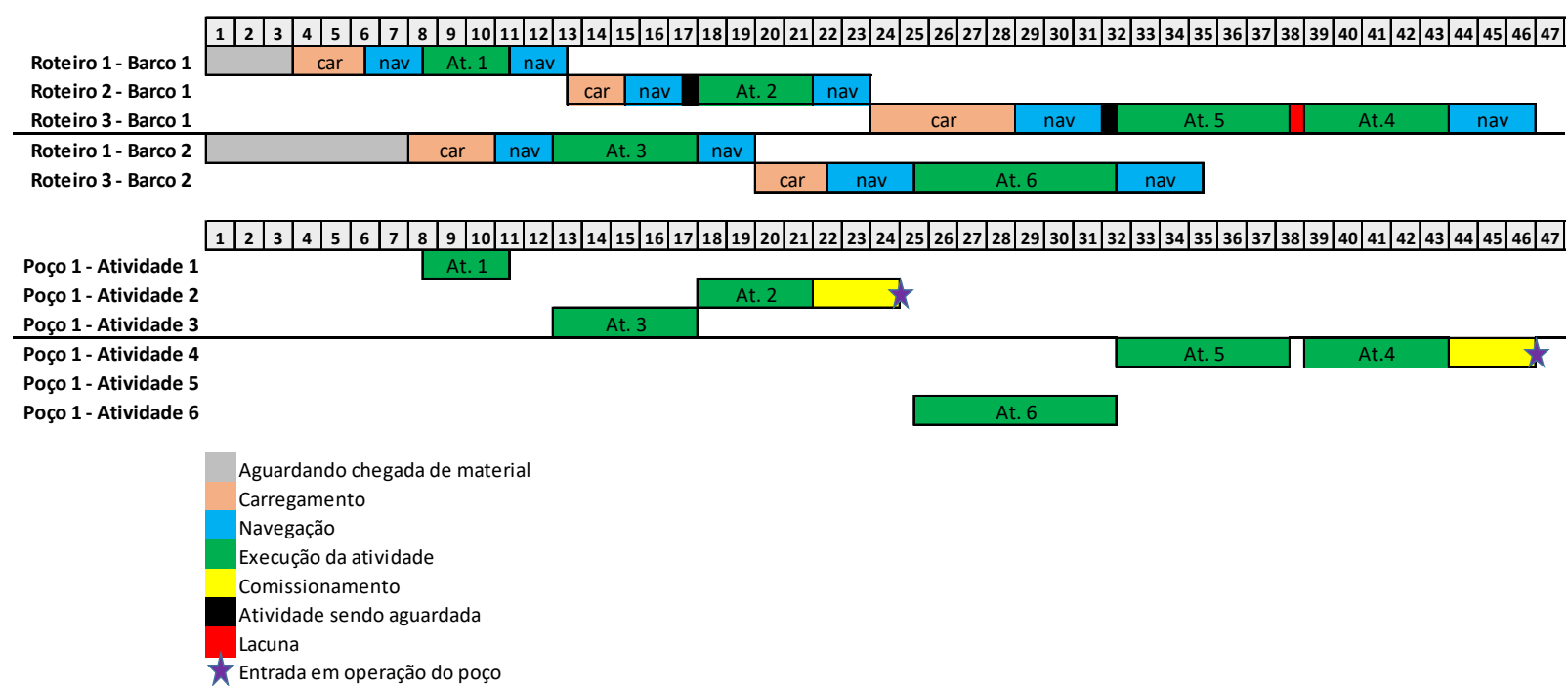

- os tempos de carregamento são calculados de acordo com as restrições (9) e (10);

- a Tabela 6 apresenta a quantidade de dutos em cada roteiro bem como o tempo, em dias, esperado para o carregamento dos mesmos, em cada roteiro;

Tabela 6 - Quantidade de dutos e tempos de carregamento para caso piloto

\begin{tabular}{|c|c|c|c|c|}
\hline & Atividades & $\begin{array}{l}\text { Quantidade de duto } \\
\text { (Km) }\end{array}$ & $\begin{array}{c}\text { Tempo de } \\
\text { carregamento (d) }\end{array}$ & F. Obj. \\
\hline Roteiro 1 - Barco 1 & 1 & 5 & 2,5 & \multirow{5}{*}{16357,83} \\
\hline Roteiro 2 - Barco 1 & 2 & 4 & 2 & \\
\hline Roteiro 3 - Barco 1 & 5 e 4 & 10 & 5 & \\
\hline Roteiro 1 - Barco 2 & 3 & 6 & 3 & \\
\hline Roteiro 3 - Barco 2 & 6 & 5 & 2,5 & \\
\hline
\end{tabular}

- quando se realiza uma alteração na quantidade de barcos disponíveis tem-se, como esperado, resultados diferentes na otimização. As Figuras 7 e 8 trazem os resultados para, respectivamente, os casos de acréscimo de uma embarcação ( 3 embarcações, factíveis para todas as atividades, de capacidade igual ao caso original, com até 2 roteiros por $P L S V$ ) e caso de decréscimo de uma embarcação (1 embarcação, factível para todas as atividades, de capacidade ainda igual, com até 6 roteiros no $P L S V$ ). Quanto mais embarcações se possui disponíveis para a geração da roteirização, mais antecipado é o trabalho, em geral. Um quadro resumo pode ser visto na Tabela 7. 
Figura 7 - Gráfico de Gantt com visão recursos e atividades para caso piloto com acréscimo de um PLSV

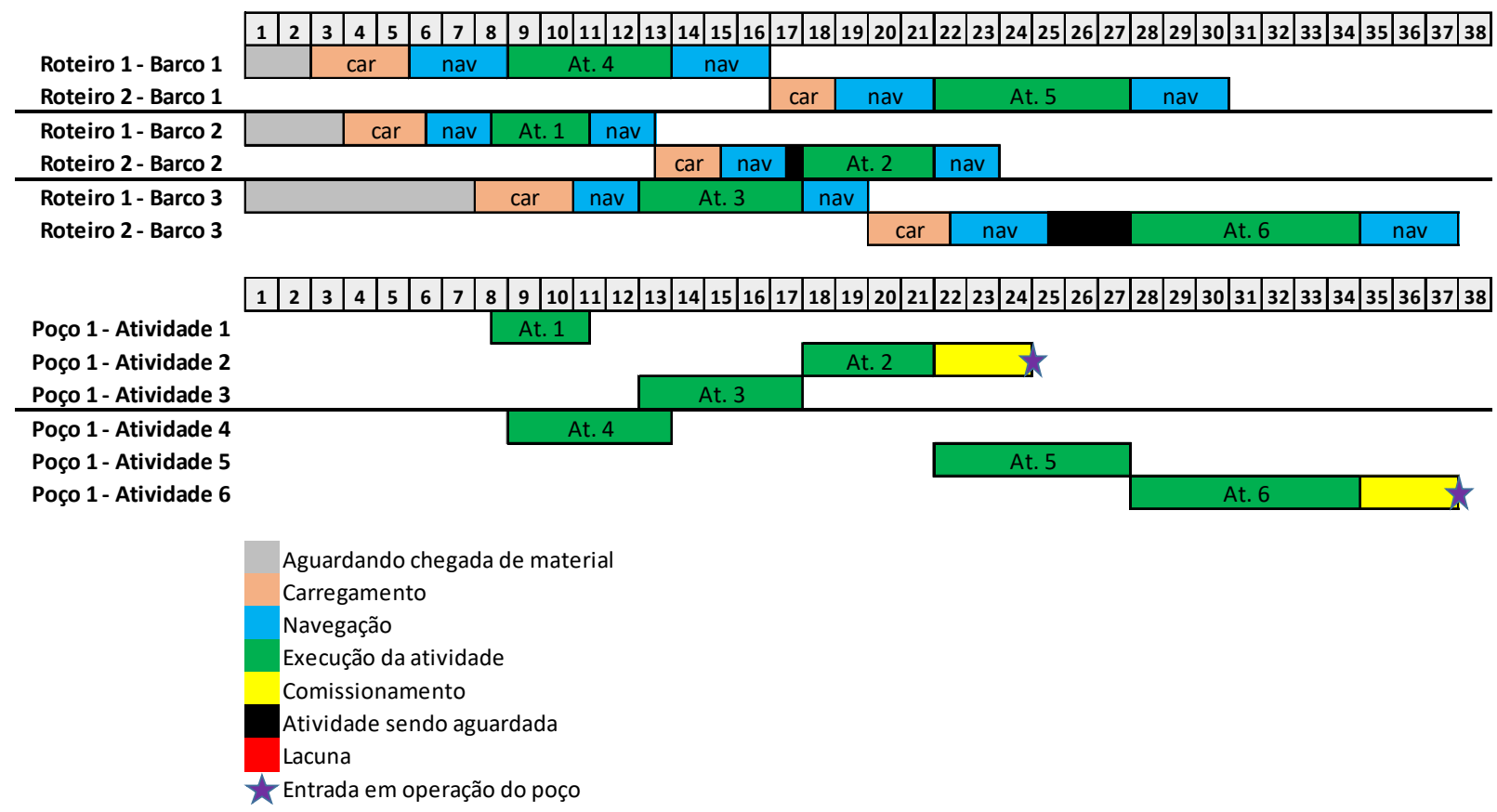

Figura 8 - Gráfico de Gantt com visão recursos para caso piloto com redução de um PLSV

Roteiro 1 - Barco 1 Roteiro 2 - Barco 1

\begin{tabular}{|c|c|c|c|c|c|c|c|c|c|c|c|c|c|c|c|c|c|c|c|c|c|}
\hline \multirow[t]{2}{*}{1} & \multirow{2}{*}{\multicolumn{2}{|c|}{\begin{tabular}{l|l}
2 & 3 \\
\end{tabular}}} & \multicolumn{2}{|c|}{\begin{tabular}{l|l}
4 & 5 \\
\end{tabular}} & 6 & 7 & 8 & \begin{tabular}{l|l|}
9 & 10 \\
\end{tabular} & \begin{tabular}{|l|l|l|l|}
12 & 1 \\
\end{tabular} & \begin{tabular}{l|l|}
13 & 14 \\
\end{tabular} & 15 & 16 & 18 & \begin{tabular}{|l|l|}
19 & 2 \\
\end{tabular} & 20 & \begin{tabular}{|l|l|}
22 & 23 \\
\end{tabular} & \begin{tabular}{|l|l}
25 & 2 \\
\end{tabular} & \begin{tabular}{|l|l|l|}
6 & 27 & 28 \\
\end{tabular} & \begin{tabular}{|l|l|}
30 & 31 \\
\end{tabular} & \multirow[t]{2}{*}{\begin{tabular}{l|l|l|}
1 & 32 & 3 \\
\end{tabular}} & \begin{tabular}{|l|l|}
33 & 34 \\
\end{tabular} \\
\hline & & 3 & & car & & nav & & At. 1 & nav & & & & & & & & & & & & \\
\hline & & & & & & & & & & & car & & & nav & & At. 3 & & At. 2 & nav & & \\
\hline & & & & & & & & & & & & & & & & & & & & car & nav \\
\hline
\end{tabular}

Roteiro 3 - Barco 1 Roteiro 4 - Barco 1

\begin{tabular}{|l|l|l|l|l|l|l|l|l|l|l|l|l|l|l|l|l|l|l|l|l|l|l|l|l|l|l|l|l|l|l|l|l|l|}
\hline 35 & 36 & 37 & 38 & 39 & 40 & 41 & 42 & 43 & 44 & 45 & 46 & 47 & 48 & 49 & 50 & 51 & 52 & 53 & 54 & 55 & 56 & 57 & 58 & 59 & 60 & 61 & 62 & 63 & 64 & 65 & 66 & 67 & 68 \\
\hline
\end{tabular} \begin{tabular}{|c|c|c|c|}
\hline nav & At. 5 & nav & \\
\hline
\end{tabular}

\begin{tabular}{|l|l|l|l|l|l|l|l|l|l|l|l|l|l|l|l|l|l|l|l|l|l|l|l|l|l|l|l|l|l|l|l|l|l|}
\hline 1 & 2 & 3 & 4 & 5 & 6 & 7 & 8 & 9 & 10 & 11 & 12 & 13 & 14 & 15 & 16 & 17 & 18 & 19 & 20 & 21 & 22 & 23 & 24 & 25 & 26 & 27 & 28 & 29 & 30 & 31 & 32 & 33 & 34 \\
\hline
\end{tabular}

Poço 1 - Atividade 1

Poço 1 - Atividade 2

Poço 1 - Atividade 3

Poço 1 - Atividade 4

Poço 1 - Atividade 5

Poço 1 - Atividade 6

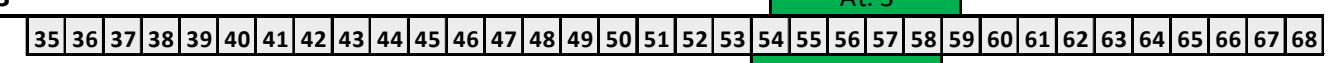
At. 1
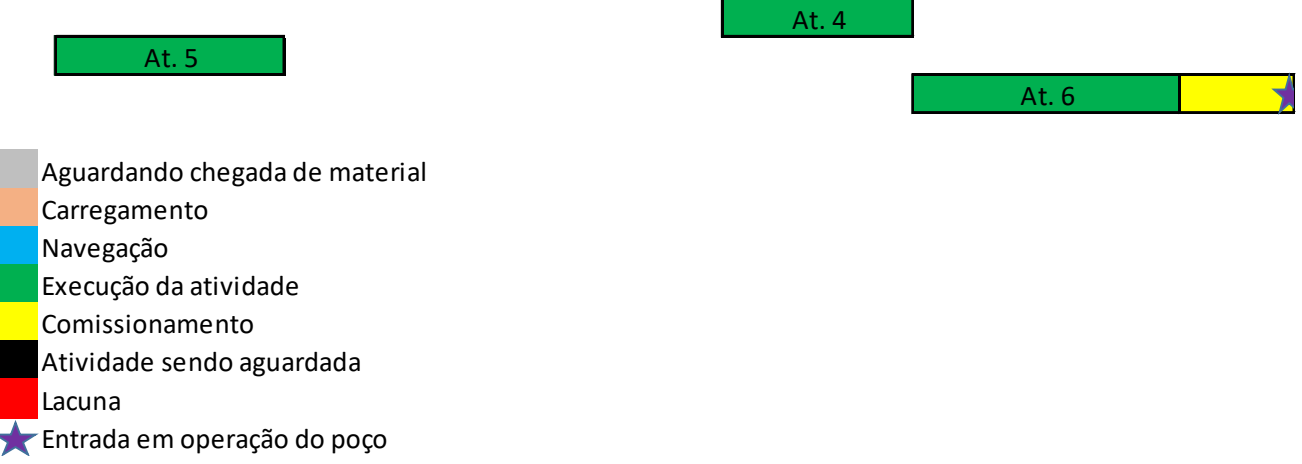
Tabela 7 - Quadro resumo dos casos piloto para teste da formulação matemática

\begin{tabular}{|c|c|c|c|c|c|c|c|c|c|}
\cline { 2 - 10 } \multicolumn{1}{c|}{} & \multicolumn{4}{c|}{ Instante fim da atividade } & \multicolumn{3}{c|}{ Instante entrada poço } & \multirow{2}{*}{ F. Obj. } \\
\cline { 2 - 11 } \multicolumn{1}{c|}{} & At.1 & At. 2 & At.3 & At.4 & At.5 & At.6 & Poço 1 & Poço 2 & \\
\hline 1 PLSV & 10,5 & 28,5 & 24,5 & 58 & 41,5 & 65 & 32 & 68 & $16.059,36$ \\
\hline 2 PLSVs & 10,5 & 21 & 20 & 43 & 37,5 & 31,5 & 24 & 46 & $16.357,83$ \\
\hline 3 PLSVs & 10,5 & 21 & 17 & 13 & 27 & 34 & 24 & 37 & $16.401,84$ \\
\hline
\end{tabular}

A Tabela 7 mostra que, de maneira geral, quanto mais $P L S V s$ são utilizados, o término das tarefas é antecipado e, com isto, os poços entram em operação antes e o valor da função objetivo aumenta. Uma série de testes foram realizados, variando-se a quantidade de PLSVs, número de roteiros por embarcação utilizada, quantidade de poços e atividades a serem efetuadas, verificandose a variação em termos de tempo de processamento e resultado da função objetivo. Foram mapeadas também a quantidade de restrições e de variáveis binárias e reais utilizadas na configuração de cada um dos problemas.

Para a realização do teste completo, o caso inicial apresentado foi extrapolado para um de 9 atividades. A Tabela 8 e a Figura 9 resumem os dados de entrada para os testes computacionais ampliados.

Tabela 8 - Insumos para os testes computacionais ampliados

\begin{tabular}{|c|c|c|c|c|c|c|}
\hline$p$ & $\mathbf{i}$ & si & qi & $\mathrm{DCi}$ & DMi & Plataforma \\
\hline \multirow{3}{*}{ p1 } & 1 & 3 & 5 & 4 & 3 & \multirow{3}{*}{ U1 } \\
\hline & 2 & 4 & 4 & 4 & 8 & \\
\hline & 3 & 5 & 6 & 4 & 7 & \\
\hline \multirow{3}{*}{ p2 } & 4 & 5 & 6 & 6 & 2 & \multirow{3}{*}{ U2 } \\
\hline & 5 & 6 & 4 & 6 & 10 & \\
\hline & 6 & 7 & 5 & 6 & 12 & \\
\hline \multirow{3}{*}{ p3 } & 7 & 6 & 4 & 4 & 3 & \multirow{3}{*}{ U3 } \\
\hline & 8 & 5 & 7 & 4 & 4 & \\
\hline & 9 & 3 & 5 & 4 & 17 & \\
\hline
\end{tabular}


Figura 9 - Esquema de localização dos poços e UEPs para os testes computacionais ampliados

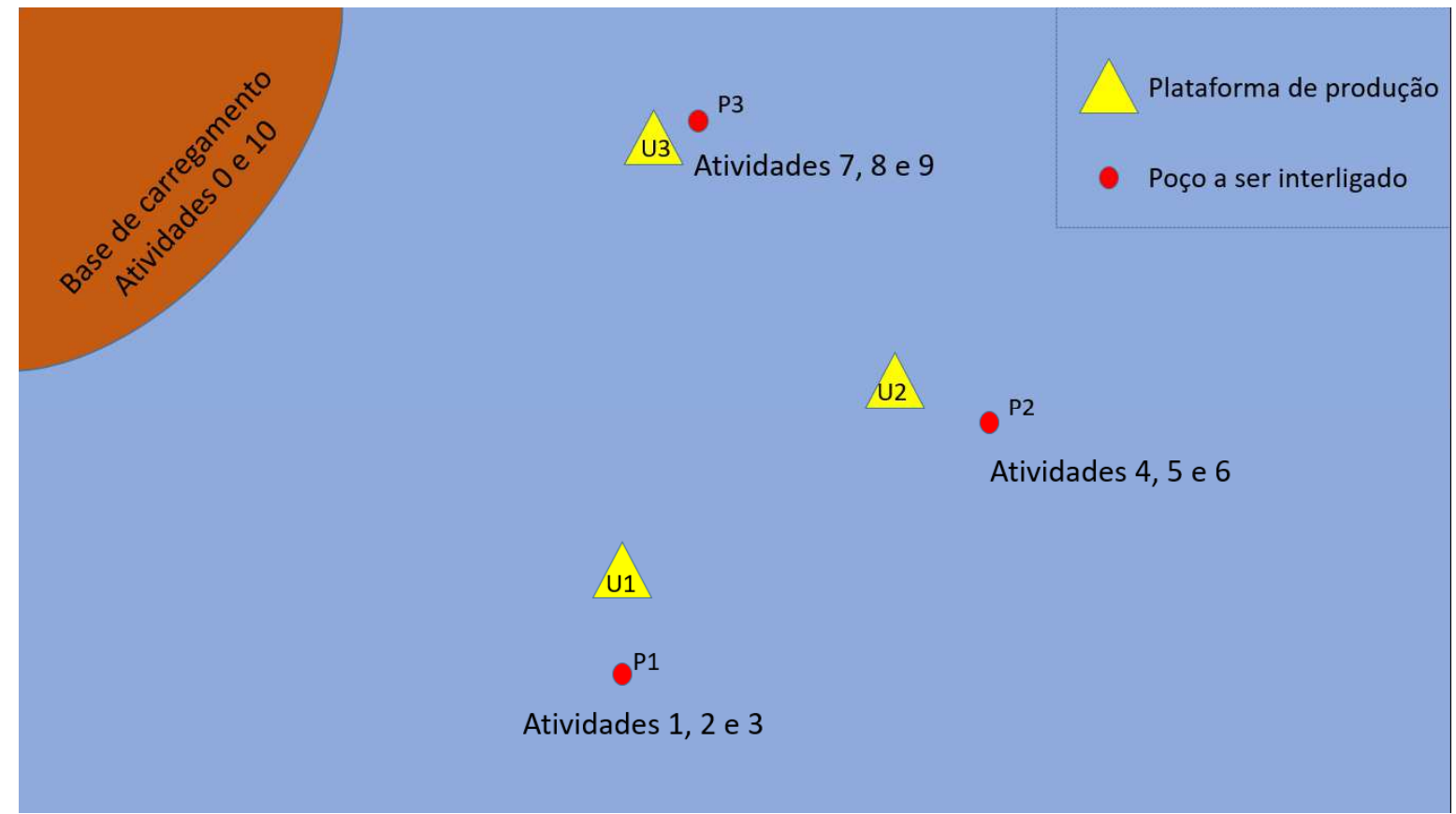

Foi utilizada a mesma unidade computacional para a realização de todos os testes (Dell Studio XPS 8100, de processador Intel Core i7 de 2,93 GHz e memória RAM de 16Gb). A Tabela 9 apresenta os resultados destes testes. 
Tabela 9 - Testes computacionais realizados utilizando o modelo proposto

\begin{tabular}{|c|c|c|c|c|c|c|c|c|c|c|c|}
\hline \multicolumn{12}{|c|}{ Testes realizados } \\
\hline Teste & Poços & Atividades & PLSVs & Roteiros & Variáveis Binárias & Variáveis reais & Restrições & Horizonte & Fobj & Tempo processamento & Tempo (s) \\
\hline 1 & 2 & 6 & 1 & 2 & 506 & 43 & 871 & 180 & infact & $0,11 \mathrm{~s}$ & 0,1 \\
\hline II & 2 & 6 & 1 & 3 & 576 & 60 & 1018 & 180 & 15866,52 & 30 & 30,0 \\
\hline III & 2 & 6 & 1 & 4 & 646 & 77 & 1165 & 180 & 16059,36 & $3 \mathrm{~min} 06 \mathrm{~s}$ & 186,0 \\
\hline IV & 2 & 6 & 1 & 5 & 716 & 98 & 1312 & 180 & 16059,36 & $9 \min 33 \mathrm{~s}$ & 573,0 \\
\hline v & 2 & 6 & 1 & 6 & 786 & 111 & 1459 & 180 & 16059,36 & $23 \min 26 s$ & 1406,0 \\
\hline VI & 2 & 6 & 1 & 7 & 856 & 128 & 1606 & 180 & 16059,36 & $1 \mathrm{~h} 20 \mathrm{~min} 00 \mathrm{~s}$ & 4800,0 \\
\hline VII & 2 & 6 & 2 & 1 & 506 & 43 & 870 & 180 & infact & $0,11 \mathrm{~s}$ & 0,1 \\
\hline VIII & 2 & 6 & 2 & 2 & 646 & 77 & 1164 & 180 & 16319,7 & $1 \mathrm{~min} 42 \mathrm{~s}$ & 102,0 \\
\hline IX & 2 & 6 & 2 & 3 & 786 & 111 & 1458 & 180 & 16357,83 & $12 \min 56 s$ & 776,0 \\
\hline$x$ & 2 & 6 & 2 & 4 & 926 & 145 & 1752 & 180 & 16357,83 & $44 \min 41 \mathrm{~s}$ & 2681,0 \\
\hline$X I$ & 2 & 6 & 3 & 1 & 576 & 60 & 1016 & 180 & 16341,84 & $4,47 \mathrm{~s}$ & 4,5 \\
\hline XII & 2 & 6 & 3 & 2 & 786 & 111 & 1457 & 180 & 16401,84 & $2 \min 31 s$ & 191,0 \\
\hline XIII & 2 & 6 & 3 & 3 & 996 & 162 & 1898 & 180 & 16401,84 & $2 \mathrm{~h} 9 \min 55 \mathrm{~s}$ & 7795,0 \\
\hline XIV & 2 & 6 & 3 & 4 & 1206 & 213 & 2339 & 180 & 16401,84 & $24 \mathrm{~h} 13 \min 52 \mathrm{~s}$ & 87232,0 \\
\hline$x V$ & 2 & 6 & 4 & 1 & 646 & 77 & 1162 & 180 & 16381,98 & $6,3 \mathrm{~s}$ & 6,3 \\
\hline $\mathrm{XVI}$ & 2 & 6 & 4 & 2 & 926 & 145 & 1750 & 180 & 16427,34 & $3 \min 10 \mathrm{~s}$ & 190,0 \\
\hline$X V I I$ & 2 & 6 & 4 & 3 & 1206 & 213 & 2338 & 180 & 16427,34 & $4 \mathrm{~h} 31 \mathrm{~min} 40 \mathrm{~s}$ & 16300,0 \\
\hline XVIII & 2 & 6 & 4 & 4 & 1486 & 281 & 2926 & 180 & 16427,34 & $108 \mathrm{~h} 44 \mathrm{~min} 14 \mathrm{~s}$ & 391454,0 \\
\hline$X I X$ & 2 & 6 & 5 & 1 & 716 & 94 & 1308 & 180 & 16417,05 & $7,4 \mathrm{~s}$ & 7,4 \\
\hline$x x$ & 2 & 6 & 5 & 2 & 1066 & 179 & 2043 & 180 & 16432,53 & $1 \mathrm{~h} 42 \mathrm{~min} 42 \mathrm{~s}$ & 6162,0 \\
\hline$X X I$ & 2 & 6 & 6 & 1 & 786 & 111 & 1454 & 180 & 16432,53 & $16,89 \mathrm{~s}$ & 16,9 \\
\hline XXII & 3 & 9 & 2 & 3 & 1149 & 151 & 2034 & 180 & out $(3,47 \%)$ & $36 \mathrm{~h} 34 \mathrm{~min} 15 \mathrm{~s}$ & 131655,0 \\
\hline
\end{tabular}


As colunas da Tabela 9 expressam o seguinte:

- teste: mera ordenação do teste;

- poços: quantidade de poços que foi utilizada naquele determinado teste. Foram realizados testes com 2 e 3 poços;

- atividades: dado que cada poço é assumido de ter 3 atividades, o número desta coluna é a multiplicação do número de poços por 3;

- PLSVs: número de embarcações PLSVs utilizadas como disponíveis em cada um dos testes realizados;

- roteiros: número de roteiros disponíveis, por PLSV, em cada um dos testes realizados;

- variáveis binárias: número de variáveis binárias que o modelo utiliza em cada um dos testes. Ou seja, a quantidade de $X_{i j}^{r b}, Y_{i}^{r b}, \mu_{p^{*}}^{\pi}, \gamma_{p^{\prime}}^{\pi}$ e $a_{i 1, i 2}$ que o problema precisa naquela configuração;

- variáveis reais: como a formulação apresentada vale-se apenas de variáveis binárias e reais, é o número de todas as variáveis que não são binárias. Portanto, é o somatório dos $t_{i}^{r b}, g_{i}^{r b}$, $\sigma^{r b}, \alpha_{i}$ e $k_{p}$

- restrições: número de restrições em cada um dos testes realizados e reflete a quantidade requerida expressa nos conjuntos de (2) a (32) na formulação matemática apresentada. Pode-se notar que a quantidade de variáveis binárias, reais e restrições influencia a complexidade computacional do mesmo e o número das mesmas cresce conforme o porte do problema. Porém, isto não significa, necessariamente, que o problema seja mais demorado de se resolver dado que a quantidade de restrições pode fazer o problema aproximar-se da envoltório convexa, o que facilita sua resolução;

- horizonte: foi utilizado o mesmo horizonte de tempo para apuração do volume de produção possível em cada teste. Ou seja, no decorrer de 180 dias apurar-se-á qual a produção que é obtida no cenário ótimo;

- função objetivo: valor da função objetivo no cenário ótimo de cada teste, que refere-se ao volume produzido acumulado no horizonte de tempo de análise, com a configuração de interligação desejada e sujeita às restrições. Pode-se notar que, nesta coluna, estão utilizadas as expressões "infact" e "out". A primeira refere-se a situações em que não foi possível obter nenhuma solução viável, ou seja, o problema foi infactível. Isto se explica porque a quantidade $(\mathrm{Km})$ de dutos a serem carregados superou a capacidade de armazenamento das embarcações. A segunda refere-se à 
capacidade de processamento ser excedida, quando a árvore do branch-and-bound ficou de tamanho superior à capacidade do computador, o que o levou ao problema "out-of-memory" no CPLEX;

- Tempo de processamento: tempo que o computador, através do software CPLEX 12.1, levou para obter a configuração ótima. Esta informação foi obtida através da janela de estatísticas do próprio software;

- Tempo(s): tempo de processamento de cada teste nivelado na unidade de segundos.

Pode-se notar que, para testes realizados a partir de 3 poços - ou seja, 9 atividades -, não foi possível a resolução ótima por conta de exceder a capacidade de processamento de um computador padrão - conforme esperado dado que o Problema de Roteamento de Veículos clássico é classificado como NP-hard -, o que mostra que será necessário um procedimento heurístico de resolução, dado que o volume de dados que se pretende tratar é da ordem de centenas de poços.

Como resultado, na Tabela 9, obteve-se o esperado no valor da função objetivo, dado que um maior número de roteiros por embarcação ou um incremento do número de $P L S V s$ propicia um aumento da disponibilidade de recursos para realizar o carregamento e interligação no momento exato que seus pré-requisitos são atendidos. Ou seja, com um aumento de recursos, as atividades de interligação podem ocorrer cada vez mais just in time, propiciando que haja uma antecipação e, consequentemente, uma produção de óleo antecipada. As Figuras 10 e 11 apresentam detalhes dos resultados dos testes ampliados para a formulação matemática.

Figura 10 - Tempo de processamento versus o número de roteiros por embarcação, por cenário de $P L S V s$

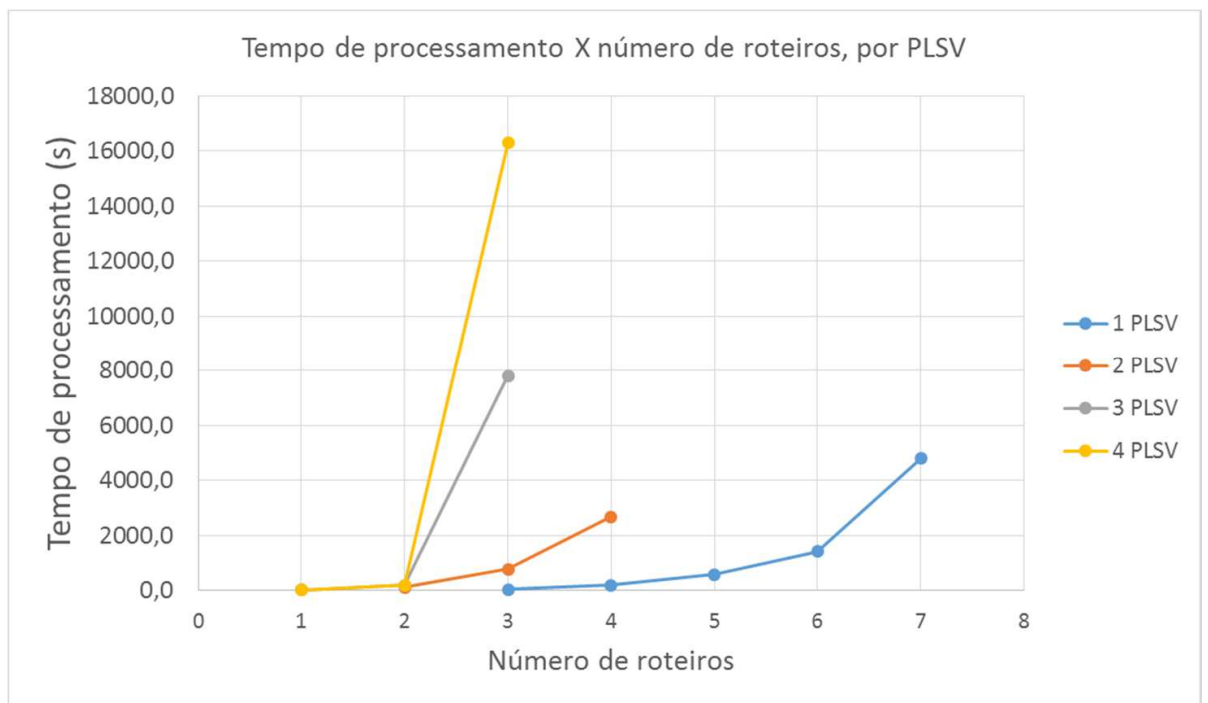


Figura 11 - Tempo de processamento versus valor da função objetivo em cenários de igual quantidade total de roteiros

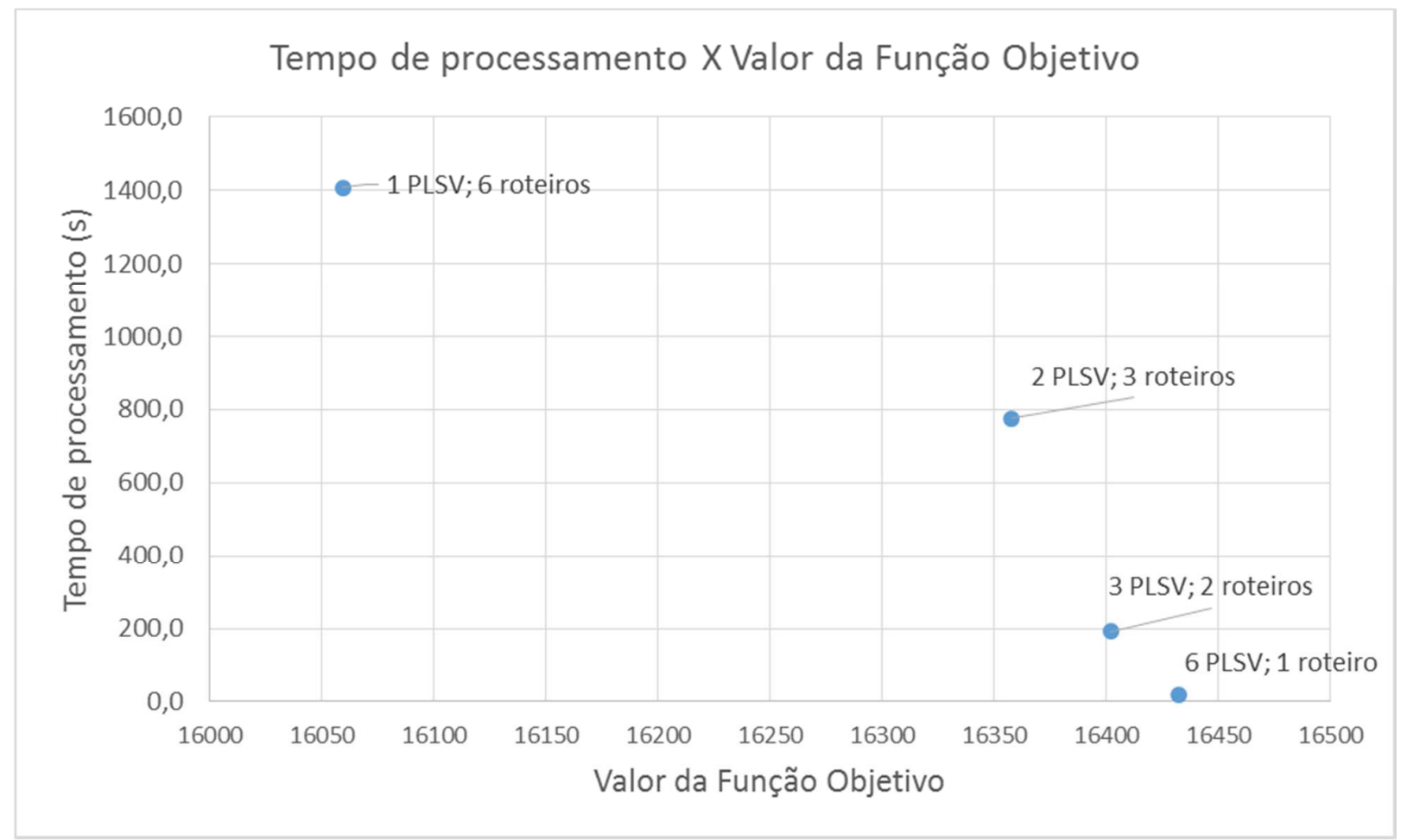

A Figura 10 mostra que os cenários com menor número de $P L S V s$ apresentam menor tempo computacional para se atingir o resultado ótimo. Cada curva representa um cenário com determinada quantia de PLSVs. O eixo das abscissas apresenta o número de roteiros por embarcação. Ou seja, a curva azul apresenta os cenários nos quais 1 PLSV podia ter de 3 a 7 roteiros para se obter a solução ótima. Pode-se notar, graficamente, que ocorre o esperado: quanto maior o número de variáveis e restrições do modelo, maior o tempo de processamento para se obter a melhor solução. Pode-se notar também que, quanto maior o número de PLSVs para uma mesma quantidade de roteiros possíveis em cada um, aumenta-se o tempo de processamento também.

Já a Figura 11 apresenta o comportamento para testes que possuem a mesma quantidade total de roteiros. Em todos estes casos, há um total de 6 roteiros (resultado da multiplicação do número de barcos pelo número de roteiros em cada um). Este gráfico esclarece que a formulação traz melhores resultados, tanto em termos de tempo de processamento quando em valor da função objetivo, para os testes que possuem uma quantidade maior de PLSVs. Este comportamento faz 
bastante sentido pois quanto mais embarcações disponíveis, mais prontamente atendida uma atividade será.

Nos testes abordados na Figura 11, há também o mesmo número de variáveis inteiras e reais e quase o mesmo número de restrições, o que garante um bom comparativo entre os resultados das instâncias. Para explicar este fato, outra informação interessante de ser abordada é a função geral que fornece a quantidade de variáveis binárias, de variáveis reais e de restrições, com base nas dimensões das principais informações de entrada do problema. Isto é, de acordo com a quantidade de atividades que serão trabalhadas $(I)$, horizonte de tempo trabalhado( $T$ ), número de embarcações $(B)$ e número de roteiros por $\operatorname{barco}(R)$, pode-se estabelecer uma função que nos apresenta o porte do problema a ser trabalhado computacionalmente.

Para as variáveis binárias, compostas pelas variáveis $X_{i j}^{r b}, Y_{i}^{r b}, \mu_{p^{*}}^{\pi}, \gamma_{p^{\prime}}^{\pi}$ e $a_{i 1, i 2}$, tem-se que a função geral é o apresentado nas equações 1 e 2, de acordo com o somatório das dimensões de cada um dos conjuntos de variáveis.

$$
\begin{gathered}
f(T, I, B, R)=(I+2)^{2} R B+I R B+T+T+I \\
f(T, I, B, R)=2 T+I+R B\left(I^{2}+5 I+4\right)
\end{gathered}
$$

A equação 1 é apenas o desenvolvimento algébrico intermediário da equação 2. Pode-se notar que existe um termo dependente da multiplicação $R B$, ou seja, do número de roteiros por embarcação vezes o número de $P L S V s$ do teste em questão. As equações 3 e 4 apresentam a mesma análise para as variáveis reais, que é o conjunto das variáveis $t_{i}^{r b}, k_{p}, \sigma^{r b}, g_{i}^{r b}$ e $\alpha_{i}$.

$$
\begin{gathered}
f(T, I, B, R)=2(I+2) R B+\frac{I}{3}+R B+I+1 \\
f(T, I, B, R)=R B(2 I+5)+\frac{4 I}{3}+1
\end{gathered}
$$

Eq. 3

Pode-se notar que, analogamente ao que ocorre com as equações 1 e 2, existe um termo dependente de $R B$. Dado que, nos primeiros testes (aqueles de 6 atividades), tem-se um valor constante de $I$ e $T$, acaba que a variação do número de variáveis binárias e reais varia de acordo com os valores de $R$ e $B$, predominantemente. Como os casos expressos na Figura 10 possuem 
todos um valor de $R B$ constante e igual a 6 , seus números de variáveis são iguais. Porém, conforme já abordado, o comportamento da formulação se apresenta diferenciado.

Já a função geral para o número de restrições apresenta uma leve diferença entre estes casos analisados. As equações 5 e 6 explicam o porquê isto ocorre.

$$
\begin{array}{cc}
f(T, I, B, R)= & 9 R I B+\frac{19 I}{3}+4 R B+3 T+B(R-1)+(I+2)^{2} R B+3(I+2) R B \\
f(T, I, B, R)=\frac{19 I}{3}+3 T+R B\left(I^{2}+16 I+15\right)-B & \text { Eq. } 5
\end{array}
$$

A equação 6 (e seu desenvolvimento intermediário, equação 5) apresenta o mesmo termo $R B$ abordado nas equações anteriores, porém traz um termo isolado $(-B)$, o que explica a queda de uma restrição com o aumento de um $P L S V$ embora haja manutenção do valor do termo $R B$ nestes casos analisados na Figura 11.

Ainda sobre a Figura 11 e as diferenças sobre o tempo computacional despendido, pôde-se extrair através do CPLEX dados sobre o branch-and-bound realizado para estas instâncias. Estas informações referem-se às iterações realizadas pelo software e sobre a quantidade de nós em aberto (ainda a serem analisados). A partir da análise destas informações será possível a inferência do comportamento que leva a um tempo mais favorável para as instâncias de maior número de PLSVS. As Figuras 12 e 13 apresentam, graficamente, os dados obtidos. 
Figura 12 - Número de nós restantes versus o número da iteração na resolução dos casos de multiplicação RB constante apresentados

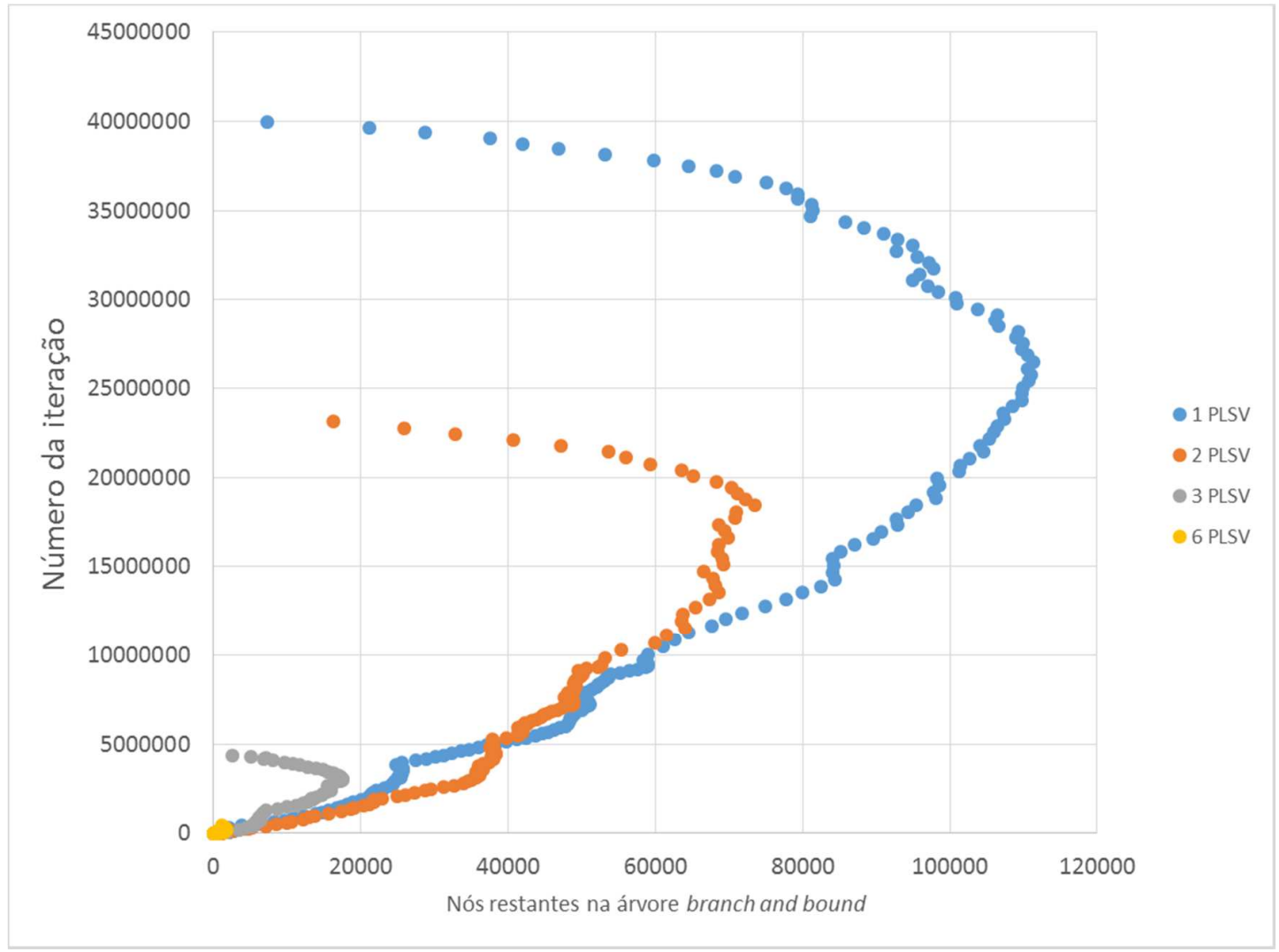

Figura 13 - Detalhe do número de nós restantes versus o número da iteração para o caso de 6 PLSVs

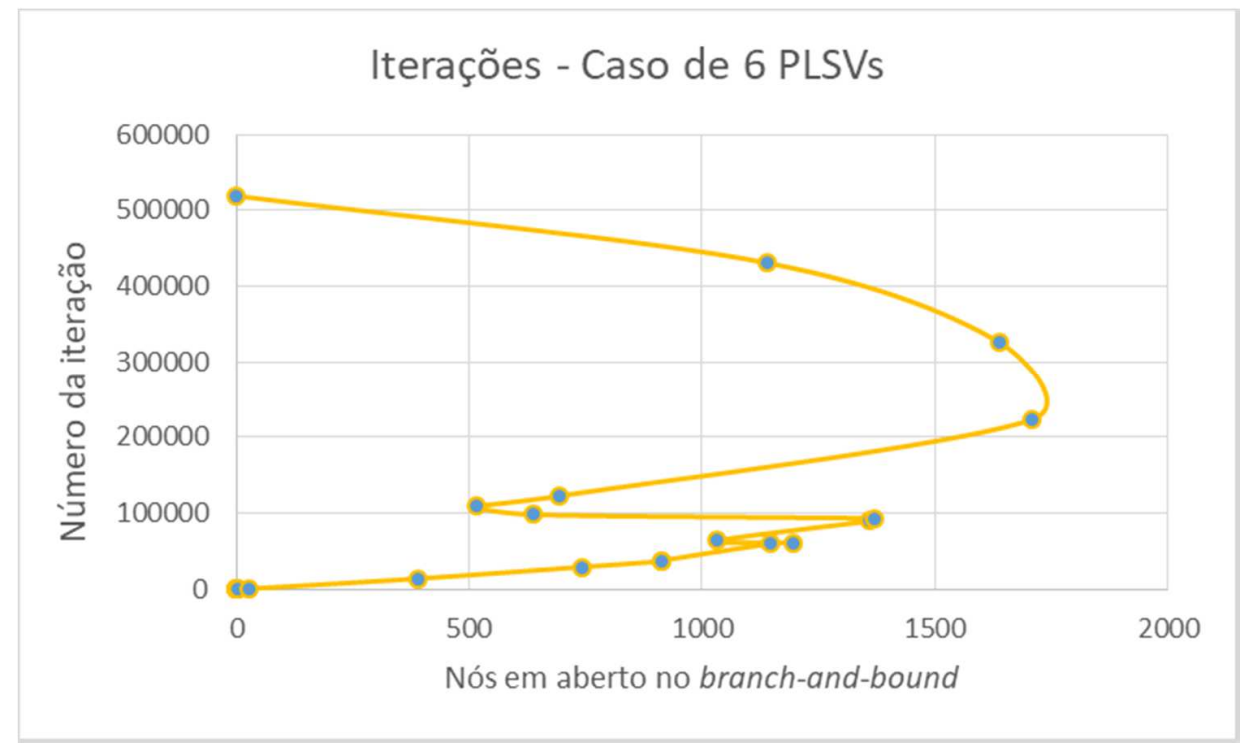


A Figura 12 apresenta, no eixo ordenado, o número sequencial da iteração realizada no CPLEX e, no eixo das abscissas, o número de nós em aberto na árvore de análise do branch-andbound. Assim, constitui-se a linha do tempo daquilo que o algoritmo do software está realizando nestes 4 cenários ( 1 PLSV e 6 roteiros cada; 2 PLSVs e 3 roteiros cada; 3 PLSVs e 2 roteiros cada; e, 6 PLSVs e 1 roteiro cada). Nota-se que, independente do cenário, o comportamento ao longo do tempo é o mesmo: aumenta-se o número de nós em aberto da árvore, com períodos de suaves estabilizações deste número até se chegar a um pico, a partir do qual começa a ser reduzido este valor, até que todos os nós sejam avaliados. Esta configuração de dados também nos permite inferir que o CPLEX está realizando maiores cortes de ramos das árvores no cenário de mais PLSVs, dado que não permite que o número de nós em aberto cresça muito. Esta é uma evidência de que sempre cortes de grande proporção são realizados, provavelmente, com valores muito bons de função objetivo tendo sido encontrados desde o início da resolução computacional.

A Tabela 10 apresenta os valores de número total de nós analisados e número de iterações realizadas pelo software, o que corrobora com o que foi discutido até o momento sobre este tópico.

Tabela 10 - Número total de iterações versus número de nós analisados

\begin{tabular}{ccc}
\hline Cenário & Total de nós analisados & Iterações \\
\hline 1 PLSV; 6 roteiros & 2.161 .850 & 40.012 .535 \\
2 PLSV; 3 roteiros & 1.421 .432 & 23.346 .143 \\
3 PLSV; 2 roteiros & 277.547 & 4.431 .317 \\
6 PLSV; 1 roteiro & 31.711 & 519.072 \\
\hline
\end{tabular}

Portanto, dadas as análises sobre os resultados obtidos na formulação matemática, entendese que os mesmos são de grande relevância e representam fielmente as características do problema em questão. Contudo, em decorrência da obtenção de solução ótima apenas para pequenas instâncias, faz-se necessário aprofundar os estudos para o desenvolvimento de uma heurística, o que será tratado no capítulo 5. 


\section{Elaboração das heurísticas construtivas}

O objetivo deste capítulo é a elaboração de procedimentos heurísticos que sejam capazes de resolver instâncias maiores - os problemas de cunho real são da ordem de centenas de atividades - do problema de interligação de poços de petróleo offshore com a utilização de embarcações do tipo PLSV. Como verificou-se no capítulo 4, com a formulação matemática do problema foi possível obter soluções ótimas para instâncias pequenas deste problema (6 atividades) com sucesso. As etapas percorridas até o momento - especialmente a revisão de literatura e elaboração do modelo matemático, com os resultados ótimos obtidos - denotam o conhecimento das circunstâncias do problema para a elaboração de uma heurística adequada.

Para tanto, serão elaboradas duas heurísticas construtivas (HC1 e HC2) pautadas nas características principais e limitantes da situação: instante de chegada dos materiais na base, instante de finalização da completação, viabilidade técnica das embarcações, capacidade de carregamento de cada embarcação, distâncias entre plataformas (e seus poços) e não-paralelismo de atividades de um mesmo poço. $\mathrm{O}$ intuito dela será prover uma solução de boa qualidade para o problema de alocação das embarcações às atividades de interligação.

A seguir, serão abordadas as duas estratégias heurísticas e seus resultados.

\subsection{Heurística Construtiva 1 (HC1)}

A ideia geral da primeira heurística é criar uma lista de prontidão (lista_pro) a partir da qual exista uma ordem de alocação das atividades aos PLSVs, os quais se encontrarão vazios no momento inicial do algoritmo. O conceito genérico da lista de prontidão é inserir as atividades em ordem crescente de sua data de disponibilidade (isto é, tanto de materiais quanto de completação finalizada). Em paralelo a esta relação, é criada uma outra listagem (ativ_pri) com os números das atividades às quais se referem os instantes expressos na lista de prontidão. No decorrer das alocações, as rotinas e loopings do algoritmo traduzirão as principais características do problema, evitando que as restrições sejam infringidas. O algoritmo alocará os tempos de carregamento, navegação e a duração da atividade em si e também indicará os momentos nos quais deve-se fechar o carregamento e voltar à base para dar prosseguimento a novas atividades. 
O pseudocódigo da HC1 encontra-se na Figura 14. Para os dados de entrada (índices e parâmetros), foi utilizada a mesma notação constante no modelo matemático. As demais variáveis são autoexplicativas. Em seguida ao pseudocódigo, serão detalhadas as principais etapas deste algoritmo. 
1 Dados de entrada: $d_{i j}\left(i, j \in N^{+}\right), s_{i}(i \in N), m_{i}^{b}(i \in N, b \in B), W_{p *}^{\pi}\left(p^{*} \in N^{p r o d}, \pi \in \Pi\right), D C_{i}(i \in N), D M_{i}(i \in N), q_{i}(i$ $2 \in N), Q_{b}(b \in B)$, comis, $\operatorname{Inj}_{p^{\prime}}^{\pi}\left(p^{\prime} \in N^{i n j}, \pi \in \Pi\right), \beta$

3 Saída: alocação de atividades aos barcos, atendendo às condições do problema

4 Inicializar os barcos, sem nenhuma pré-alocação

5 Criar lista de prontidão (lista_pro) onde constarão os instantes de liberação, considerando os desempates

6 Ordenar as atividades dentro da lista de prioridades (ativ_pri) em ordem crescente de prontidão,

7 fazendo relação/paralelo com a lista de prontidão (lista_pro)

$8 t=0$

9 Enquanto $t<T$ faça

Enquanto lista_pro[0] $\leq t$ e há barco com espaço disponível faça

$$
b=0
$$$$
\text { cont_n_viab }=-1
$$

Enquanto $b<B$ faça

Se $\left(m[b]\left[a t i v \_p r i[0]\right]>0\right.$ e barco $b$ estiver vago no intervalo $t$ e a disponibilidade do material for até o momento de início do carregamento) então

Se há espaço para armazenagem da linha no barco $b$ então

Atribuir linha da atividade da primeira posição ao barco $b$

Aloque, na programação do barco $b$, os dias necessários para realização da operação (car + nav + ativ)

Marcar atividade como alocada

Reorganizar atividades do mesmo poço

$b=B-1$

Senão

/*Analisar a factibilidade em termos de espaço na embarcação das atividades ainda não alocadas* /

Enquanto não forem esgotadas as atividades não-alocadas e não ser encontrada uma atividade factível (viabilidade técnica, espaço na embarcação e material disponível no início do carregamento) para aquele barco faça

Se houver alguma atividade passível de ser alocada no barco $b$ naquele intervalo $t$ então Inserir a atividade nas primeiras posições das listas Fim Se

Fim enquanto

Se não houver atividade a ser alocada então

Fecha carregamento do barco $b$

Enviar barco de volta à base e computa a navegação do mesmo

\section{Fim Se}

Fim Se 
Se não tiver sido alocada a ativ_pri[0] por conta de disponibilidade de material no momento de início do carregamento então

Enquanto não forem varridas todas atividades ainda não alocadas ou encontrada alguma com disponibilidade de carregamento para aquele barco naquele instante $t$ faça

Se for encontrada atividade que atende restrição de viabilidade técnica, disponibilidade na base para carregamento e capacidade do barco então

Trazer tal atividade para o topo da lista Fim Se

Fim Enquanto

Se não foi encontrada atividade alocável então

Fecha carregamento do barco $b$

Enviar barco de volta à base e computa a navegação do mesmo

\section{Fim Se}

\section{Fim Se}

Se determinado barco não for viável tecnicamente ou não estiver vago ou a atividade não estava com prontidão no início deste roteiro do barco então cont_n_viab=cont_n_viab+1;

\section{Fim Se}

\section{Fim Se}

$b=b+1$

Se cont_n_viab $=B-1$ então

Adiciona 1 unidade de tempo na primeira atividade da lista de priorização

Reordena atividades da lista de prioridades

\section{Fim Se}

Fim Enquanto

\section{Fim Enquanto}

$$
t=t+1
$$

\section{Fim Enquanto}

Figura 14 - Pseudocódigo da heurística construtiva 1

Neste algoritmo, todos os barcos iniciam-se vagos, sem nenhuma pré-alocação (linha 4). A seguir, é criada uma lista de prontidão das atividades de interligação com base na ordem crescente do máximo entre a data de disponibilidade dos materiais na base e a data fim da completação menos 
o tempo de navegação até a locação do poço (a este cálculo, chama-se de prontidão da atividade). Importante salientar que a lista de prontidão é uma lista na qual constam os tempos (instantes) mínimos para início do carregamento da atividade. Em paralelo, há uma lista que traz o número das atividades, que será chamada de lista de prioridades. A atividade que consta em determinada posição nesta lista possui seu tempo na mesma posição na lista de prontidão. Nos movimentos que ocorrerem no decorrer do algoritmo, elas continuam mantendo esta relação entre posições nas listas para uma atividade e seu respectivo tempo. São critérios de desempate, na ordem, para a classificação da atividade nas listas de prontidão e de prioridade: se o poço é produtor e seu potencial de produção; número de linhas interligadas no mesmo poço desta atividade; se injetor, número de linhas já interligadas ao produtor em que está atrelado; e menor comprimento de linha (isto é apresentado resumidamente nas linhas 5 a 7 do algoritmo). Transformando isto em uma fórmula, o critério de desempate é uma ponderação por atividade do seguinte modo:

$$
\begin{aligned}
& \text { Desempate }[i]=100000 . t i p o . p o t e n c i a l+10000 .(\text { interl_demais_linhas_poço })+ \\
& + \text { 1000.(linhas_poço_prod_atrelado })+100-q[i]
\end{aligned}
$$

Onde:

- tipo: parâmetro binário, que vale 1 se é uma atividade de poço produtor e 0 , se é uma atividade de um poço injetor;

- potencial: potencial do poço produtor/injetor;

- interl_demais_linhas_poço: interligação das demais linhas do poço em questão; como cada poço tem 3 linhas, aqui é apurado se as outras duas linhas do poço já foram interligadas, resultando em um valor 0 ou 1 ou 2 ;

- linhas_poço_prod_atrelado: em caso de estarmos tratando de um poço injetor, esta parcela releva o fato de que o poço produtor ao qual ele está associado já teve suas linhas interligadas, seja parcialmente ou integralmente;

- 100 - q[i]: quanto menor o comprimento da linha da atividade em questão, maior será sua ponderação; isto faz com que poços que tenham menor comprimento de linha tenham prioridade para interligação, no caso em que todos os outros quesitos tenham empatado.

Se ainda assim houver empate entre atividades, é escolhida a de menor índice como mais prioritária. 
O looping principal do algoritmo (linhas 9 a 73) tem como base o tempo, que inicia no 0 . Neste determinado instante $t$, verifica-se se há algum barco disponível (vago) e também alguma atividade que tenha prontidão neste instante; se sim, verificar, na ordem sequencial dos barcos, se o barco em questão possui viabilidade técnica e o material está disponível no início do carregamento de determinado roteiro daquele barco (expresso nas linhas 8 a 15 do algoritmo).

Caso estejam satisfeitas as condições do parágrafo anterior, verifica-se se o barco possui capacidade de estocagem livre para receber a linha em questão (linha 16); se sim, alocar a atividade ao barco (carregamento, navegação e tempo de atividade), realocando na lista de prioridades as atividades do mesmo poço para o instante imediatamente seguinte ao fim da atividade recémalocada, e atribuindo-se um tempo $M$ (número grande) para esta que fora alocada (linhas 17 a 22 do algoritmo); se não, verificar se este barco pode ter seu carregamento fechado (através da verificação de que não há outra atividade que pode ainda ser realizada neste barco, o que ocorre a partir da linha 23). No caso de o barco não poder ter seu carregamento fechado, localizar a atividade que pode ser realizada neste barco ainda neste determinado instante e trazê-la para o topo da lista de prioridades (linhas 26 a 34).

Se o barco puder ter seu carregamento fechado por não comportar a estocagem de mais uma linha disponível para iniciar a operação de lançamento no instante $t$, fechar o carregamento e já planejar também a volta do barco à base (linhas 35 a 39). Caso a questão que restringe a alocação não seja o espaço na embarcação mas sim a disponibilidade para carregamento na base no início daquele determinado carregamento, percorrer a lista de atividades procurando alguma que tenha tal disponibilidade e possa ter seu lançamento iniciado no instante $t$ sendo que, caso ela seja encontrada, deve ser colocada no topo da lista (linhas 42 a 52); caso não tenha sido encontrada atividade neste $t$ que atenda tais condições, fecha-se o carregamento (linhas 53 a 57).

Nas linhas 59 a 62, há uma condicional que adiciona uma unidade em um contador caso naquele instante $t$ o barco tenha possuído uma limitação de capacidade técnica ou não estiver vago ou a atividade a ser alocada não tinha disponibilidade no início do carregamento em questão. Ou seja, para um determinado instante $t$, percorre-se toda a frota de barcos (linha 65) e a mesma está com todo barcos indisponíveis por algum motivo. Este indicador vai ser importante pois quando ele se iguala ao número de barcos da frota, deve-se incrementar o contador de tempo do algoritmo, o que ocorre nas linhas 65 a 69. As linhas 70 a 73 acabam por finalizar os loopings. O algoritmo 
termina quando todas as datas de prontidão das tarefas forem maiores (possuírem valor de $M$ grande) que o limite máximo $(T)$, o que sempre acabará por infringir as condições de entrada no looping nas linhas 9 e 10.

\subsection{Comparação da HC1 com os resultados ótimos}

O primeiro teste a ser realizado com a então proposta de heurística construtiva é comparála com os resultados obtidos através da programação do modelo MILP (seção 4.2) no CPLEX. Este é um bom parâmetro para verificar qual é o gap médio que está se obtendo com relação à melhor solução possível. Para esta etapa, foram utilizados 30 problemas de pequeno porte. Estes 30 problemas foram obtidos em 6 conjuntos, todos eles utilizando-se 5 instâncias, que variam em quantidade de PLSVs e roteiros: 1 PLSV e 6 roteiros; 2 PLSVs e 3 roteiros; 3 PLSVs e 2 roteiros; 4 $P L S V s$ e 2 roteiros; $3 P L S V s$ e 2 roteiros. Os demais dados são iguais àqueles utilizados na seção que trata dos testes da formulação matemática (seção 4.1).

O primeiro conjunto (I) é idêntico a alguns dos testes já realizados e apresentados na Tabela 3. Os 5 outros conjuntos foram obtidos com as seguintes variações:

II) inversão das distâncias das plataformas à base (o que era a distância de uma plataforma até a base no caso original agora é a distância da outra plataforma até a base e vice-versa);

III) colocando-se um comprimento das linhas igual a $4 \mathrm{Km}$, de modo que caibam até 3 linhas em cada roteiro;

IV) alterando-se o comprimento das linhas para $8 \mathrm{Km}$, de modo que caiba apenas 1 linha por roteiro;

V) modificando os tempos de interligação para maiores - de $(3,4,5,5,6,7)$ para $(10,12,15,7,9,10)$;

VI) e com a completação do poço injetor sendo finalizada antes daquela do poço produtor.

Assim, chega-se a uma gama de problemas com diferentes características que formam um conjunto teste que possibilita testar o comportamento da heurística de um modo mais abrangente. Os resultados podem ser verificados na Tabela 11. 
Tabela 11 - Comparativo dos resultados ótimos e da HC1

\begin{tabular}{|c|c|c|c|c|c|c|c|c|c|}
\hline \multicolumn{10}{|c|}{ Ótimo } \\
\hline Conjunto & Poços & Atividades & PLSVs & Roteiros & Fobj & Tempo processamento & Tempo (s) & K1 & K2 \\
\hline \multirow{5}{*}{ I } & 2 & 6 & 1 & 6 & $16.059,4$ & $23 \min 26 \mathrm{~s}$ & 1406 & 31,5 & 68 \\
\hline & 2 & 6 & 2 & 3 & $16.357,8$ & $12 \min 56 \mathrm{~s}$ & 776 & 24 & 46 \\
\hline & 2 & 6 & 3 & 2 & $16.401,8$ & $2 \min 31 s$ & 191 & 24 & 37 \\
\hline & 2 & 6 & 4 & 2 & $16.427,3$ & $3 \min 10 s$ & 190 & 24 & 31,5 \\
\hline & 2 & 6 & 5 & 2 & $16.432,5$ & $1 \mathrm{~h} 42 \min 42 \mathrm{~s}$ & 6162 & 24 & 31 \\
\hline \multirow{5}{*}{ II } & 2 & 6 & 1 & 6 & $15.963,0$ & $1 \mathrm{~h} 21 \mathrm{~min} 11 \mathrm{~s}$ & 4871 & 35 & 69 \\
\hline & 2 & 6 & 2 & 3 & $16.291,9$ & $9 \mathrm{~min} 01 \mathrm{~s}$ & 541 & 27 & 46 \\
\hline & 2 & 6 & 3 & 2 & $16.369,7$ & $2 \min 35 s$ & 155 & 26 & 35 \\
\hline & 2 & 6 & 4 & 2 & $16.396,4$ & $6 \min 34 s$ & 214 & 25 & 34 \\
\hline & 2 & 6 & 5 & 2 & $16.417,3$ & $29 \min 39 \mathrm{~s}$ & 1779 & 25 & 30 \\
\hline \multirow{5}{*}{ III } & 2 & 6 & 1 & 6 & $16.155,3$ & $1 \mathrm{~h} 47 \min 50 \mathrm{~s}$ & 6470 & 30 & 59 \\
\hline & 2 & 6 & 2 & 3 & $16.387,3$ & $1 \mathrm{~h} 28 \mathrm{~min} 32 \mathrm{~s}$ & 5312 & 23 & 44 \\
\hline & 2 & 6 & 3 & 2 & $16.426,6$ & $6 \min 47 \mathrm{~s}$ & 407 & 23 & 36 \\
\hline & 2 & 6 & 4 & 2 & $16.452,1$ & $6 \mathrm{~h} 07 \min 11 \mathrm{~s}$ & 22031 & 23 & 31 \\
\hline & 2 & 6 & 5 & 2 & $16.452,1$ & 7h58min57s & 28737 & 23 & 31 \\
\hline \multirow{5}{*}{ IV } & 2 & 6 & 1 & 6 & $15.712,7$ & $3 \mathrm{~s}$ & 3 & 40 & 87 \\
\hline & 2 & 6 & 2 & 3 & $16.268,0$ & $1 \mathrm{~s}$ & 1 & 27 & 51 \\
\hline & 2 & 6 & 3 & 2 & $16.356,2$ & $0,82 \mathrm{~s}$ & 0,82 & 25 & 42 \\
\hline & 2 & 6 & 4 & 2 & $16.381,1$ & $1 \mathrm{~s} 85$ & 1,85 & 25 & 37 \\
\hline & 2 & 6 & 5 & 2 & $16.401,6$ & $1 \mathrm{~s} 98$ & 1,98 & 25 & 33 \\
\hline \multirow{5}{*}{ V } & 2 & 6 & 1 & 6 & $14.866,9$ & $17 \min 12 \mathrm{~s}$ & 1032 & 57 & 101 \\
\hline & 2 & 6 & 2 & 3 & $15.489,6$ & $3 \min 38 s$ & 218 & 48 & 63 \\
\hline & 2 & 6 & 3 & 2 & $15.567,4$ & $1 \mathrm{~min} 31 \mathrm{~s}$ & 91 & 48 & 46,5 \\
\hline & 2 & 6 & 4 & 2 & $15.567,4$ & $1 \mathrm{~min} 48 \mathrm{~s}$ & 108 & 47,5 & 45 \\
\hline & 2 & 6 & 5 & 2 & $15.567,4$ & $1 \mathrm{~h} 05 \mathrm{~min} 25 \mathrm{~s}$ & 3925 & 47,5 & 39 \\
\hline \multirow{5}{*}{ VI } & 2 & 6 & 1 & 6 & $15.712,1$ & $13 \min 49 \mathrm{~s}$ & 829 & 41 & 77,5 \\
\hline & 2 & 6 & 2 & 3 & $16.061,9$ & $13 \min 18 \mathrm{~s}$ & 798 & 35 & 48 \\
\hline & 2 & 6 & 3 & 2 & $16.129,8$ & $1 \mathrm{~min}$ & 60 & 35 & 35 \\
\hline & 2 & 6 & 4 & 2 & $16.129,8$ & $6 s 57$ & 6,57 & 35 & 31,5 \\
\hline & 2 & 6 & 5 & 2 & $16.129,8$ & $24 \mathrm{~s}$ & 24 & 35 & 33 \\
\hline
\end{tabular}

\begin{tabular}{|c|c|c|c|}
\hline \multicolumn{3}{|c|}{ Heurística Construtiva } & \multirow{2}{*}{ Gap } \\
\hline Fobj & K1 & K2 & \\
\hline $14.923,7$ & 59 & 65 & $7,07 \%$ \\
\hline $16.192,5$ & 32 & 40 & $1,01 \%$ \\
\hline $16.288,3$ & 29 & 37 & $0,69 \%$ \\
\hline $16.288,3$ & 29 & 37 & $0,85 \%$ \\
\hline $16.288,3$ & 29 & 37 & $0,88 \%$ \\
\hline $14.636,3$ & 64 & 60 & $8,31 \%$ \\
\hline $16.149,7$ & 34 & 37 & $0,87 \%$ \\
\hline $16.155,1$ & 34 & 36 & $1,31 \%$ \\
\hline $16.155,1$ & 34 & 36 & $1,47 \%$ \\
\hline $16.155,1$ & 34 & 36 & $1,60 \%$ \\
\hline $15.397,6$ & 50 & 63 & $4,69 \%$ \\
\hline $16.133,9$ & 34 & 40 & $1,55 \%$ \\
\hline $16.318,2$ & 28 & 36 & $0,66 \%$ \\
\hline $16.318,2$ & 28 & 36 & $0,81 \%$ \\
\hline $16.318,2$ & 28 & 36 & $0,81 \%$ \\
\hline $13.994,0$ & 72 & 87 & $10,94 \%$ \\
\hline $15.876,4$ & 40 & 51 & $2,41 \%$ \\
\hline $16.045,2$ & 36 & 45 & $1,90 \%$ \\
\hline $16.045,2$ & 36 & 45 & $2,05 \%$ \\
\hline $16.045,2$ & 36 & 45 & $2,17 \%$ \\
\hline $12.606,0$ & 89 & 98 & $15,21 \%$ \\
\hline $15.076,1$ & 57 & 49 & $2,67 \%$ \\
\hline $15.134,8$ & 56 & 48 & $2,78 \%$ \\
\hline $15.134,8$ & 56 & 48 & $2,78 \%$ \\
\hline $15.134,8$ & 56 & 48 & $2,78 \%$ \\
\hline $14.219,2$ & 70 & 57 & $9,50 \%$ \\
\hline $15.649,8$ & 45 & 37 & $2,57 \%$ \\
\hline $15.804,3$ & 43 & 37 & $2,02 \%$ \\
\hline $15.804,3$ & 43 & 37 & $2,02 \%$ \\
\hline $15.804,3$ & 43 & 37 & $2,02 \%$ \\
\hline & méc & & $3,21 \%$ \\
\hline
\end{tabular}


A Tabela 11 apresenta, em seu lado esquerdo, os resultados tendo por base o modelo matemático proposto no Capítulo 4. Cada conjunto de 5 linhas nesta Tabela referem-se a um dos subgrupos citados no início deste capítulo. Em seu lado direito, constam os resultados obtidos na heurística construtiva. Pode-se notar que os gaps com relação aos resultados ótimos variaram entre $0,66 \%$ e 15,21\%. Os maiores gaps foram observados nas instâncias com apenas $1 P L S V$, o que guarda coerência com o esperado pois mostra que, numa situação de grande restrição, a solução heurística se afasta do resultado ótimo devido à pequena quantidade de embarcações disponíveis em cada $t$. Sendo assim, quanto mais restrita a quantidade de barcos, mais importante o critério de escolha que a heurística apresenta.

Nas instâncias que possuem 2 PLSVs ou mais, o maior gap foi de 2,67\%, no cenário em que se aumentou os tempos de interligação, no conjunto V. Pode-se observar também que, a heurística construtiva apresenta um patamar de resultado constante ou muito similar nas instâncias de 3 a 5 PLSVs para todos os conjuntos analisados. Ou seja, pode-se constatar que a inclusão de $P L S V s$ não alterou o funcionamento da heurística e seu resultado nestes conjuntos a partir deste ponto. Para os casos de resolução ótima, esta mesma formação de patamar foi observada nos conjuntos V (estabilização do resultado ótimo em 15.567,42) e VI (estabilização do resultado ótimo em 16.129,80) e em menor escala nos demais conjuntos. Portanto, há uma convergência de comportamento de ambas as resoluções.

A média de gaps com relação ao cenário ótimo nestas pequenas instâncias foi de 3,21\%, o que representa um resultado bastante interessante para uma heurística construtiva.

Os resultados da heurística podem sofrer significativas variações de acordo com os dados de entrada e sua dispersão. Ou seja, o comportamento de estabilização do resultado a partir da inclusão de um determinado número de $P L S V s$ pode ser algo atrelado também à configuração dos dados. Para ampliar o entendimento sobre a heurística, portanto, é necessário verificar como ela se comporta com dados reais, o que será visto no item 5.3.

\subsection{Casos-piloto de aplicação da HCl}

Nesta etapa, para testar a eficácia dos resultados desta heurística construtiva, foram realizados testes com instâncias reduzidas do problema, utilizando-se dados reais. Esta etapa será importante para verificar se o comportamento apresentado está de acordo com esperado e se o mesmo apresenta peculiaridades não mapeadas até então. 
Os dados reais foram coletados considerando o planejamento de um ano inteiro (janeiro a dezembro) e versam sobre:

- o potencial de produção (se poço produtor);

- declínio de produção do poço (se poço produtor);

- taxa de injeção (se poço injetor);

- informações de viabilidade técnica de cada PLSV para cada atividade;

- data fim de completação de cada poço;

- data da chegada de materiais de cada atividade;

- comprimento de cada linha;

- duração prevista da atividade de interligação;

- tempo de navegação entre unidades de produção (para poços que são interligados a uma mesma plataforma de produção, foi considerado tempo de translado nulo);

- informações de qual(is) injetor(es) atende qual produtor;

Foram tomados os devidos cuidados para se manter o sigilo dos dados reais, de modo a não caracterizar os poços ou plataformas específicas sobre as quais se está falando, bem como para informações específicas técnicas de PLSVs e demais. A produção, por exemplo, foi alterada pela aplicação de fator multiplicativo, o que não prejudica as características do problema.

Para melhor avaliar, foram divididas as instâncias em 9 cenários, de acordo com dois critérios: o número de PLSVs a serem utilizados e a flexibilidade dos mesmos. A flexibilidade foi definida através do número de atividades que determinado PLSV atende dentro do portfolio de tarefas. Aqueles que atendiam a poucas tarefas dentro do portfolio como um todo foram caracterizados como de baixa flexibilidade. Do contrário, aqueles que atendiam a elevado número de tarefas dentro do portfolio, foram considerados como de alta flexibilidade. Os intermediários, foram incluídos no grupo de média flexibilidade. Tomou-se o cuidado de que, nos casos mais restritivos, houvesse ao menos um PLSV que atendesse a cada atividade.

Trabalhando-se com 3 níveis em cada critério (utilização de 4, 5 ou 6 PLSVs e categorias de alta, média e baixa flexibilidade) e efetuando o cruzamento entre critérios, chegou-se aos 9 cenários. Para verificar uma representatividade estatística, foram consideradas 30 instâncias de dados, cada uma composta pelas atividades a serem interligadas em duas plataformas distintas. Cada uma destas instâncias possui entre 33 e 45 atividades para interligação. Dado que há 30 instâncias e cada uma possui 9 cenários, foram realizados 270 testes no total. 
Importante salientar que cada caso utilizado possui características próprias, isto é, pode possuir datas de completação e chegada de materiais mais próximas ou mais espaçadas; pode contar com PLSVs mais ou menos flexíveis. Pode ocorrer de PLSVs de média flexibilidade para alguma atividade em específico serem mais restritivos do que PLSVs de baixa flexibilidade, dado que se olhou a flexibilidade do ponto de vista do portfolio de atividades e não para cada atividade isoladamente. Não seria possível considerar a flexibilidade de $P L S V$ por atividade pois, assim, haveria PLSVS caracterizados de modo diferente a serem destinados para um mesmo conjunto de atividades que formam uma instância. Ou seja, para uma atividade, um $P L S V$ poderia ser de baixa flexibilidade enquanto, para outra, este mesmo $P L S V$ poderia ser de média flexibilidade. Sendo assim, o critério de classificá-lo do ponto de vista do portfolio parece adequado. Os resultados dos testes são apresentados na Tabela 12. 
Tabela 12 - Resultados de potencial de produção nos testes da HC1 com dados reais

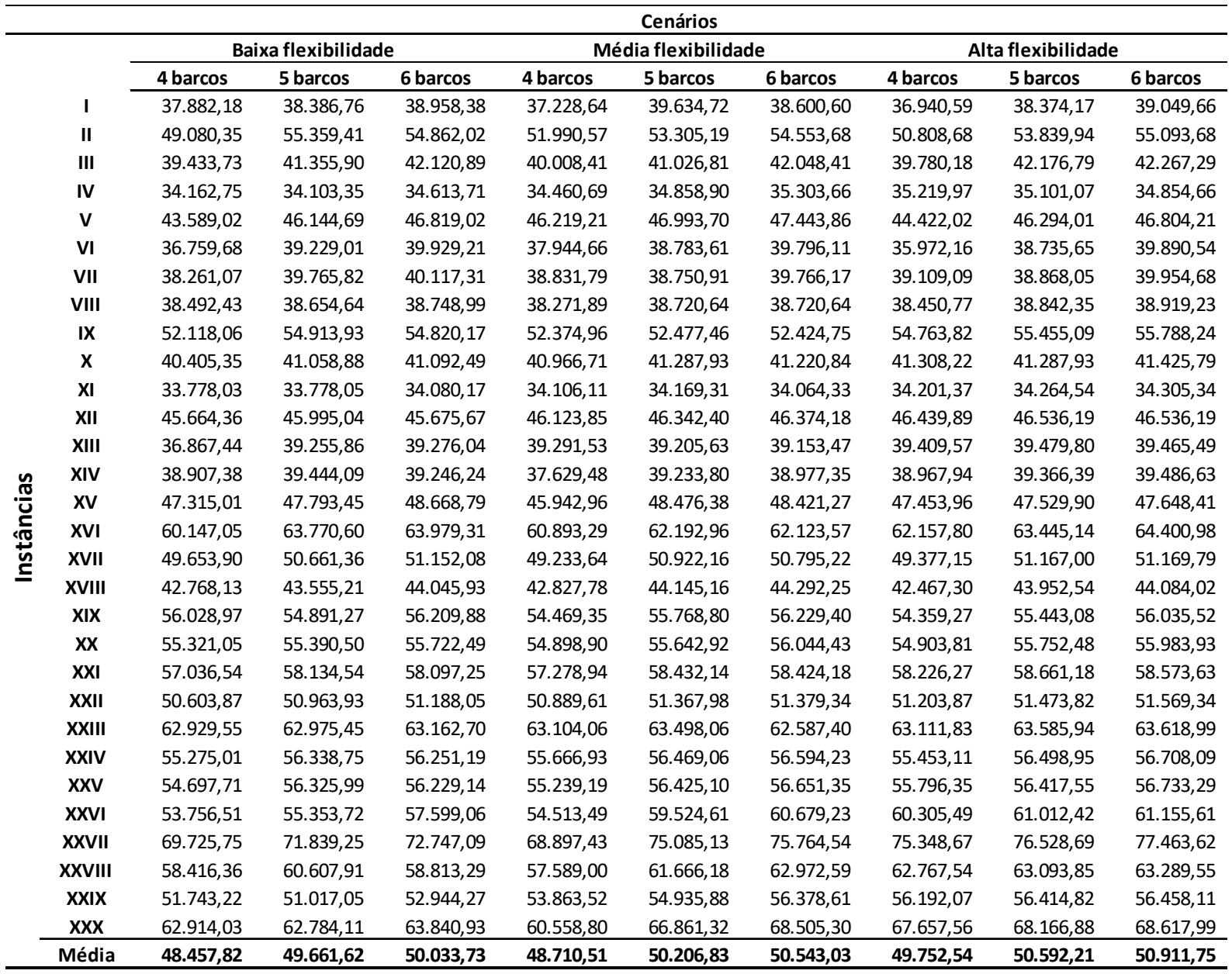

Todos os procedimentos referentes a heurísticas foram programados e rodados em um computador HP Pavilion, de processador Intel Celeron, $2.13 \mathrm{GHz}, 4 \mathrm{~Gb}$ de memória RAM. O tempo de processamento de cada instância, quando rodada separadamente, foi da ordem de $0,1 \mathrm{~s}$, o que pode ser devido a imprecisão na medição, por ser um valor muito baixo.

Ao analisar os dados da Tabela 12, percebe-se que, na grande maioria dos casos, os resultados comportam-se de acordo com o esperado. Ou seja, quando se compara apenas testes de 4 PLSVs, dentro de uma mesma instância, o resultado obtido para embarcações de baixa flexibilidade é menor que o resultado para barcos de média flexibilidade que, por sua vez, possuem valor menor de função objetivo que os cenários de $P L S V s$ de alta flexibilidade. Analogamente, para testes considerando apenas 5 PLSVs ou 6 PLSVs dentro de uma mesma instância. Já quando se compara, dentro de uma mesma instância, resultados obtidos dentro de barcos de um mesmo tipo de flexibilidade, tem-se resultados melhores com 6 PLSVs do que com 5 PLSVs que, por sua vez, são melhores que os resultados com 4 PLSVs. 
Todavia, existem alguns casos em que pode-se notar que, dentro de uma mesma instância, em seus 9 cenários, nem sempre os resultados melhoram com o aumento do número de PLSVs ou com a melhora de sua flexibilidade. Isto deve-se ao fato que esta heurística construtiva é míope, isto é, ela não enxerga a consequência da alocação de atividades no futuro para que isto interfira nas alocações presentes. Sendo assim, qualquer alteração, sob a óptica e lógica da heurística, interfere nas disponibilidades imediatas de embarcações para se realizar a alocação. A priori, a interligação de poços injetores frente a poços produtores garantem um acréscimo menor à curva de produção de óleo, dado que poços injetores não produzem por si só, mas sim incrementam a produção de poços produtores já em operação.

O que se verifica nas instâncias resolvidas é que, ao realizar o somatório de todos os instantes de conclusão de todas as atividades em testes de uma mesma instância, verifica-se uma redução conforme o incremento de PLSVs ou aumento de sua flexibilidade, o que é um bom indicador de que as atividades estão sendo antecipadas. Contudo, pela miopia da heurística, acabam sendo antecipadas, quando comparado às instâncias mais restritivas, as atividades de injeção e o critério de desempate acaba não sendo suficiente para corrigir este desvio, afinal, ele apenas é um desempate entre as tarefas que tem prontidão para aquele instante no qual está sendo analisada a alocação.

De todo modo, ao analisar-se o resultado global, nota-se que o comportamento da heurística está dentro do esperado, de acordo com dois critérios de análise. O primeiro, pela média de produção das 30 instâncias de cada cenário (como apresenta a Tabela 12); e o segundo, através de normalização, na qual, para cada instância, define-se o melhor resultado de um cenário como 100. Para os demais resultados, sempre iguais ou inferiores, calcula-se a proporção em uma escala de 0 a 100 e tira-se a média das 30 instâncias. O resultado, de acordo com este segundo critério de análise, encontra-se na Tabela 13. 
Tabela 13 - Resultados normalizados dos testes da $\mathrm{HC} 1$ com dados reais

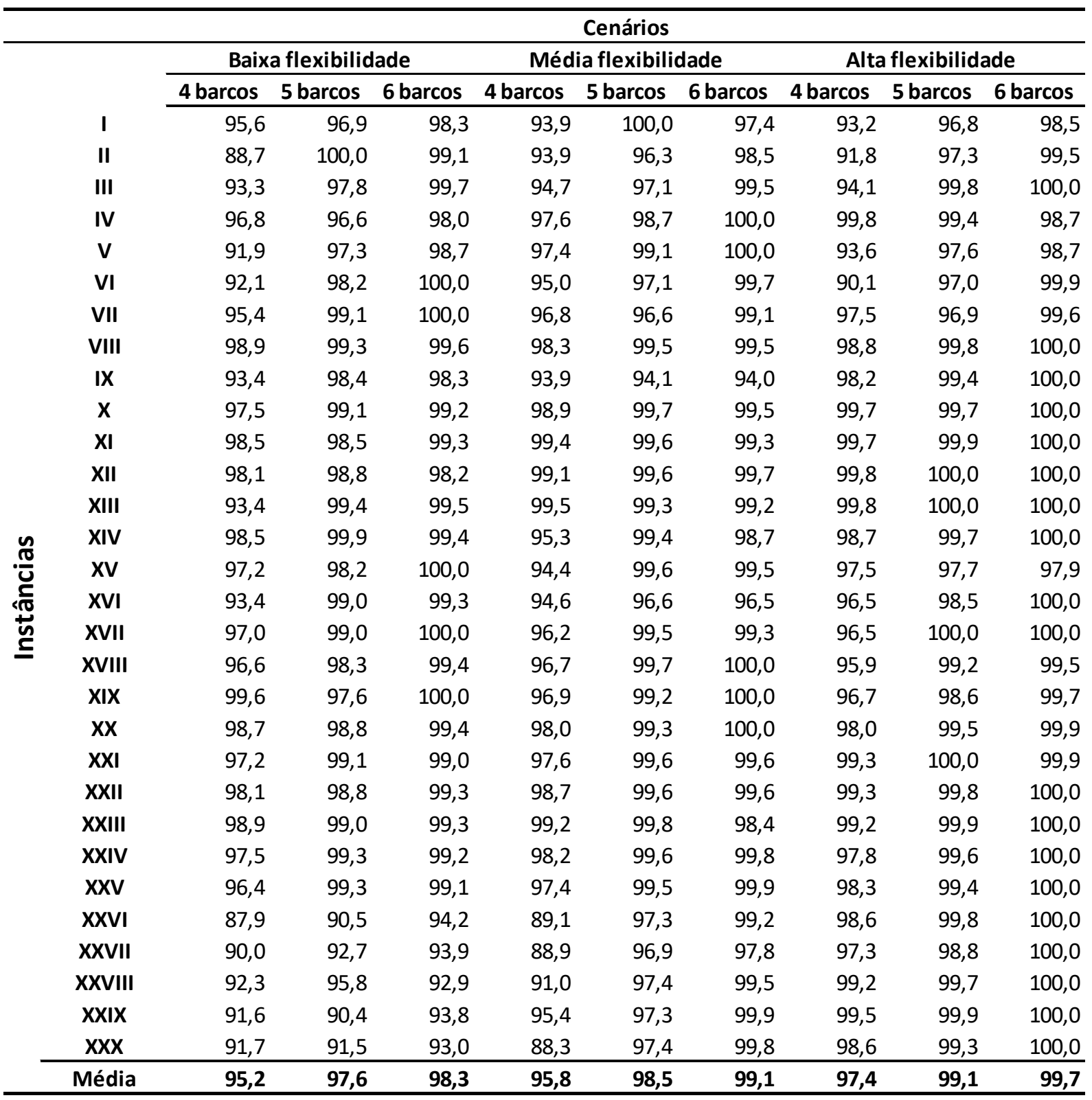

A partir da Tabela 13, pode-se ver mais claramente - sem a interferência dos diferentes volumes de potencial de produção ou número de atividades em questão - que o resultado obtido pela heurística é bastante satisfatório em termos de coerência com a flexibilidade e número de embarcações utilizadas.

Para melhor verificar o fenômeno que ocorre em algumas instâncias de, em cenários com maior flexibilidade ocorrer um resultado inferior ao de um cenário de menor flexibilidade, será detalhado um pouco o comportamento dos cenários de 4 PLSVs da instância I. 
A Tabela 14 apresenta informações sobre os poços considerados bem como as datas finais de interligação de cada atividade e de cada poço.

Tabela 14 - Detalhe dos resultados dos cenários de 4 PLSVs da instância I dos testes da HC1 com dados reais

\begin{tabular}{|c|c|c|c|c|c|c|c|}
\hline \multirow{3}{*}{ Atividade } & \multicolumn{2}{|c|}{\begin{tabular}{|l|} 
Baixa Flexibilidade \\
\end{tabular}} & \multicolumn{2}{|c|}{ Média Flexibilidade } & \multicolumn{2}{|c|}{ Alta Flexibilidade } & \multirow{3}{*}{ Tipo } \\
\hline & \multicolumn{6}{|c|}{ tempo (dias) } & \\
\hline & Fim Ativ & Fim poço & \begin{tabular}{|l|} 
Fim Ativ \\
\end{tabular} & Fim poço & \begin{tabular}{|l|} 
Fim Ativ \\
\end{tabular} & Fim poço & \\
\hline 0 & 27 & \multirow{3}{*}{103} & 49 & \multirow{3}{*}{104} & 62 & \multirow{3}{*}{108} & \multirow{3}{*}{ Prod } \\
\hline 1 & 48 & & 22 & & 21 & & \\
\hline 2 & 100 & & 101 & & 105 & & \\
\hline 3 & 44 & \multirow{3}{*}{63} & 66 & \multirow{3}{*}{69} & 37 & \multirow{3}{*}{62} & \multirow{3}{*}{ Prod } \\
\hline 4 & 19 & & 18 & & 15 & & \\
\hline 5 & 60 & & 37 & & 59 & & \\
\hline 6 & 94 & \multirow{3}{*}{97} & 90 & \multirow{3}{*}{93} & 40 & \multirow{3}{*}{94} & \multirow{3}{*}{ Prod } \\
\hline 7 & 35 & & 18 & & 18 & & \\
\hline 8 & 70 & & 72 & & 91 & & \\
\hline 9 & 130 & \multirow{3}{*}{133} & 130 & \multirow{3}{*}{133} & 130 & \multirow{3}{*}{133} & \multirow{3}{*}{ Inj } \\
\hline 10 & - & & - & & - & & \\
\hline 11 & 98 & & 93 & & 76 & & \\
\hline 12 & - & \multirow{3}{*}{74} & - & \multirow{3}{*}{49} & - & \multirow{3}{*}{87} & \multirow{3}{*}{ Inj } \\
\hline 13 & 71 & & 29 & & 36 & & \\
\hline 14 & 32 & & 46 & & 84 & & \\
\hline 15 & 160 & & 100 & & 57 & & \\
\hline 16 & - & 163 & - & 103 & - & 95 & Inj \\
\hline 17 & 122 & & 70 & & 92 & & \\
\hline 18 & 77 & & 79 & & 42 & & \\
\hline 19 & - & 80 & - & 82 & - & 45 & Inj \\
\hline 20 & - & & - & & - & & \\
\hline 21 & 100 & & 44 & & 61 & & \\
\hline 22 & - & 103 & - & 47 & - & 64 & Inj \\
\hline 23 & - & & - & & - & & \\
\hline 24 & 32 & & 79 & & 70 & & \\
\hline 25 & - & 35 & - & 82 & - & 73 & Prod \\
\hline 26 & 17 & & 22 & & 19 & & \\
\hline 27 & 24 & & 11 & & 24 & & \\
\hline 28 & 14 & 40 & 19 & 34 & 16 & 49 & Prod \\
\hline 29 & 37 & & 31 & & 46 & & \\
\hline 30 & 24 & & 27 & & 42 & & \\
\hline 31 & - & 27 & - & 30 & - & 45 & Inj \\
\hline 32 & - & & - & & - & & \\
\hline 33 & 118 & & 113 & & 113 & & \\
\hline 34 & - & 121 & - & 116 & - & 116 & Inj \\
\hline 35 & 106 & & 24 & & 24 & & \\
\hline
\end{tabular}

Uma primeira informação que pode-se extrair da tabela é que, de modo geral, alguns poços produtores estão sendo postergados em instâncias mais flexíveis enquanto poços injetores estão sendo antecipados. Como se mensura a eficiência da alocação através da medida de potencial de produção de óleo, tem-se que poços produtores são mais valorados. Porém, ocorre que devido à limitação de viabilidade técnica das embarcações ocorrem diferenças que, à primeira vista, podem parecer incoerentes. Esta diferente alocação é explicada pela diferença 
entre os PLSVs. O conceito de flexibilidade dos PLSVs advém do conceito de flexibilidade para com o portfolio e não levando em consideração apenas o conjunto de atividades de cada um dos testes. Isto fará sentido com o problema como um todo.

Portanto, foram utilizados 9 conjuntos de $P L S V s$ para que os mesmos cenários, em diferentes instâncias, fossem passíveis de comparação. Por exemplo, todas instâncias de alta flexibilidade e utilização de 6 PLSVs contaram com os mesmos 6 barcos servindo como base para os testes. Assim, há o bônus de trabalhar na mesma base mas pode-se ter o ônus de, em algumas instâncias, pontualmente, termos $P L S V s$ mais flexíveis em instâncias de baixa flexibilidade do que na de média.

Como citado anteriormente, ao somarmos os instantes de finalização de todas as atividades de um teste, pode-se verificar que, quanto mais flexível a instância, menor este somatório. Isto é um indicativo de que o algoritmo da heurística está considerando uma antecipação de atividades. Contudo, ainda podem ser obtidas melhorias no que se refere à visão de futuro da heurística. Ou seja, ao optar-se pela alocação de uma atividade, a heurística não consegue, naquele momento, prever os impactos que isto traz nas atividades ainda por alocar. Neste caso da Tabela 14, observa-se que, ao somarmos os instantes de finalização das atividades de baixa flexibilidade, tem-se um total de 1659 dias; na média flexibilidade, tem-se 1390 dias; já na alta flexibilidade, tem-se o total de 1380 dias. Contudo, essa redução não é verificada diretamente nos poços produtores, como seria o desejado.

Vale salientar que algumas atividades não possuem instante de término descrito na Tabela 14 pois são atividades dummy: quando algum poço precisava sofrer manutenção para voltar a operar ou quando alguma linha do poço já havia sido anteriormente interligada, inseriuse uma linha fictícia que possui duração nula e comprimento nulo. Assim, ela pode ser considerada interligada a qualquer momento pelo algoritmo e isto não afeta os resultados.

Mais detalhes sobre esta instância podem ser vistos na Figura 15. 
Figura 15 - Recorte do gráfico de Gantt com o detalhe dos cenários de 4 PLSVs da instância I do teste da HC1 com dados reais

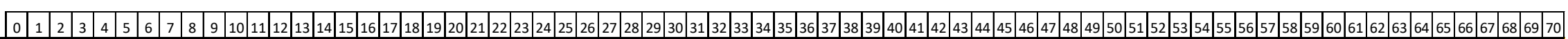

\begin{tabular}{|c|c|c|}
\hline \multirow{4}{*}{ 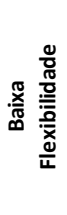 } & Barco 0 & car \\
\hline & Barco 1 & car \\
\hline & Barco 2 & car \\
\hline & Barco 3 & \\
\hline
\end{tabular}

\begin{tabular}{|c|c|c|c|c|c|c|c|c|}
\hline \multicolumn{8}{|c|}{ Poço 0 (Ativ. 0) } & \\
\hline \multicolumn{2}{|c|}{ Poço 9 (Ativ. 28) } & \begin{tabular}{|c|} 
Poço 8 \\
(Ativ. 26)
\end{tabular} & $n$ & \multicolumn{5}{|c|}{ Poço 4 (Ativ. 14) } \\
\hline \multirow[t]{2}{*}{ nav } & \multicolumn{3}{|c|}{ Poço 1 (Ativ. 4) } & $n$ & $\begin{array}{l}\text { Poço 10 } \\
\text { (Ativ. 30) }\end{array}$ & $n$ & & Poço 2 (Ativ. 7 \\
\hline & & \begin{tabular}{l|l}
$\operatorname{ar}$ & $n$ \\
\end{tabular} & Poç & 91 & Ativ. 27) & n & c 1 n & $\begin{array}{c}\text { Poço } 8 \\
\text { (Ativ. 24) } \\
\end{array}$ \\
\hline
\end{tabular}
Poço 1 (Ativ. 3)

\begin{tabular}{c|c|c|c|c|c|} 
n & $\begin{array}{c}\text { Poço 9 } \\
\text { (Ativ. 29) }\end{array}$ & n & car & nav \\
\hline
\end{tabular}

Poço 6 (Ativ. 18)

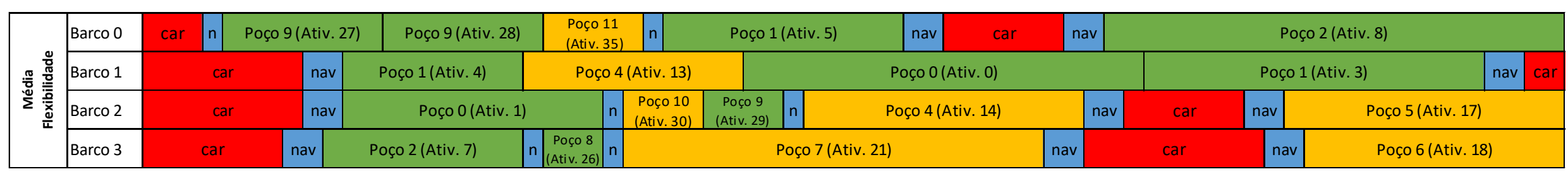

\begin{tabular}{|c|c|c|c|c|c|c|c|c|c|c|c|c|c|c|c|c|c|c|c|}
\hline \multirow{4}{*}{ 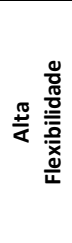 } & \multirow{2}{*}{\begin{tabular}{|l|} 
Barco 0 \\
Barco 1 \\
\end{tabular}} & \multirow[t]{2}{*}{ car } & \multirow[t]{2}{*}{ nav } & \multicolumn{2}{|c|}{ Poço 1 (Ativ. 4) } & \multicolumn{2}{|c|}{ Poço 9 (Ativ. 27) } & \multirow[t]{2}{*}{$\mathrm{n}$} & Poço 4 (Ativ. 13) & \multicolumn{5}{|c|}{ Poço 5 (Ativ. 15) } & nav & \multicolumn{2}{|c|}{ car } & \multicolumn{2}{|c|}{\begin{tabular}{c|c}
$n \mathrm{n}$ & Poço 8 \\
(Ativ. 24)
\end{tabular}} \\
\hline & & & & nav & \multicolumn{2}{|c|}{ Poço 0 (Ativ. 1) } & \multicolumn{4}{|c|}{ Poço 6 (Ativ. 18) } & & \multicolumn{5}{|c|}{ Poço 0 (Ativ. 0) } & nav & \multicolumn{2}{|r|}{ car } \\
\hline & Barco 2 & & & $n$ & Poço 9 (Ativ. 28) & \begin{tabular}{|c|} 
Poço 8 \\
(Ativ. 26)
\end{tabular} & ? & & 1 (Ativ. 3) & $n$ & $\begin{array}{l}\text { Poço } 10 \\
\text { (Ativ. 30) }\end{array}$ & $\begin{array}{c}\text { Poço } 9 \\
\text { (Ativ. 29) }\end{array}$ & $n$ & Poço 1 (Ativ. 5) & & nav & & ar & nav \\
\hline & Barco 3 & ci & & nav & Poço 2 (Ativ. 7 & $n$ & $\begin{array}{l}\text { Poço } 11 \\
\text { (Ativ. 35) }\end{array}$ & $\mathrm{n}$ & Poço 2 (Ativ. & & & & & (Ativ. 21) & & & nav & car & nav \\
\hline
\end{tabular}

Atividade de poço produtor

Atividade de poço injetor

Atividade de navegação

Carregamento 
Neste gráfico de Gantt da Figura 15, pode-se ver mais claramente que é dada preferência a atividades de poços injetores do que de produtores nos cenários de barcos de maior flexibilidade. Pode-se ver, através da escala de cores a ordem de alocação neste recorte do início do período bem como a quais poços do teste e atividade elas se referem. Os números das atividades encontram-se em parênteses.

Vale ressaltar que o exemplo dado na Figura 15 é aquele apresentado pelas exceções dado que, olhando o comportamento dos testes como um todo e, especialmente, dos resultados nas Tabelas 12 e 13, pode-se afirmar que o comportamento está dentro do esperado. Isto significa que, na visão consolidada, resultados com maior número de $P L S V s$ são superiores àqueles com menor número destas embarcações. De mesmo modo, no conjunto de testes, PLSVs de maior flexibilidade apresentam melhores resultados do que aqueles cenários com PLSV de menor flexibilidade.

Quanto maior o número de dados com os quais se trabalha, espera-se um melhor resultado em termos de aproveitamento de ociosidade nas embarcações pois haverá um problema combinatório maior e mais opções de antecipação de atividades produtoras e injetoras. Quando há poucas atividades, corre-se o risco de, no decorrer do ano, haver concentração de atividades a serem interligadas em determinados períodos. Em um portfolio de atividades maior isso tende a ser minimizado, com mais tarefas a serem realizadas em todos os períodos. Ou seja, o funcionamento da heurística depende também da dispersão das tarefas no decorrer do tempo.

Como tentativa de sanar algumas distorções e melhorar o resultado do procedimento heurístico, será elaborada uma segunda versão de heurística construtiva, a HC2, como será apresentado na sequência.

\subsection{Heurística Construtiva 2 (HC2)}

Buscando a obtenção de melhores resultados, foi elaborada uma segunda heurística construtiva, a HC2, tendo por base o próprio algoritmo da HC1. A Figura 16 apresenta o algoritmo desta nova heurística construtiva. Em sequência, as principais diferenças com a $\mathrm{HC} 1$ serão destacadas. 
Dados de entrada: $d_{i j}\left(i, j \in N^{+}\right), s_{i}(i \in N), m_{i}^{b}(i \in N, b \in B), W_{p *}^{\pi}\left(p^{*} \in N^{p r o d}, \pi \in \Pi\right), D C_{i}(i \in N), D M_{i}(i \in N), q_{i}(i$ $\in N), Q_{b}(b \in B)$, comis, $\operatorname{Inj}_{p \prime}^{\pi}\left(p^{\prime} \in N^{\text {inj }}, \pi \in \Pi\right), \beta$

Saída: alocação de atividades aos barcos, atendendo às condições do problema

- Inicializar os barcos, sem nenhuma pré-alocação

- Ordenar os barcos, do menos flexível $(b=0)$ para o mais flexível $(b=B-1)$

- Criar lista de prontidão (lista_pro) onde constarão os instantes de liberação, considerando os desempates

- Criar lista de datas finais de interligação (df_pr) onde constará a menor data de término de interligação de cada atividade, considerando o tempo atual do algoritmo, duração da atividade e navegação

- Ordenar as atividades, dentro da lista de prioridades (ativ_pri) em ordem crescente de prontidão, fazendo relação/paralelo com a lista de prontidão (lista_pro). Após isso, para as atividades que já tiverem prontidão imediata, ordenar pela ordem crescente data final de interligação (df_pr) $t=0$

\section{Enquanto $t<T$ faça}

Enquanto lista_pro[0] $\leq t$ e há barco com espaço disponível faça

$$
\begin{aligned}
& b=0 \\
& \text { cont_n_viab }=-1
\end{aligned}
$$

\section{Enquanto $b<B$ faça}

Se $\left(m[b]\left[a t i v \_p r i[1]\right]>0\right.$ e barco $b$ estiver vago no intervalo $t$ e a disponibilidade do material for até o momento de início do carregamento e for uma atividade de poço produtor) então

Se as demais atividades deste mesmo poço produtor em análise já tiverem sido efetuadas então

Se ativ_pri[0] não é produtora ou é produtora e não teve as outras atividades do mesmo poço interligadas então

- Inverter ativ_pri[0] e ativ_pri[1], realizando as alterações relacionadas em lista_pro e $d f \_p r$

- Calcular ociosidade do barco até alocação de ativ_pri[1]

\section{Fim Se}

Se ativ_pri[0] é produtora e teve as outras atividades do mesmo poço interligadas então

Se potencial adicionado pelo poço da ativ_pri[1] até o fim do horizonte de tempo for maior que o adicionado pelo poço da ativ_pri[0] então

- Inverter ativ_pri[0] e ativ_pri[1], realizando as alterações relacionadas em lista_pro e $d f \_p r$

- Calcular ociosidade do barco até alocação de ativ_pri[1]

\section{Fim Se}

\section{Fim Se}

Fim Se 
Se $\left(m[b]\left[a t i v \_p r i[0]\right]>0\right.$ e barco $b$ estiver vago no intervalo $t$ e a disponibilidade do material for até o momento de início do carregamento) então

Se há espaço para armazenagem da linha no barco $b$ então

- Atribuir linha da atividade da primeira posição ao barco $b$

- Aloque, na programação do barco $b$, os dias necessários para realização da operação (car + nav + ativ + ociosidade, quando esta for aplicável)

- Marcar atividade como alocada

- Reorganizar atividades do mesmo poço, colocando tempo $M$ para lista_pro[0] e df_pr[0], organizando primeiramente em ordem crescente de lista_pro e usando o critério de desempate; para as atividades que já possuem valor de lista_pro $<=t$, reordenar em ordem crescente de $d f_{-} p r$

$b=B-1$

Senão

/*Analisar a factibilidade em termos de espaço na embarcação das atividades ainda não alocadas*/

Enquanto não forem esgotadas as atividades não-alocadas e não ser encontrada uma atividade factível (viabilidade técnica, espaço na embarcação e material disponível no início do carregamento) para aquele barco faça

Se houver alguma atividade passível de ser alocada no barco $b$ naquele intervalo $t$ então

Inserir a atividade nas primeiras posições das listas (ativ_pri[0], lista_pro[0] e df_pr[0])

Fim Se

Fim enquanto

Se não houver atividade a ser alocada então

- Fecha carregamento do barco $b$

- Enviar barco de volta à base e computa a navegação do mesmo

\section{Fim Se}

Fim Se

Senão

Se não tiver sido alocada a ativ_pri[0] por conta de disponibilidade de material no momento de início do carregamento então

Enquanto não forem varridas todas atividades ainda não alocadas ou encontrada alguma com disponibilidade de carregamento para aquele barco naquele instante $t$ faça

Se for encontrada atividade que atende restrição de viabilidade técnica, disponibilidade na base para carregamento e capacidade do barco então 
Trazer tal atividade para o topo da lista

Fim Se

\section{Fim Enquanto}

Se não foi encontrada atividade alocável então

- Fecha carregamento do barco $b$

- Enviar barco de volta à base e computa a navegação do mesmo

\section{Fim Se}

\section{Fim Se}

Se determinado barco não for viável tecnicamente ou não estiver vago ou a atividade não estava com prontidão no início deste roteiro do barco então cont_n_viab $=$ cont_n_viab +1 ;

Fim Se

\section{Fim Se}

$b=b+1$

Se cont_n_viab $=B$ - 1 então

- Adiciona 1 unidade de tempo na primeira atividade da lista de priorização

- Reordenar atividades do mesmo poço, organizando primeiramente em ordem crescente de lista_pro e usando o critério de desempate; para as atividades que já possuem valor de lista_pro $<=t$, reordenar em ordem crescente de $d f \_p r$, usando também o desempate

\section{Fim Se}

Fim Enquanto

\section{Fim Enquanto}

$$
t=t+1
$$

Fim Enquanto

As principais alterações que foram realizadas com relação ao algoritmo da Heurística Construtiva anterior (HC1) são:

- ordenação dos PLSVs é realizada em ordem crescente de flexibilidade (linha 5), ou seja, os barcos de menor numeração são aqueles mais restritos. $\mathrm{O}$ intuito de ordenar os barcos desta forma é que as embarcações mais flexíveis sejam deixadas disponíveis para momentos em que haja uma maior concorrência entre as atividades por disponibilidade nos barcos. $\mathrm{O}$ fato de alocar, mais cedo, uma atividade em um $P L S V$ mais restrito, mantém barcos mais viáveis para as demais alocações, o que 
resulta em uma maior probabilidade de se ter opção (disponibilidade) de alocação de sucesso para as outras tarefas. Tal flexibilidade é medida pelo número de tarefas que são factíveis de ser realizada em cada embarcação neste conjunto de atividades analisado. Aqueles que possuem viabilidade técnica para realizar maior número das tarefas em questão são considerados mais flexíveis. Com isso, pode-se obter uma ordenação de barcos de acordo com a flexibilidade; - a criação da lista $d f \_p r$ (linhas 7 e 8) é um artifício para que sejam computadas as datas mínimas de finalização de interligação de cada atividade. Esta lista é utilizada para que o critério de alocação não seja exclusivamente dependente do instante de prontidão e seu respectivo critério de desempate. A primeira triagem das reordenações das listas - que acontecem quando houve alguma alocação de atividade, alteração do tempo $t$ do algoritmo, alteração do instante de prontidão de alguma atividade por indisponibilidade de barcos no momento, além do início do algoritmo continua ocorrendo pela ordem crescente da lista_pro. Contudo, para todas as atividades que têm seu instante de prontidão menor ou igual ao tempo $t$ do algoritmo (ou seja, todas aquelas que já teriam material e completação disponíveis para serem alocadas), é realizada uma nova ordenação que tem por base a lista $d f \_p r$, que ordena este conjunto de atividades em ordem crescente de data fim de interligação. A estimativa utilizada para o valor de $d f \_p r$ para cada atividade é a soma do tempo atual com a duração da interligação, carregamento e navegação daquelas atividades em específico. Em caso de empate, o mesmo critério de desempate apresentado anteriormente, no algoritmo da heurística construtiva 1 (Figura 14), continua sendo utilizado. O conceito de alocação segundo este critério de $d f_{-} p r$ é que as atividades sejam finalizadas o quanto antes pois, como existem atividades de durações diversas, é de interesse que as atividades sejam finalizadas e, com isso, é provável que as partidas de poços, após a interligação de suas 3 linhas, venham a ocorrer mais cedo. Sendo assim, de modo geral, atividades mais curtas e que já tenham prontidão acabam tendo maior prioridade neste critério de alocação;

- entre as linhas 18 e 40 deste algoritmo, foi inserida uma rotina prévia à análise da alocação. Esta nova rotina tem por objetivo avaliar, pontualmente, casos de alteração da ordenação proposta quando o valor de produção adicionado pela atividade que se encontra na segunda posição da lista for maior que o valor adicionado de produção da atividade da primeira posição da lista. Para que esta inversão da ordem das atividades possa ocorrer, o primeiro critério a ser atendido é a atividade da segunda posição (ativ_pri[1]) atender aos quesitos de viabilidade técnica no barco em questão, bem como este barco estar vago no instante da alocação; necessita também possuir disponibilidade 
do material no momento do início daquele específico carregamento do barco em questão e ser uma atividade de poço produtor. Atendendo a estas condições, avalia-se se as duas outras atividades do poço (da atividade que se encontra na segunda posição) já foram efetuadas. Esta é uma condição importante pois a inversão só ocorrerá caso seja possível ganho "imediato" de óleo, logo após esta interligação ocorrer. Importante ressaltar que esta inversão de atividades possibilita que aquelas que ainda não atingiram o momento de prontidão possam já ser alocadas caso atendam estas condições, deixando aquele barco específico ocioso durante alguns dias, recebendo a atividade logo em seguida. Há dois casos a serem pontuados como possíveis de ocorrer. O primeiro, quando a atividade que está na primeira posição (ativ_pri[0]) é uma atividade produtora e que já possuiu as suas duas outras atividades do poço interligadas. Neste caso, é efetuada uma comparação do potencial de produção que cada um dos poços poderia adicionar para escolher se as posições são mantidas ou ocorre a inversão. Esta comparação é uma estimativa baseada na multiplicação do potencial inicial de produção vezes o tempo que o mesmo poderia produzir, ou seja, o horizonte de tempo total analisado, menos a data fim desta atividade, reduzido do tempo de comissionamento. O segundo caso, em que a atividade na primeira posição advém de um poço injetor ou, então, de um poço produtor que ainda não possuiu seus outros dois dutos interligados. Nesta situação, a inversão é feita sem nenhuma outra análise prévia além daquelas que já foram realizadas. Esta inversão pode, ocasionalmente, gerar um tempo de ociosidade - a diferença entre o tempo atual e o efetivo momento de prontidão da atividade, quando o material da mesma ainda não se encontra disponível -, que é importante que seja devidamente alocado e interfira na extensão das atividades e utilização das embarcações;

- as rotinas expressas entre as linhas 49-53 e 101-104 apresentam as execuções das reordenações das listas de atividades. A alteração que ocorreu já foi explicada, anteriormente, no tópico referente à criação da lista $d f \_p r$ : ocorre uma primeira ordenação, tal qual no algoritmo da heurística 1 , com base na lista_pro; todavia, foi incluída uma continuidade desta rotina, que ordena as atividades que, no instante $t$ do algoritmo, já atingiram a prontidão. Para este conjunto de atividades, que já estão no topo da lista, ocorre uma nova reordenação pela ordem crescente dos valores de $d f \_p r$, data fim de interligação. O critério de desempate apresentado continua sendo utilizado; - importante que seja esclarecido e definido que a notação ativ_pri[1] refere-se à segunda atividade na lista de priorização, tal qual ativ_pri[0] é a atividade na primeira posição nesta determinada lista. 


\section{Tabela 15 - Comparativo dos resultados ótimos, HC1 e HC2}

\begin{tabular}{|c|c|c|c|}
\hline \multicolumn{3}{|c|}{ HC2 } & \multirow{2}{*}{ Gap } \\
\hline Fobj & K1 & K2 & \\
\hline $15.770,6$ & 41 & 65 & $1,80 \%$ \\
\hline $16.215,2$ & 31 & 41 & $0,87 \%$ \\
\hline $16.230,7$ & 31 & 38 & $1,04 \%$ \\
\hline $16.230,7$ & 31 & 38 & $1,20 \%$ \\
\hline $16.230,7$ & 31 & 38 & $1,23 \%$ \\
\hline $15.736,7$ & 42 & 64 & $1,42 \%$ \\
\hline $16.149,7$ & 34 & 37 & $0,87 \%$ \\
\hline $16.155,1$ & 34 & 36 & $1,31 \%$ \\
\hline $16.155,1$ & 34 & 36 & $1,47 \%$ \\
\hline $16.155,1$ & 34 & 36 & $1,60 \%$ \\
\hline $15.741,5$ & 42 & 63 & $2,56 \%$ \\
\hline $16.158,5$ & 33 & 41 & $1,40 \%$ \\
\hline $16.262,6$ & 30 & 37 & $1,00 \%$ \\
\hline $16.262,6$ & 30 & 37 & $1,15 \%$ \\
\hline $16.262,6$ & 30 & 37 & $1,15 \%$ \\
\hline $15.712,7$ & 40 & 87 & $0,00 \%$ \\
\hline $15.871,3$ & 40 & 52 & $2,44 \%$ \\
\hline $16.040,1$ & 36 & 46 & $1,93 \%$ \\
\hline $16.040,1$ & 36 & 46 & $2,08 \%$ \\
\hline $16.040,1$ & 36 & 46 & $2,20 \%$ \\
\hline $11.782,2$ & 98 & 60 & $20,75 \%$ \\
\hline $15.076,1$ & 57 & 48 & $2,67 \%$ \\
\hline $15.134,8$ & 56 & 49 & $2,78 \%$ \\
\hline $15.134,8$ & 56 & 49 & $2,78 \%$ \\
\hline $15.134,8$ & 56 & 49 & $2,78 \%$ \\
\hline $15.409,9$ & 49 & 70 & $1,92 \%$ \\
\hline $15.665,3$ & 46 & 38 & $2,47 \%$ \\
\hline $15.759,0$ & 44 & 38 & $2,30 \%$ \\
\hline $15.759,0$ & 44 & 38 & $2,30 \%$ \\
\hline $15.759,0$ & 44 & 38 & $2,30 \%$ \\
\hline & & & $2,39 \%$ \\
\hline
\end{tabular}

$$
\begin{array}{r}
4 \\
0 \\
0 \\
0 \\
0 \\
0 \\
0 \\
0 \\
0 \\
0 \\
0 \\
0 \\
0 \\
0 \\
0 \\
0 \\
0 \\
0 \\
0 \\
0 \\
0 \\
0 \\
0 \\
0 \\
0 \\
0 \\
0 \\
0 \\
0 \\
0 \\
0
\end{array}
$$

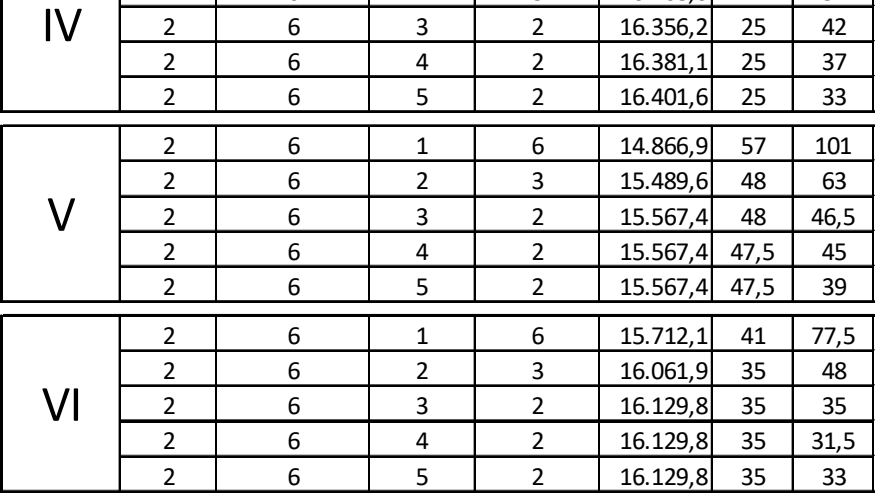

K1 - instante de início de operação do poço 1 (produtor)

K2 - instante de início de operação do poço 2 (injetor)

\begin{tabular}{|c|c|c|c|c|c|c|c|}
\hline \multicolumn{8}{|c|}{ Ótimo } \\
\hline Conjunto & Poços & Atividades & PLSVs & Roteiros & Fobj & K1 & K2 \\
\hline \multirow{5}{*}{ I } & 2 & 6 & 1 & 6 & $16.059,4$ & 31,5 & 68 \\
\hline & 2 & 6 & 2 & 3 & $16.357,8$ & 24 & 46 \\
\hline & 2 & 6 & 3 & 2 & $16.401,8$ & 24 & 37 \\
\hline & 2 & 6 & 4 & 2 & $16.427,3$ & 24 & 31,5 \\
\hline & 2 & 6 & 5 & 2 & $16.432,5$ & 24 & 31 \\
\hline \multirow{5}{*}{ II } & 2 & 6 & 1 & 6 & $15.963,0$ & 35 & 69 \\
\hline & 2 & 6 & 2 & 3 & $16.291,9$ & 27 & 46 \\
\hline & 2 & 6 & 3 & 2 & $16.369,7$ & 26 & 35 \\
\hline & 2 & 6 & 4 & 2 & $16.396,4$ & 25 & 34 \\
\hline & 2 & 6 & 5 & 2 & $16.417,3$ & 25 & 30 \\
\hline \multirow{5}{*}{ III } & 2 & 6 & 1 & 6 & $16.155,3$ & 30 & 59 \\
\hline & 2 & 6 & 2 & 3 & $16.387,3$ & 23 & 44 \\
\hline & 2 & 6 & 3 & 2 & $16.426,6$ & 23 & 36 \\
\hline & 2 & 6 & 4 & 2 & $16.452,1$ & 23 & 31 \\
\hline & 2 & 6 & 5 & 2 & $16.452,1$ & 23 & 31 \\
\hline \multirow{5}{*}{ IV } & 2 & 6 & 1 & 6 & $15.712,7$ & 40 & 87 \\
\hline & 2 & 6 & 2 & 3 & $16.268,0$ & 27 & 51 \\
\hline & 2 & 6 & 3 & 2 & $16.356,2$ & 25 & 42 \\
\hline & 2 & 6 & 4 & 2 & $16.381,1$ & 25 & 37 \\
\hline & 2 & 6 & 5 & 2 & $16.401,6$ & 25 & 33 \\
\hline \multirow{5}{*}{ V } & 2 & 6 & 1 & 6 & $14.866,9$ & 57 & 101 \\
\hline & 2 & 6 & 2 & 3 & $15.489,6$ & 48 & 63 \\
\hline & 2 & 6 & 3 & 2 & $15.567,4$ & 48 & 46,5 \\
\hline & 2 & 6 & 4 & 2 & $15.567,4$ & 47,5 & 45 \\
\hline & 2 & 6 & 5 & 2 & $15.567,4$ & 47,5 & 39 \\
\hline \multirow{5}{*}{ VI } & 2 & 6 & 1 & 6 & $15.712,1$ & 41 & 77,5 \\
\hline & 2 & 6 & 2 & 3 & $16.061,9$ & 35 & 48 \\
\hline & 2 & 6 & 3 & 2 & $16.129,8$ & 35 & 35 \\
\hline & 2 & 6 & 4 & 2 & $16.129,8$ & 35 & 31,5 \\
\hline & 2 & 6 & 5 & 2 & $16.129,8$ & 35 & 33 \\
\hline
\end{tabular}

\begin{tabular}{|c|c|c|c|}
\hline \multicolumn{3}{|c|}{ HC1 } & \multirow{2}{*}{ Gap } \\
\hline Fobj & K1 & K2 & \\
\hline $14.923,7$ & 59 & 65 & $7,07 \%$ \\
\hline $16.192,5$ & 32 & 40 & $1,01 \%$ \\
\hline $16.288,3$ & 29 & 37 & $0,69 \%$ \\
\hline $16.288,3$ & 29 & 37 & $0,85 \%$ \\
\hline $16.288,3$ & 29 & 37 & $0,88 \%$ \\
\hline $14.636,3$ & 64 & 60 & $8,31 \%$ \\
\hline $16.149,7$ & 34 & 37 & $0,87 \%$ \\
\hline $16.155,1$ & 34 & 36 & $1,31 \%$ \\
\hline $16.155,1$ & 34 & 36 & $1,47 \%$ \\
\hline $16.155,1$ & 34 & 36 & $1,60 \%$ \\
\hline $15.397,6$ & 50 & 63 & $4,69 \%$ \\
\hline $16.133,9$ & 34 & 40 & $1,55 \%$ \\
\hline $16.318,2$ & 28 & 36 & $0,66 \%$ \\
\hline $16.318,2$ & 28 & 36 & $0,81 \%$ \\
\hline $16.318,2$ & 28 & 36 & $0,81 \%$ \\
\hline $13.994,0$ & 72 & 87 & $10,94 \%$ \\
\hline $15.876,4$ & 40 & 51 & $2,41 \%$ \\
\hline $16.045,2$ & 36 & 45 & $1,90 \%$ \\
\hline $16.045,2$ & 36 & 45 & $2,05 \%$ \\
\hline $16.045,2$ & 36 & 45 & $2,17 \%$ \\
\hline $12.606,0$ & 89 & 98 & $15,21 \%$ \\
\hline $15.076,1$ & 57 & 49 & $2,67 \%$ \\
\hline $15.134,8$ & 56 & 48 & $2,78 \%$ \\
\hline $15.134,8$ & 56 & 48 & $2,78 \%$ \\
\hline $15.134,8$ & 56 & 48 & $2,78 \%$ \\
\hline $14.219,2$ & 70 & 57 & $9,50 \%$ \\
\hline $15.649,8$ & 45 & 37 & $2,57 \%$ \\
\hline $15.804,3$ & 43 & 37 & $2,02 \%$ \\
\hline $15.804,3$ & 43 & 37 & $2,02 \%$ \\
\hline $15.804,3$ & 43 & 37 & $2,02 \%$ \\
\hline Gap & mó & & $3,21 \%$ \\
\hline
\end{tabular}

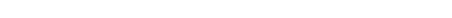

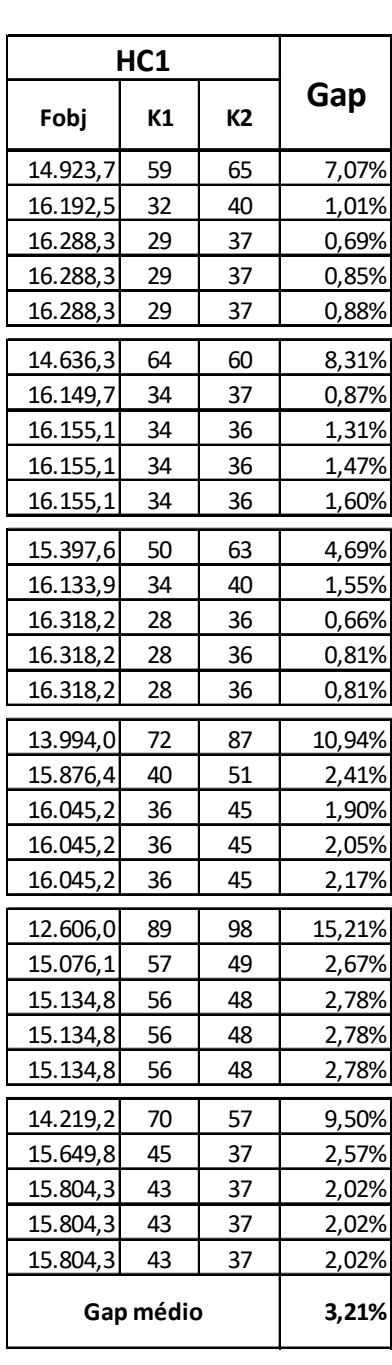

Gap médio 
Pode-se notar na Tabela 15 que a aplicação da HC2 em comparação com a HC1 apresentou melhores resultados, em geral, em situações mais restritivas (com 1 e 2 PLSVs). Para as demais instâncias, o resultado ficou igual ou sensivelmente menor, devido ao novo critério de alocação. Houve o atingimento de um resultado ótimo no cenário de $1 P L S V$ do conjunto IV, favorecido pelo novo critério de alocação que privilegia atividades de menor duração em uma situação de igual prontidão. Neste caso em específico, sempre haverá uma linha por embarcação em cada roteiro devido ao seu comprimento fixo e a ordem de alocação fica em função da data fim de interligação, o que acaba coincidindo com a alocação ótima.

Em contrapartida, também houve um teste no qual houve um delta de 20,75\% com relação ao ótimo, pois foram privilegiadas as interligações de menor duração que, neste caso, são as de poços injetores. Sendo assim, para esta configuração específica testada, a heurística não teve uma boa performance.

O comportamento de estabilização do resultado da função objetivo, dentro de cada conjunto, a partir dos cenários de 3 PLSVs mantém-se, assim como foi observado no comparativo entre os resultados ótimos e os alcançados através da HC1.

De modo global, o resultado médio de gap dos testes com a $\mathrm{HC} 2$ foi reduzido, de 3,21\% para $2,39 \%$. Pelas situações que serão trabalhadas posteriormente, com um maior número de atividades, estarem sujeitas a uma maior restrição de número de PLSVs, induz-se que o comportamento desta heurística, provavelmente, será adequado, haja visto o que se pôde verificar nas instâncias de 1 e 2 PLSVs.

É importante salientar que os gaps obtidos nesta fase do trabalho, a priori, apresentam-se pequenos pois o horizonte de trabalho é de 180 dias. Caso este horizonte fosse sendo reduzido, a tendência do gap seria aumentar pois haveria uma menor diferença entre os dias de efetiva produção entre os casos ótimo e simulado pela heurística. Contudo, trabalhar com um horizonte maior de tempo faz sentido com o caso real, haja vista a ordem de grandeza da duração das atividades de interligação.

A seguir, na seção 5.6, será apresentado o comportamento da $\mathrm{HC} 2$ em instâncias pequenas com dados reais. 


\subsection{Casos-piloto de aplicação da HC2}

Assim como foi feito com a $\mathrm{HC} 1$ na seção 5.3, foram realizados testes com pequenas instâncias de modo a verificar o comportamento do algoritmo. Os dados de testes também são os mesmos utilizados na $\mathrm{HC1}$, com 30 instâncias e 9 cenários, com os níveis de 4, 5 e 6 PLSVs, de baixa, média e alta flexibilidade. Os resultados são expressos na Tabela 16.

Tabela 16 - Resultados de potencial de produção nos testes da HC2 com dados reais

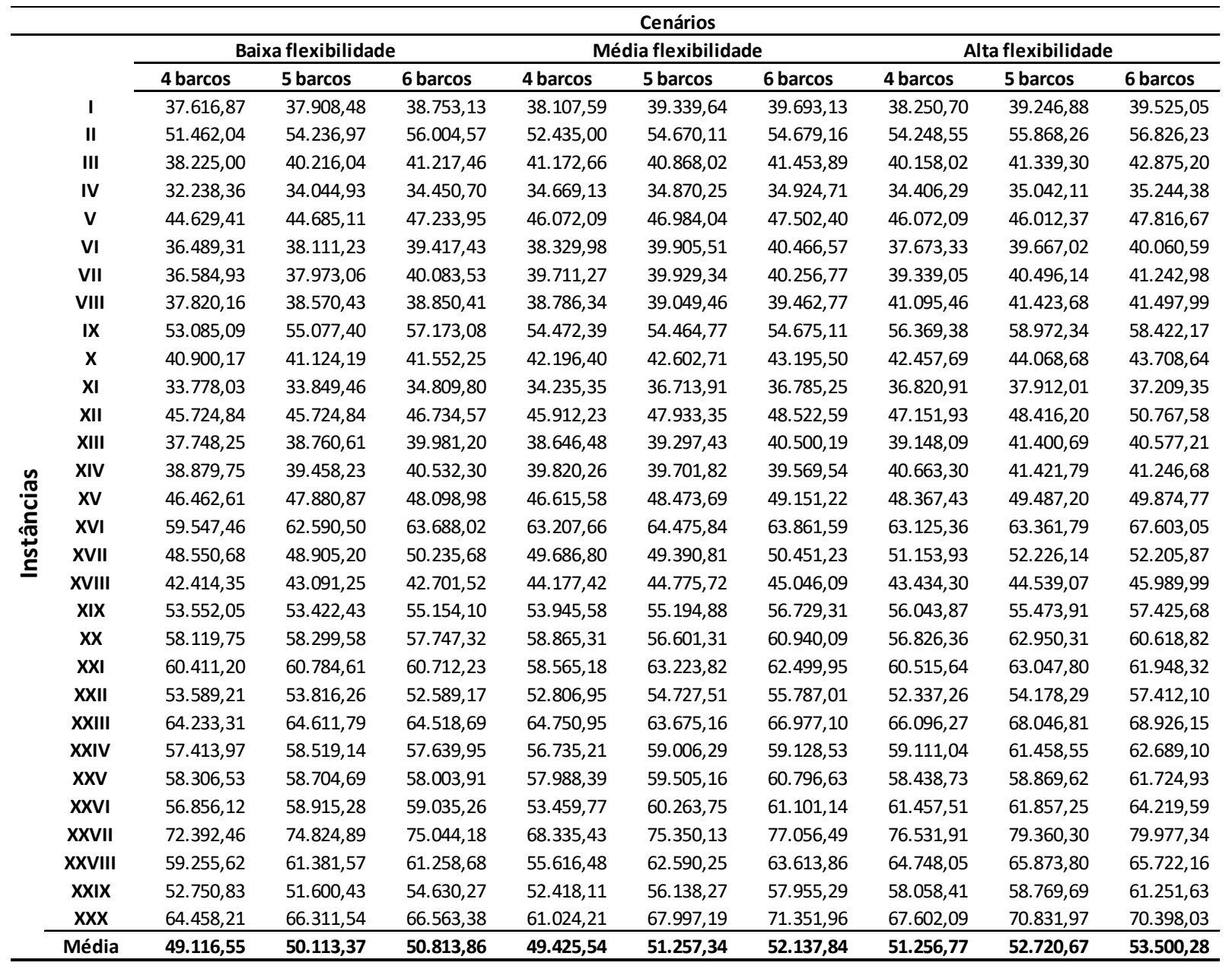

Assim como ocorreu com os resultados da $\mathrm{HC} 1$ em pequenas instâncias com dados reais, ao verificar-se os resultados obtidos, na Tabela 16, nota-se que, na grande maioria dos testes, os resultados comportaram-se de acordo com o esperado. Isto é, quando comparados apenas cenários 
de 4 PLSVs, dentro de uma mesma instância, o resultado obtido para embarcações de baixa flexibilidade é menor que o resultado para barcos de média flexibilidade que, por sua vez, possuem valor menor de função objetivo que os cenários de PLSVs de alta flexibilidade. O mesmo ocorre para testes considerando apenas 5 PLSVs ou 6 PLSVs dentro de uma mesma instância. Já quando se compara, dentro de uma mesma instância, resultados obtidos dentro de barcos de um mesmo tipo de flexibilidade, são obtidos resultados superiores com 6 PLSVs do que com 5 PLSVs que, por sua vez, são melhores que aqueles com 4 PLSVs.

Contudo, há alguns casos em que se pode verificar que, dentro de uma mesma instância, em seus 9 cenários, nem sempre os resultados melhoram com o aumento do número de PLSVs ou com o nível de flexibilidade. Ou seja, a mudança do critério de alocação melhorou o resultado obtido, como será apresentado à frente, mas não acabou totalmente com a miopia da heurística e algumas distorções continuam a ocorrer, neste sentido.

Sendo assim, ao analisar-se o resultado global, nota-se que o comportamento da heurística está dentro do esperado, de acordo com mesmos dois critérios de análise. O primeiro, pela média de produção das 30 instâncias de cada cenário (como apresenta a Tabela 16); e o segundo, através de normalização do resultado, como mostra a Tabela 17. 
Tabela 17 - Resultados normalizados dos testes da HC2 com dados reais

\begin{tabular}{|c|c|c|c|c|c|c|c|c|c|c|}
\hline & & & & & & Cenários & & & & \\
\hline & & Baixa & Baixa & Baixa & Média & Média & Média & Alta & Alta & Alta \\
\hline & & 4 barcos & 5 barcos & 6 barcos & 4 barcos & 5 barcos & 6 barcos & 4 barcos & 5 barcos & 6 barcos \\
\hline & I & 94,8 & 95,5 & 97,6 & 96,0 & 99,1 & 100,0 & 96,4 & 98,9 & 99,6 \\
\hline & II & 90,6 & 95,4 & 98,6 & 92,3 & 96,2 & 96,2 & 95,5 & 98,3 & 100,0 \\
\hline & III & 89,2 & 93,8 & 96,1 & 96,0 & 95,3 & 96,7 & 93,7 & 96,4 & 100,0 \\
\hline & IV & 91,5 & 96,6 & 97,7 & 98,4 & 98,9 & 99,1 & 97,6 & 99,4 & 100,0 \\
\hline & V & 93,3 & 93,5 & 98,8 & 96,4 & 98,3 & 99,3 & 96,4 & 96,2 & 100,0 \\
\hline & VI & 90,2 & 94,2 & 97,4 & 94,7 & 98,6 & 100,0 & 93,1 & 98,0 & 99,0 \\
\hline & VII & 88,7 & 92,1 & 97,2 & 96,3 & 96,8 & 97,6 & 95,4 & 98,2 & 100,0 \\
\hline & VIII & 91,1 & 92,9 & 93,6 & 93,5 & 94,1 & 95,1 & 99,0 & 99,8 & 100,0 \\
\hline & IX & 90,0 & 93,4 & 96,9 & 92,4 & 92,4 & 92,7 & 95,6 & 100,0 & 99,1 \\
\hline & $x$ & 92,8 & 93,3 & 94,3 & 95,8 & 96,7 & 98,0 & 96,3 & 100,0 & 99,2 \\
\hline & $\mathbf{X I}$ & 89,1 & 89,3 & 91,8 & 90,3 & 96,8 & 97,0 & 97,1 & 100,0 & 98,1 \\
\hline & XII & 90,1 & 90,1 & 92,1 & 90,4 & 94,4 & 95,6 & 92,9 & 95,4 & 100,0 \\
\hline & XIII & 91,2 & 93,6 & 96,6 & 93,3 & 94,9 & 97,8 & 94,6 & 100,0 & 98,0 \\
\hline & XIV & 93,9 & 95,3 & 97,9 & 96,1 & 95,8 & 95,5 & 98,2 & 100,0 & 99,6 \\
\hline & $X V$ & 93,2 & 96,0 & 96,4 & 93,5 & 97,2 & 98,5 & 97,0 & 99,2 & 100,0 \\
\hline & XVI & 88,1 & 92,6 & 94,2 & 93,5 & 95,4 & 94,5 & 93,4 & 93,7 & 100,0 \\
\hline$\ddot{n}$ & XVII & 93,0 & 93,6 & 96,2 & 95,1 & 94,6 & 96,6 & 97,9 & 100,0 & 100,0 \\
\hline & XVIII & 92,2 & 93,7 & 92,8 & 96,1 & 97,4 & 97,9 & 94,4 & 96,8 & 100,0 \\
\hline & XIX & 93,3 & 93,0 & 96,0 & 93,9 & 96,1 & 98,8 & 97,6 & 96,6 & 100,0 \\
\hline & $x x$ & 92,3 & 92,6 & 91,7 & 93,5 & 89,9 & 96,8 & 90,3 & 100,0 & 96,3 \\
\hline & XXI & 95,6 & 96,1 & 96,0 & 92,6 & 100,0 & 98,9 & 95,7 & 99,7 & 98,0 \\
\hline & XXII & 93,3 & 93,7 & 91,6 & 92,0 & 95,3 & 97,2 & 91,2 & 94,4 & 100,0 \\
\hline & XXIII & 93,2 & 93,7 & 93,6 & 93,9 & 92,4 & 97,2 & 95,9 & 98,7 & 100,0 \\
\hline & XXIV & 91,6 & 93,3 & 91,9 & 90,5 & 94,1 & 94,3 & 94,3 & 98,0 & 100,0 \\
\hline & $X X V$ & 94,5 & 95,1 & 94,0 & 93,9 & 96,4 & 98,5 & 94,7 & 95,4 & 100,0 \\
\hline & XXVI & 88,5 & 91,7 & 91,9 & 83,2 & 93,8 & 95,1 & 95,7 & 96,3 & 100,0 \\
\hline & XXVII & 90,5 & 93,6 & 93,8 & 85,4 & 94,2 & 96,3 & 95,7 & 99,2 & 100,0 \\
\hline & XXVIII & 90,0 & 93,2 & 93,0 & 84,4 & 95,0 & 96,6 & 98,3 & 100,0 & 99,8 \\
\hline & XXIX & 86,1 & 84,2 & 89,2 & 85,6 & 91,7 & 94,6 & 94,8 & 95,9 & 100,0 \\
\hline & $X X X$ & 90,3 & 92,9 & 93,3 & 85,5 & 95,3 & 100,0 & 94,7 & 99,3 & 98,7 \\
\hline & Média & 91,4 & 93,3 & 94,7 & 92,5 & 95,6 & 97,1 & 95,4 & 98,1 & 99,5 \\
\hline
\end{tabular}

A partir da Tabela 17, normalizada, pode-se confirmar aquilo que já foi visto na Tabela 15 , através de suas médias, e verificar, sem a interferência dos diferentes volumes de potencial de produção ou número de atividades do teste, que o resultado obtido pela HC2 é coerente tanto com o aumento/redução da flexibilidade quanto com o número de embarcações utilizadas. É possível verificar que, na maioria dos casos o melhor resultado é obtido com 6 PLSVs de alta flexibilidade. 
Pode-se, neste momento, também traçar um comparativo entre os resultados da HC1 e HC2 para este conjunto de 270 testes. A Tabela 18 apresenta a evolução percentual do volume de produção obtido através dos dois algoritmos.

Tabela 18 - Evolução percentual dos volumes de produção entre HC2 e HC1 nas instâncias com dados reais

\begin{tabular}{|c|c|c|c|c|c|c|c|c|c|c|}
\hline & & \multicolumn{9}{|c|}{ Cenários } \\
\hline & & \multicolumn{3}{|c|}{ Baixa flexibilidade } & \multicolumn{3}{|c|}{ Média flexibilidade } & \multicolumn{3}{|c|}{ Alta flexibilidade } \\
\hline & & 4 barcos & 5 barcos & 6 barcos & 4 barcos & 5 barcos & 6 barcos & 4 barcos & 5 barcos & 6 barcos \\
\hline \multirow{31}{*}{ 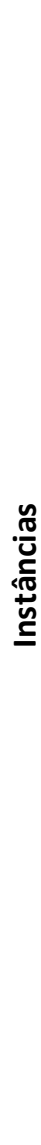 } & I & $-0,7 \%$ & $-1,2 \%$ & $-0,5 \%$ & $2,4 \%$ & $-0,7 \%$ & $2,8 \%$ & $3,5 \%$ & $2,3 \%$ & $1,2 \%$ \\
\hline & II & $4,9 \%$ & $-2,0 \%$ & $2,1 \%$ & $0,9 \%$ & $2,6 \%$ & $0,2 \%$ & $6,8 \%$ & $3,8 \%$ & $3,1 \%$ \\
\hline & III & $-3,1 \%$ & $-2,8 \%$ & $-2,1 \%$ & $2,9 \%$ & $-0,4 \%$ & $-1,4 \%$ & $0,9 \%$ & $-2,0 \%$ & $1,4 \%$ \\
\hline & IV & $-5,6 \%$ & $-0,2 \%$ & $-0,5 \%$ & $0,6 \%$ & $0,0 \%$ & $-1,1 \%$ & $-2,3 \%$ & $-0,2 \%$ & $1,1 \%$ \\
\hline & v & $2,4 \%$ & $-3,2 \%$ & $0,9 \%$ & $-0,3 \%$ & $0,0 \%$ & $0,1 \%$ & $3,7 \%$ & $-0,6 \%$ & $2,2 \%$ \\
\hline & VI & $-0,7 \%$ & $-2,8 \%$ & $-1,3 \%$ & $1,0 \%$ & $2,9 \%$ & $1,7 \%$ & $4,7 \%$ & $2,4 \%$ & $0,4 \%$ \\
\hline & VII & $-4,4 \%$ & $-4,5 \%$ & $-0,1 \%$ & $2,3 \%$ & $3,0 \%$ & $1,2 \%$ & $0,6 \%$ & $4,2 \%$ & $3,2 \%$ \\
\hline & VIII & $-1,7 \%$ & $-0,2 \%$ & $0,3 \%$ & $1,3 \%$ & $0,8 \%$ & $1,9 \%$ & $6,9 \%$ & $6,6 \%$ & $6,6 \%$ \\
\hline & IX & $1,9 \%$ & $0,3 \%$ & $4,3 \%$ & $4,0 \%$ & $3,8 \%$ & $4,3 \%$ & $2,9 \%$ & $6,3 \%$ & $4,7 \%$ \\
\hline & $x$ & $1,2 \%$ & $0,2 \%$ & $1,1 \%$ & $3,0 \%$ & $3,2 \%$ & $4,8 \%$ & $2,8 \%$ & $6,7 \%$ & $5,5 \%$ \\
\hline & $\mathbf{X I}$ & $0,0 \%$ & $0,2 \%$ & $2,1 \%$ & $0,4 \%$ & $7,4 \%$ & $8,0 \%$ & $7,7 \%$ & $10,6 \%$ & $8,5 \%$ \\
\hline & XII & $0,1 \%$ & $-0,6 \%$ & $2,3 \%$ & $-0,5 \%$ & $3,4 \%$ & $4,6 \%$ & $1,5 \%$ & $4,0 \%$ & $9,1 \%$ \\
\hline & XIII & $2,4 \%$ & $-1,3 \%$ & $1,8 \%$ & $-1,6 \%$ & $0,2 \%$ & $3,4 \%$ & $-0,7 \%$ & $4,9 \%$ & $2,8 \%$ \\
\hline & XIV & $-0,1 \%$ & $0,0 \%$ & $3,3 \%$ & $5,8 \%$ & $1,2 \%$ & $1,5 \%$ & $4,4 \%$ & $5,2 \%$ & $4,5 \%$ \\
\hline & $X V$ & $-1,8 \%$ & $0,2 \%$ & $-1,2 \%$ & $1,5 \%$ & $0,0 \%$ & $1,5 \%$ & $1,9 \%$ & $4,1 \%$ & $4,7 \%$ \\
\hline & XVI & $-1,0 \%$ & $-1,9 \%$ & $-0,5 \%$ & $3,8 \%$ & $3,7 \%$ & $2,8 \%$ & $1,6 \%$ & $-0,1 \%$ & $5,0 \%$ \\
\hline & XVII & $-2,2 \%$ & $-3,5 \%$ & $-1,8 \%$ & $0,9 \%$ & $-3,0 \%$ & $-0,7 \%$ & $3,6 \%$ & $2,1 \%$ & $2,0 \%$ \\
\hline & XVIII & $-0,8 \%$ & $-1,1 \%$ & $-3,1 \%$ & $3,2 \%$ & $1,4 \%$ & $1,7 \%$ & $2,3 \%$ & $1,3 \%$ & $4,3 \%$ \\
\hline & XIX & $-4,4 \%$ & $-2,7 \%$ & $-1,9 \%$ & $-1,0 \%$ & $-1,0 \%$ & $0,9 \%$ & $3,1 \%$ & $0,1 \%$ & $2,5 \%$ \\
\hline & $\mathbf{X X}$ & $5,1 \%$ & $5,3 \%$ & $3,6 \%$ & $7,2 \%$ & $1,7 \%$ & $8,7 \%$ & $3,5 \%$ & $12,9 \%$ & $8,3 \%$ \\
\hline & XXI & $5,9 \%$ & $4,6 \%$ & $4,5 \%$ & $2,2 \%$ & $8,2 \%$ & $7,0 \%$ & $3,9 \%$ & $7,5 \%$ & $5,8 \%$ \\
\hline & XXII & $5,9 \%$ & $5,6 \%$ & $2,7 \%$ & $3,8 \%$ & $6,5 \%$ & $8,6 \%$ & $2,2 \%$ & $5,3 \%$ & $11,3 \%$ \\
\hline & XXIII & $2,1 \%$ & $2,6 \%$ & $2,1 \%$ & $2,6 \%$ & $0,3 \%$ & $7,0 \%$ & $4,7 \%$ & $7,0 \%$ & $8,3 \%$ \\
\hline & XXIV & $3,9 \%$ & $3,9 \%$ & $2,5 \%$ & $1,9 \%$ & $4,5 \%$ & $4,5 \%$ & $6,6 \%$ & $8,8 \%$ & $10,5 \%$ \\
\hline & XXV & $6,6 \%$ & $4,2 \%$ & $3,2 \%$ & $5,0 \%$ & $5,5 \%$ & $7,3 \%$ & $4,7 \%$ & $4,3 \%$ & $8,8 \%$ \\
\hline & XXVI & $5,8 \%$ & $6,4 \%$ & $2,5 \%$ & $-1,9 \%$ & $1,2 \%$ & $0,7 \%$ & $1,9 \%$ & $1,4 \%$ & $5,0 \%$ \\
\hline & XXVII & $3,8 \%$ & $4,2 \%$ & $3,2 \%$ & $-0,8 \%$ & $0,4 \%$ & $1,7 \%$ & $1,6 \%$ & $3,7 \%$ & $3,2 \%$ \\
\hline & XXVIII & $1,4 \%$ & $1,3 \%$ & $4,2 \%$ & $-3,4 \%$ & $1,5 \%$ & $1,0 \%$ & $3,2 \%$ & $4,4 \%$ & $3,8 \%$ \\
\hline & XXIX & $1,9 \%$ & $1,1 \%$ & $3,2 \%$ & $-2,7 \%$ & $2,2 \%$ & $2,8 \%$ & $3,3 \%$ & $4,2 \%$ & $8,5 \%$ \\
\hline & XXX & $2,5 \%$ & $5,6 \%$ & $4,3 \%$ & $0,8 \%$ & $1,7 \%$ & $4,2 \%$ & $-0,1 \%$ & $3,9 \%$ & $2,6 \%$ \\
\hline & Média & $1,4 \%$ & $0,9 \%$ & $1,6 \%$ & $1,5 \%$ & $2,1 \%$ & $3,2 \%$ & $3,0 \%$ & $4,2 \%$ & $5,1 \%$ \\
\hline
\end{tabular}

Os percentuais apresentados na Tabela 18 versam sobre o incremento/decréscimo do volume de produção obtido com a aplicação da HC2 em comparação com a utilização da HC1. De modo geral, pode-se notar que houve uma evolução positiva nos resultados com a aplicação da HC2, sendo mais acentuada nos PLSVs de alta flexibilidade e menos relevante nas embarcações menos flexíveis. Houve apenas 60 reduções nos 270 testes. Ou seja, em 77,8\% dos testes efetuados, a solução da $\mathrm{HC} 2$ foi igual ou superior à da $\mathrm{HC} 1$. A maior redução foi de 5,6\% em uma instância de baixa flexibilidade e 4 PLSVs. O maior incremento foi de 12,9\%, em uma instância de alta 
flexibilidade e 5 PLSVs. Considerando todos os 270 testes realizados, o aumento médio percentual foi de 2,5\% no resultado global. Sendo assim, verifica-se que o algoritmo da HC2 mostra-se mais eficiente que o da HC1.

Para uma análise um pouco mais detalhada e para efeitos de comparativo com o que foi apresentado na HC1, a Tabela 19 apresenta os resultados da instância I, em seus cenários com utilização de 4 PLSVs, o mesmo exemplo que foi utilizado para análise anteriormente.

Tabela 19 - Detalhe dos resultados dos cenários de 4 PLSVs da instância I dos testes da HC2 com dados reais

\begin{tabular}{|c|c|c|c|c|c|c|c|}
\hline \multirow{3}{*}{ Atividade } & \multicolumn{2}{|c|}{ Baixa Flexibilidade } & \multicolumn{2}{|c|}{ Média Flexibilidade } & \multicolumn{2}{|c|}{ Alta Flexibilidade } & \multirow{3}{*}{ Tipo } \\
\hline & \multicolumn{6}{|c|}{ tempo (dias) } & \\
\hline & Fim Ativ & Fim poço & Fim Ativ & Fim poço & Fim Ativ & Fim poço & \\
\hline $\mathbf{0}$ & 36 & \multirow{3}{*}{127} & 115 & \multirow{3}{*}{118} & 56 & \multirow{3}{*}{102} & \multirow{3}{*}{ Prod } \\
\hline 1 & 95 & & 30 & & 36 & & \\
\hline 2 & 124 & & 91 & & 99 & & \\
\hline 3 & 52 & \multirow{3}{*}{55} & 59 & \multirow{3}{*}{62} & 55 & \multirow{3}{*}{58} & \multirow{3}{*}{ Prod } \\
\hline 4 & 23 & & 17 & & 19 & & \\
\hline 5 & 35 & & 31 & & 31 & & \\
\hline 6 & 83 & \multirow{3}{*}{86} & 77 & \multirow{3}{*}{80} & 38 & \multirow{3}{*}{93} & \multirow{3}{*}{ Prod } \\
\hline 7 & 62 & & 19 & & 23 & & \\
\hline 8 & 40 & & 58 & & 90 & & \\
\hline 9 & 149 & \multirow{3}{*}{152} & 130 & \multirow{3}{*}{133} & 130 & \multirow{3}{*}{133} & \multirow{3}{*}{ Inj } \\
\hline 10 & - & & - & & - & & \\
\hline 11 & 81 & & 63 & & 83 & & \\
\hline 12 & - & \multirow{3}{*}{107} & - & \multirow{3}{*}{45} & - & \multirow{3}{*}{48} & \multirow{3}{*}{ Inj } \\
\hline 13 & 16 & & 28 & & 23 & & \\
\hline 14 & 104 & & 42 & & 45 & & \\
\hline 15 & 96 & & 93 & & 111 & & \\
\hline 16 & - & 99 & - & 96 & - & 114 & Inj \\
\hline 17 & 69 & & 64 & & 70 & & \\
\hline 18 & 77 & & 119 & & 81 & & \\
\hline 19 & - & 80 & - & 122 & - & 84 & Inj \\
\hline 20 & - & & - & & - & & \\
\hline 21 & 64 & & 50 & & 46 & & \\
\hline 22 & - & 67 & - & 53 & - & 49 & Inj \\
\hline 23 & - & & - & & - & & \\
\hline 24 & 33 & & 41 & & 59 & & \\
\hline 25 & - & 36 & - & 44 & - & 62 & Prod \\
\hline 26 & 10 & & 11 & & 9 & & \\
\hline 27 & 18 & & 25 & & 25 & & \\
\hline 28 & 10 & 56 & 17 & 28 & 17 & 28 & Prod \\
\hline 29 & 53 & & 9 & & 9 & & \\
\hline 30 & 13 & & 8 & & 11 & & \\
\hline 31 & - & 16 & - & 11 & - & 14 & Inj \\
\hline 32 & - & & - & & - & & \\
\hline 33 & 117 & & 113 & & 113 & & \\
\hline 34 & - & 120 & - & 116 & - & 116 & Inj \\
\hline 35 & 15 & & 16 & & 12 & & \\
\hline
\end{tabular}


No comparativo dos resultados destas instâncias entre a $\mathrm{HC} 1$ e a $\mathrm{HC}$, esta última apresentou um resultado pior em termos de produção com os $P L S V s$ de baixa flexibilidade, mas nas demais apresentou desempenho superior. Porém, ao analisarmos o somatório de tempos de finalização das atividades, verifica-se melhorias em todas as instâncias: em baixa flexibilidade, havia um somatório de 1659 dias, e agora a soma é 1475; na média flexibilidade, o somatório era de 1390 dias, e agora a soma é 1326; na alta flexibilidade, era 1380 e na HC2 é 1291.

Isto indica que o algoritmo da HC2 está considerando uma antecipação das atividades como um todo. Através da Figura 17, que apresenta o Gráfico de Gantt desta mesma instância, é possível analisar de um modo mais acurado como o algoritmo está se comportando. 


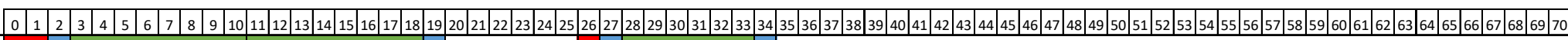

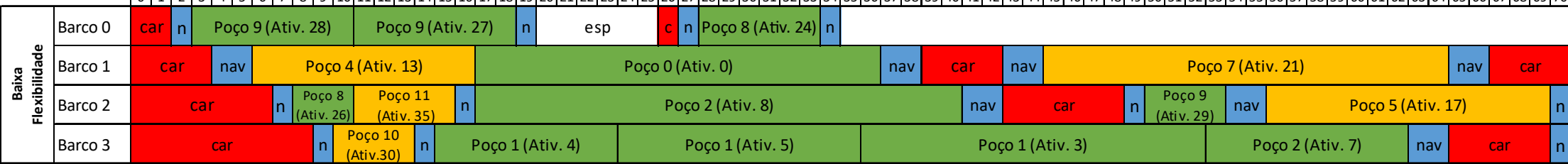

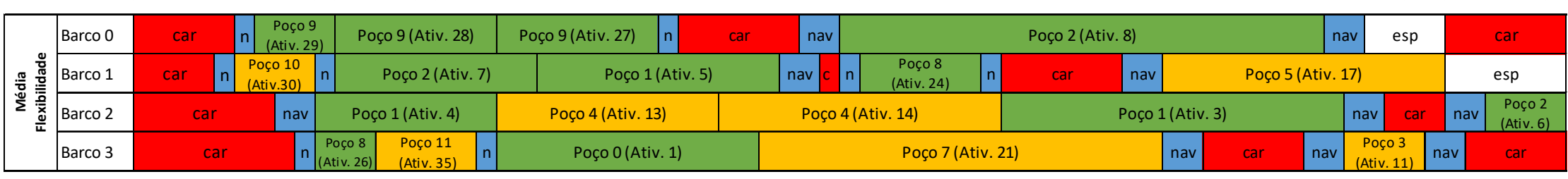

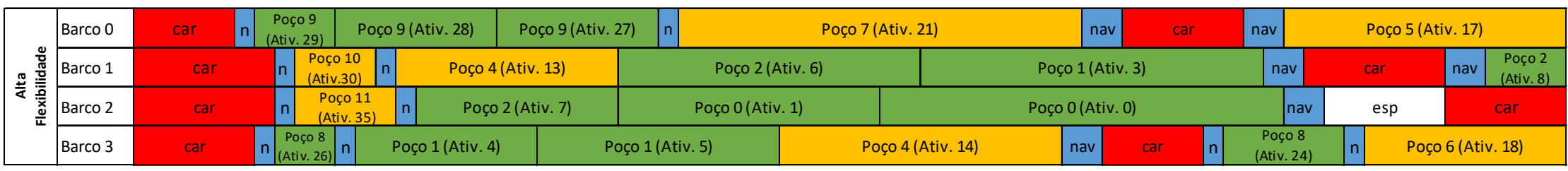

Atividade de poço produtor

Atividade de poço injetor

Atividade de navegação

Carregamento

Espera 
Quando se compara com o gráfico de Gantt originado para esta mesma instância na HC1 (Figura 15), observa-se que, conforme esperado, as primeiras atividades a serem alocadas são as de menor duração, o que está aderente com a nova lógica de priorização das atividades que possuem uma menor data fim de interligação. Nota-se também uma maior antecipação de atividades de poços produtores sendo que, considerando o recorte até o instante 70 , pode-se verificar que já há alguns poços com todas suas linhas interligadas, o que indica a possibilidade de iniciar a produção.

Ou seja, pode-se concluir que a HC2 trouxe ganhos relevantes em termos de aumento de volume de produção e redução da miopia da $\mathrm{HC} 1$, pois está tendo sucesso em antecipar um maior número de atividades e priorizando mais atividades produtoras. 


\section{Aplicação ao caso real}

\subsection{Aplicação das heurísticas construtivas ao conjunto completo de dados}

A última etapa de testes das heurísticas construtivas com dados reais foi realizada com um conjunto completo de atividades referentes ao período de um ano de interligações de novos poços e manutenções em poços da Bacia de Santos e de Campos. Há de se considerar que isto não engloba todas as atividades com a utilização de $P L S V$ dado que, algumas delas, não trazem ganho de óleo, como interligação de equipamentos, paradas programadas ou emergenciais das embarcações.

Sobre o processo de obtenção de dados, ele envolveu uma série de áreas internas da empresa. Dados técnicos das embarcações e de previsão de finalização da completação puderam ser coletados junto a sistemas da área de gestão de recursos críticos. Informações sobre viabilidade técnica dos PLSVs e previsão de duração das atividades puderam ser obtidas de sistemas das gerências de equipamentos submarinos. Já os dados sobre atividades de interligação, comprimento de linhas, tipos de poços, relação entre poços injetores foram coletados junto às gerências de projeto de desenvolvimento da produção de campos de petróleo. Já informações sobre a chegada das linhas na base de carregamento foram obtidas com a coordenação de contratação que atende a estes projetos. Potenciais de produção e de injeção bem como as estimativas de declínio foram obtidas com equipes que realizam o gerenciamento dos reservatórios. Os dados sobre os tempos de navegação entre os poços que atendem a diferentes plataformas ou entre a base de carregamento e os poços foram estimados com base na distância entre cada plataforma e as demais e entre a base de carregamento e cada plataforma. Para tal, utilizou-se uma velocidade média de navegação de um PLSV e, assim, obteve-se uma matriz de tempos entre as locações. Importante esclarecer que foi necessária a coleta de dados em dois cenários (previsto e realizado) para que pudesse ser realizado um adequado comparativo. Estas informações que foram citadas dizem respeito à previsão. Para elas, não é possível apresentar um formato único dos dados, pois cada área trabalha com os dados de um modo distinto.

Já aquelas sobre realização versam, especialmente, sobre as datas em que realmente ocorreram as atividades na prática. E tais dados de realização puderam ser acessados em sistema corporativo que traz o histórico de atividades com descrições dos poços e atividades. Em geral, os dados de realização trazem uma parcela dos dados de previsão acrescidos das datas efetivas nas 
quais ocorreram as atividades. A Tabela 20 apresenta um extrato do modelo de dados obtidos para a realização, com as principais informações necessárias.

Tabela 20 - Modelo de dados de realização das atividades com PLSVs

\begin{tabular}{|c|c|c|c|c|c|c|c|c|c|c|}
\hline $\begin{array}{c}\text { Nome da } \\
\text { locação }\end{array}$ & $\begin{array}{c}\text { Nome do } \\
\text { poço }\end{array}$ & $\begin{array}{c}\text { Tipo de } \\
\text { tarefa }\end{array}$ & Descrição & Duração & Data início & $\begin{array}{c}\text { Data } \\
\text { término }\end{array}$ & $\begin{array}{c}\text { Prefixo } \\
\text { recurso }\end{array}$ & $\begin{array}{c}\text { Tipo do } \\
\text { recurso }\end{array}$ & LDA & Bloco \\
\hline & & & & & & & & & & \\
\hline
\end{tabular}

Na Tabela 20, o significado prático de cada coluna é o seguinte:

- nome da locação: identificação de determinado poço para o projeto de desenvolvimento de produção recebendo, normalmente, um nome que identifica a parcela daquele campo e o tipo de poço. Pode ocorrer de o escopo do projeto ser alterado no seu decorrer mas manter o nome ou, então, alterar o nome do poço para o projeto mas o escopo continuar o mesmo;

- nome do poço: sigla do poço para aquele campo, normalmente, atribuído de forma contínua (sigla do campo acrescido de número sequencial). Normalmente esta nomenclatura é a conhecida pelo órgão regulador;

- tipo de tarefa: dado que este sistema do qual são extraídos os dados não trata apenas de atividades com PLSVs, este campo tem o intuito de informar se a atividade é uma interligação, manutenção, perfuração, completação ou outra que exija embarcações para sua realização. Neste trabalho, o interesse é, predominantemente, em atividades de interligação;

- descrição: breve descrição de qual é a atividade realizada. No caso de interligação, identifica qual o tipo de linha que está sendo lançada e em qual sentido (do barco para o poço ou do poço para o barco). Neste campo textual encontrou-se o principal problema. Por ser de livre escrita, era necessário realizar o filtro das informações além de contar com falta de informações que deveriam ser deduzidas a partir de outros campos da planilha ou de outras fontes de dados. Este mesmo problema ocorreu nas informações de previsão;

- duração: informa a duração da atividade de interligação em questão;

- data início e data término: datas de início da atividade de interligação em si e sua data final. Para os momentos de carregamento e navegação havia linhas separadas com a informação;

- prefixo do recurso: nome usual pelo qual é conhecido determinado recurso. Se contratado, normalmente, o nome que a embarcação recebe da própria empresa que está tendo seu recurso afretado; 
- tipo do recurso: diferentes tipos de embarcação que estão no cronograma. Em nosso caso, o interesse é apenas nas embarcações $P L S V$;

- LDA: lâmina d'água que, em geral, é um dos parâmetros que se observa para definir quais os recursos que serão viáveis tecnicamente;

- bloco: campo no qual as atividades estão sendo realizadas, ou seja, campo no qual determinado poço encontra-se.

O que deve ser salientado é que, além da dificuldade de obtenção dos dados devido ao grande número de atores envolvidos neste processo, houve necessidade de uniformizá-los, dado que cada área utiliza nomenclaturas diferentes para as atividades e poços. Algumas gerências utilizam o nome do poço para o campo, outros o nome do poço para o projeto, modos distintos de denominar as atividades ou, então, informações incompletas. Portanto, houve um intenso trabalho na coleta e manipulação de dados para que fosse possível concluir uma base de dados completa para ser utilizada neste trabalho.

Neste período de referência, havia atividades em 120 poços, totalizando 360 atividades sendo que, algumas delas são dummy pois pode haver poços que não exigem as 3 linhas por conta de já terem parte delas sido interligadas anteriormente ou por conta de ser alguma manutenção de linha necessária para que o poço volte a operar.

Na realização, o percentual de dias para os quais os $P L S V s$ realizaram atividades que não são consideradas de óleo foi de 13,9\% (697 dias em 5016 disponíveis). Foi utilizado um total de 14 barcos no caso real. Contudo, para expressar este volume de atividades, de modo a realizar a simulação do que aconteceria ao aplicarmos uma heurística construtiva, serão desconsideradas 13,9\% vezes 14 PLSVs, o que dá cerca de 2 PLSVs. Portanto, trabalhar-se-á com 12 PLSVs para realizar as alocações.

Para definir-se quais seriam os $P L S V s$ a serem desconsiderados, calculou-se uma proporção dos PLSVs existentes e aqueles que seriam utilizados. Dos 14 PLSVs de toda a frota, tem-se que 6 deles são considerados de alta flexibilidade (percentual de atendimento das atividades consideradas igual ou superior a 80\%), 5 deles são de média flexibilidade (aqueles que atendem a mais de $40 \%$ e a menos de $80 \%$ das atividades consideradas) e 4 deles são de baixa flexibilidade (aqueles que atendem a no máximo $40 \%$ das atividades do portfolio analisado).

A partir disto, foi realizada uma proporção com base nos 12 PLSVs que devem ser considerados para a frota. Ou seja, foram multiplicados os números de PLSVs de cada categoria 
pelo fator multiplicativo 12/14 (ou seja, aproximadamente 0,857) obtendo, assim, números fracionados. Através do arredondamento para o inteiro mais próximo, obtém-se uma quantidade de PLSVs que se deseja optando, deste modo, pela redução de um PLSV de alta flexibilidade e um de média flexibilidade. A Tabela 21 apresenta, resumidamente, o que se está abordando neste critério.

Tabela 21 - Número de PLSVs, por categoria, a serem utilizados na heurística construtiva

\begin{tabular}{|c|c|c|c|}
\cline { 2 - 4 } \multicolumn{1}{c|}{} & $\begin{array}{c}\text { Alta } \\
\text { flexibilidade }\end{array}$ & $\begin{array}{c}\text { Média } \\
\text { flexibilidade }\end{array}$ & $\begin{array}{c}\text { Baixa } \\
\text { flexibilidade }\end{array}$ \\
\hline Número de PLSVs original & 6 & 5 & 3 \\
\hline Fator (12/14) & \multicolumn{3}{c|}{0,857} \\
\hline Número de PLSVs aproximado & 5,1 & 4,3 & 2,6 \\
\hline Número de PLSVs arredondado & 5 & 4 & 3 \\
\hline
\end{tabular}

Dentro de cada classe de PLSVs, para que fosse feita a escolha de qual barco seria retirado da frota foi estabelecido o critério de retirada daquele que estivesse na mediana. Ou seja, na classe de média flexibilidade, por ter 5 PLSVs, o central em termos de flexibilidade (ou seja, o terceiro mais e menos flexível, concomitantemente) foi escolhido para ser retirado deste estudo. Para a frota de alta flexibilidade foi utilizado o mesmo critério. Por ter um número par de elementos, poderia haver algum critério de desempate. Porém os PLSVs que se encontravam em terceiro e quarto lugar (tanto para os mais e menos flexíveis) eram de especificação técnica igual. Portanto foi retirado um destes, dado que a escolha seria indiferente neste caso. Assim, chega-se aos PLSVs da frota que devem ser utilizados para realizar o teste com todo o portfolio de atividades.

Teve-se o cuidado de utilizar as mesmas premissas de adaptação de dados - aquelas utilizadas para manutenção da confidencialidade - nos dados de realização obtidos. Tomando por base as datas de término de cada uma das atividades, também se aplicam os valores fixos para comissionamento de poços ( 3 dias após a última atividade ser interligada), bem como os declínios constantes considerados, influência positiva dos poços injetores no potencial de produção e a ausência de paradas não-programadas para manutenção das unidades de produção que viessem a interferir no resultado. Assim, será possível traçar uma referência comparativa: qual o resultado obtido na realidade, com as premissas adaptadas versus o resultado quando se utiliza esta heurística construtiva sobre os dados planejados. 


\subsection{Comparação da HCl com o realizado}

Considerando-se o exposto na seção 6.1, pôde-se obter que o valor realizado de potencial de produção oriundo destas novas atividades de interligação é de 268,9 milhões de barris. E o valor que foi obtido através da aplicação do algoritmo da HC1 foi de 277,0 milhões de barris. Ou seja, nesta primeira heurística construtiva, ela demonstrou ser superior em 3,0\% ao valor realizado, quando igualadas as premissas, dentro deste período analisado. Vale ressaltar que houve aplicação de fator multiplicativo a alguns dados de entrada, para manutenção da confidencialidade dos mesmos, inclusive os de produção.

As Tabelas 22 e 23 apresentam as variações entre as datas e volume de potencial de produção anual dos poços entre o resultado da $\mathrm{HC1}$ e o valor realizado padronizado. Poços mensurados em atraso significam que a heurística finalizou estes poços com data mais tarde em relação ao resultado do caso real sob padronização. Do contrário, poços em antecipação são aqueles com data de finalização mais cedo do que o caso real padronizado. Ou seja, o comportamento de apresentar poços com datas antecipadas e com produção em acréscimo é aquele que valora a situação e garante o sucesso da heurística construtiva apresentada. Houve antecipação tanto de poços produtores quanto de injetores, com relevância de antecipações de grande porte (entrada do poço antecipada em mais de 60 dias). Isto reflete o fato de que, na situação realizada, havia uma maior dispersão nos instantes de conclusão das atividades de um mesmo poço, levando a ficarem prontos mais tarde.

Tabela 22 - Tabela de diferenças de datas de entrada dos poços - HC1 X Caso real

\begin{tabular}{|c|c|c|c|c|c|c|c|c|c|}
\hline & \multicolumn{4}{|c|}{ Atraso em relação ao real } & \multicolumn{4}{|c|}{ Antecipação em relação ao real } & \multirow{2}{*}{$\begin{array}{c}\text { Sem } \\
\text { alteração }\end{array}$} \\
\hline & Até 15 dias & $\begin{array}{c}\text { Entre } 16 \mathrm{e} \\
60 \text { dias }\end{array}$ & $\begin{array}{c}\text { Maior que } \\
60 \text { dias }\end{array}$ & Total & Até 15 dias & $\begin{array}{c}\text { Entre } 16 \mathrm{e} \\
60 \text { dias }\end{array}$ & $\begin{array}{c}\text { Maior que } \\
60 \text { dias }\end{array}$ & Total & \\
\hline Poços Produtores & 6 & 12 & 18 & 36 & 4 & 14 & 24 & 42 & 0 \\
\hline Poços Injetores & 2 & 2 & 7 & 11 & 5 & 5 & 21 & 31 & 0 \\
\hline Total & 8 & 14 & 25 & 47 & 9 & 19 & 45 & 73 & 0 \\
\hline
\end{tabular}


Tabela 23 - Tabela de diferenças de volume produzido - HC1 X Caso real

\begin{tabular}{|c|c|c|c|c|c|c|c|c|c|}
\cline { 2 - 10 } & \multicolumn{4}{c|}{ Redução (mil barris/ano) } & \multicolumn{3}{c|}{ Acréscimo (mil barris/ano) } & Sem \\
\cline { 2 - 10 } & Até $\mathbf{5 0 0}$ & $\begin{array}{c}\text { Entre } \mathbf{5 0 0} \mathbf{e} \\
\mathbf{3 0 0 0}\end{array}$ & $\begin{array}{c}\text { Maior que } \\
\mathbf{3 0 0 0}\end{array}$ & Total & Até $\mathbf{5 0 0}$ & $\begin{array}{c}\text { Entre } \mathbf{5 0 0} \mathbf{e} \\
\mathbf{3 0 0 0}\end{array}$ & $\begin{array}{c}\text { Maior que } \\
\mathbf{3 0 0 0}\end{array}$ & Total & alteração \\
\hline Poços Produtores & 6 & 20 & 10 & $\mathbf{3 6}$ & 6 & 27 & 9 & $\mathbf{4 2}$ & $\mathbf{0}$ \\
\hline
\end{tabular}

A HC1 também apresentou diferença de comportamento no perfil de entrada em operação dos poços no decorrer do ano. Para haver um incremento na curva de produção, é necessário que os poços operem pelo maior tempo possível no decorrer de determinado período de tempo. Porém, para que isto ocorra, é necessário que todas suas linhas sejam interligadas e não apenas parte delas. As Figuras 18 e 19 apresentam o comparativo entre os dados realizados e o comportamento desta heurística construtiva.

Figura 18 - Perfil de entrada em operação de poços produtores (Realizado x HC1)

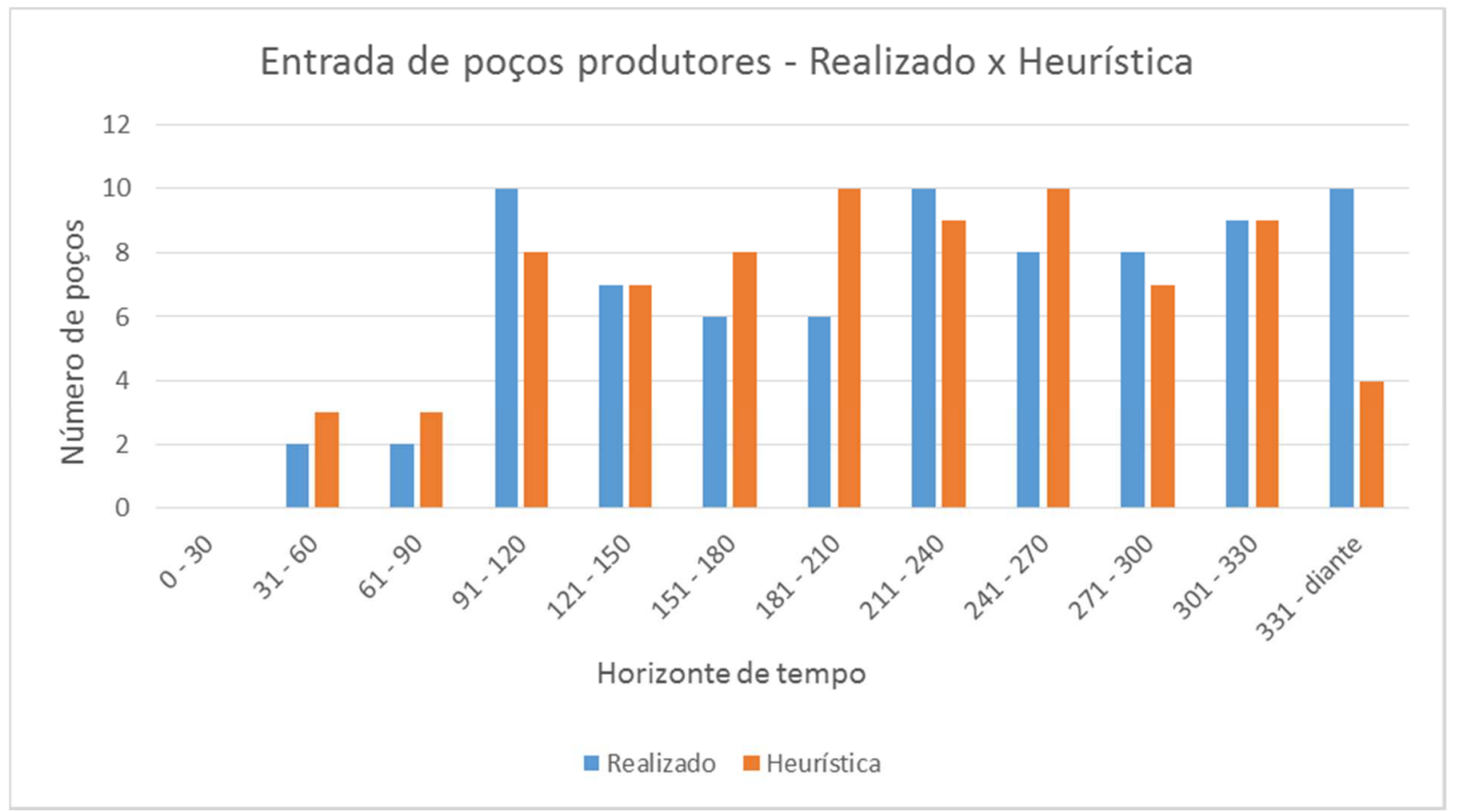


Figura 19 - Perfil de entrada em operação de poços injetores (Realizado x HC1)

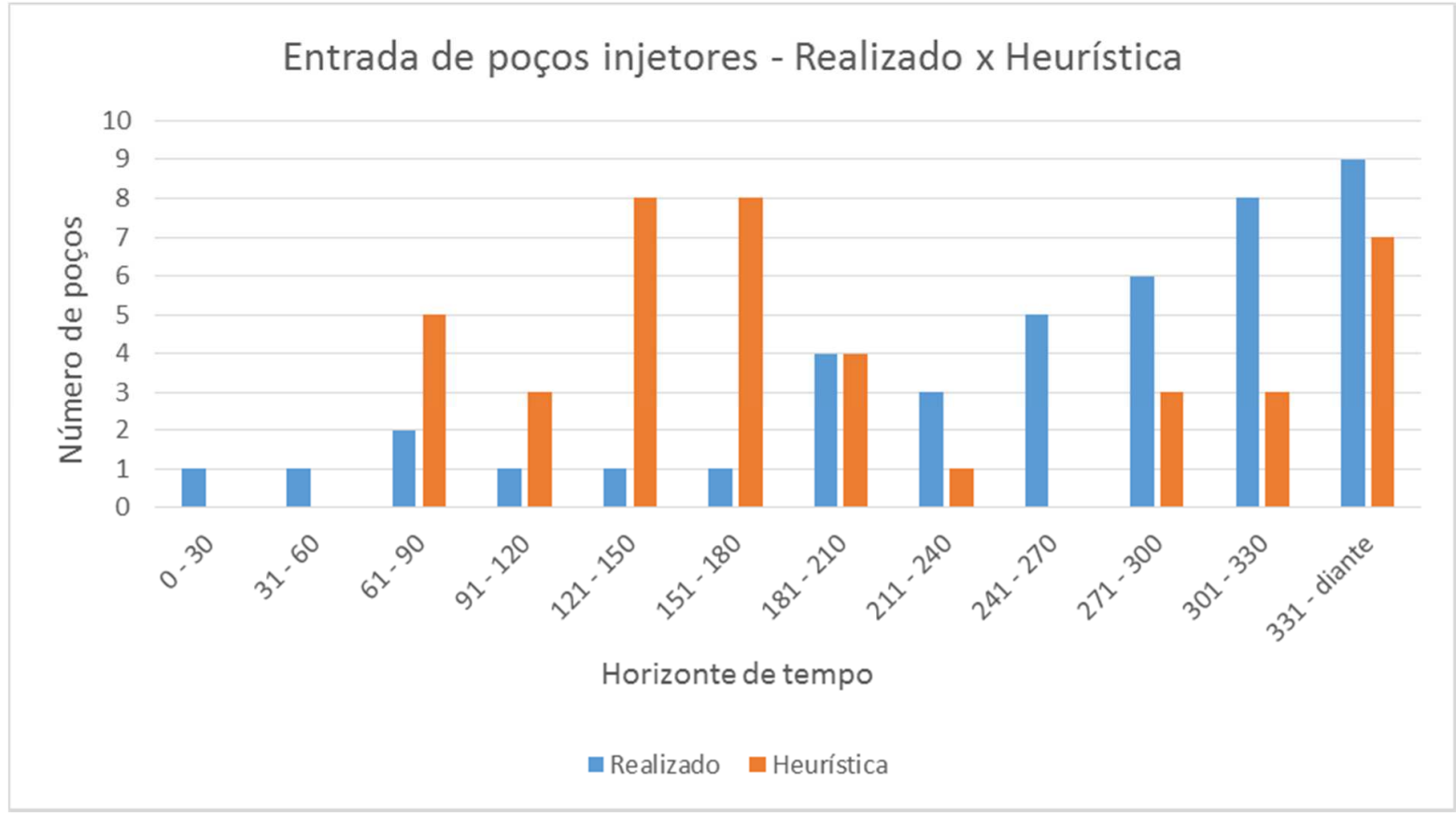

Na Figura 18, pode-se verificar uma sensível antecipação da entrada de poços produtores, especialmente nos $2^{\circ}$ e $3^{\circ}$ trimestres, onde reside o ganho da heurística dado que ocorre, ao fim do ano, de alguns poços não serem cumpridos dentro do prazo na versão realizada. Já na Figura 19, nota-se que houve uma intensa mudança no perfil dos poços injetores, com entradas irregulares e antecipadas. Isto condiz com a realidade dado que poços injetores contribuem menos para a curva de produção de óleo então são, normalmente, despriorizados. Outro fato é que poço injetor em operação antes do produtor atrelado, não possui serventia para incremento da curva de produção de óleo. Vale ressaltar aqui que, como há poços que possuem atividades dummy, algumas vezes uma ou duas linhas são suficientes para a contagem de um poço a mais em operação, dado que o que importa para a análise é a finalização total da interligação de suas linhas. 


\subsection{Comparação da HC2 com o realizado}

Após a obtenção do resultado da $\mathrm{HC} 1$, foram realizadas as melhorias apontadas na seção 5.4 deste trabalho, com vistas a obter um algoritmo mais robusto, a fim de incrementar o resultado. Assim, deu-se origem à heurística construtiva 2 (HC2). A aplicação de seu algoritmo ao mesmo conjunto completo de dados resultou em um valor de 283,1 milhões de barris no período, o que equivale a um aumento de 5,3\% com relação ao valor realizado (268,9 milhões de barris, de acordo com a seção 6.2) e 2,2\% superior ao valor encontrado pela HC1 (277,0 milhões de barris, de acordo com a seção 6.2). Aliado aos resultados obtidos nos testes intermediários, com instâncias menores, isto confirma que a estratégia $\mathrm{HC} 2$ traz relevantes ganhos para o caso em estudo. As Tabelas $24 \mathrm{e}$ 25 apresentam um resumo do comparativo entre o resultado da $\mathrm{HC} 2$ e o valor realizado.

Tabela 24 - Tabela de diferenças de datas de entrada dos poços - HC2 X Caso real

\begin{tabular}{|c|c|c|c|c|c|c|c|c|c|}
\cline { 2 - 11 } & \multicolumn{4}{c|}{ Atraso em relação ao real } & \multicolumn{4}{c|}{ Antecipação em relação ao real } & Sem \\
\cline { 2 - 11 } & Até $\mathbf{1 5}$ dias & $\begin{array}{c}\text { Entre } \mathbf{1 6} \mathbf{e} \text { e } \\
\mathbf{6 0} \text { dias }\end{array}$ & $\begin{array}{c}\text { Maior que } \\
\mathbf{6 0} \text { dias }\end{array}$ & Total & Até 15 dias & $\begin{array}{c}\text { Entre 16 e } \\
\mathbf{6 0} \text { dias }\end{array}$ & $\begin{array}{c}\text { Maior que } \\
\mathbf{6 0} \text { dias }\end{array}$ & Total & alteração \\
\hline Poços Produtores & 12 & 10 & 12 & $\mathbf{3 4}$ & 5 & 8 & 31 & $\mathbf{4 4}$ & $\mathbf{0}$ \\
\hline Poços Injetores & 2 & 5 & 11 & $\mathbf{1 8}$ & 5 & 6 & 13 & $\mathbf{2 4}$ & $\mathbf{0}$ \\
\hline Total & 14 & 15 & 23 & $\mathbf{5 2}$ & 10 & 14 & 44 & $\mathbf{6 8}$ & $\mathbf{0}$ \\
\hline
\end{tabular}

Tabela 25 - Tabela de diferenças de datas de volume produzido - HC2 X Caso real

\begin{tabular}{|c|c|c|c|c|c|c|c|c|c|}
\cline { 2 - 10 } & \multicolumn{4}{c|}{ Redução (mil barris/ano) } & \multicolumn{4}{c|}{ Acréscimo (mil barris/ano) } & Sem \\
\cline { 2 - 10 } & Até $\mathbf{5 0 0}$ & $\begin{array}{c}\text { Entre } 500 \mathrm{e} \\
\mathbf{3 0 0 0}\end{array}$ & $\begin{array}{c}\text { Maior que } \\
\mathbf{3 0 0 0}\end{array}$ & Total & Até $\mathbf{5 0 0}$ & $\begin{array}{c}\text { Entre } \mathbf{5 0 0} \mathrm{e} \\
\mathbf{3 0 0 0}\end{array}$ & $\begin{array}{c}\text { Maior que } \\
\mathbf{3 0 0 0}\end{array}$ & Total & alteração \\
\hline Poços Produtores & 13 & 10 & 11 & $\mathbf{3 4}$ & 5 & 27 & 12 & $\mathbf{4 4}$ & $\mathbf{0}$ \\
\hline
\end{tabular}

Entre os resultados obtidos pela $\mathrm{HC} 1$ e $\mathrm{HC} 2$, na Tabela 24, pode-se notar que houve um menor número de poços antecipados na HC2 (68 poços antecipados versus 73 na HC1), porém houve uma antecipação maior de poços produtores (44 poços na $\mathrm{HC} 2$ versus 42 poços na $\mathrm{HC} 1$ ) que, efetivamente, fazem a função objetivo ser mais valorada. Já a Tabela 25 nos apresenta que, além de a $\mathrm{HC} 2$ antecipar mais poços produtores, o impacto dos poços antecipados foi de um acréscimo relevante, com crescimento dos poços que contribuíram para a curva anual de produção com mais de 3 milhões de barris no ano. 
Sendo assim, a estratégia de considerar como critério de alocação as atividades que tivessem a data fim de interligação mais cedo apresentou-se consistente, dado que isso leva a uma conclusão mais precoce de tarefas curtas, o que leva a um encurtamento do prazo de entrada em produção ao fim da interligação de todas as linhas daquele poço.

Todos os procedimentos referentes a heurísticas foram programados e rodados em um computador HP Pavilion, de processador Intel Celeron, $2.13 \mathrm{GHz}, 4 \mathrm{~Gb}$ de memória RAM. O tempo de processamento da $\mathrm{HC} 1$ foi de cerca de $3,2 \mathrm{~s}$ e da $\mathrm{HC} 2$, de cerca de 8,0s.

As Figuras 20 e 21 apresentam o perfil de entrada dos poços, separadamente, produtores e injetores para melhor visualização do efeito de ambas heurísticas, na versão acumulada.

Figura 20 - Perfil acumulado de entrada em operação de poços produtores (Realizado x HC1 x HC2)

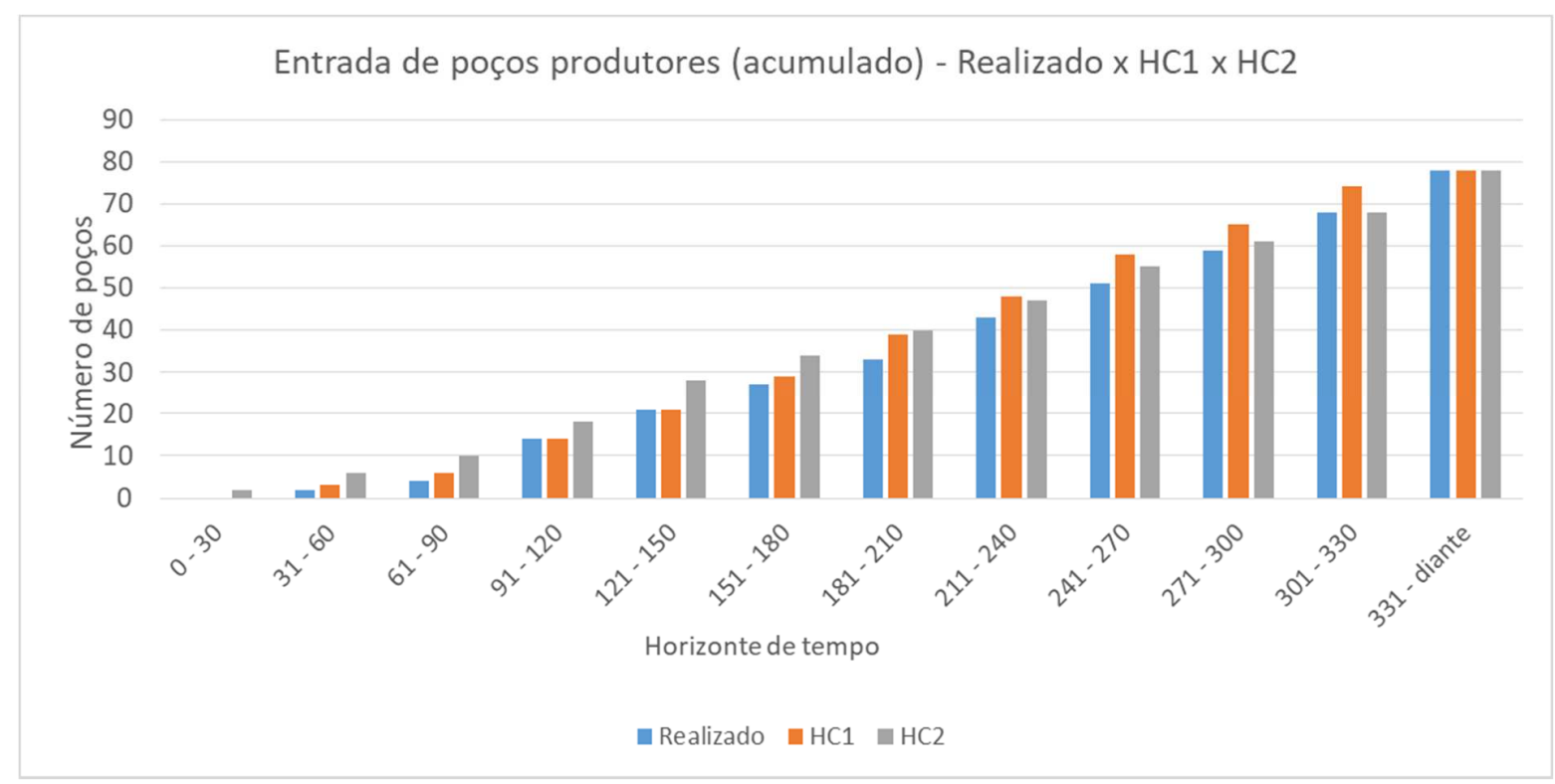


Figura 21 - Perfil acumulado de entrada em operação de poços injetores (Realizado x HC1 x HC2)

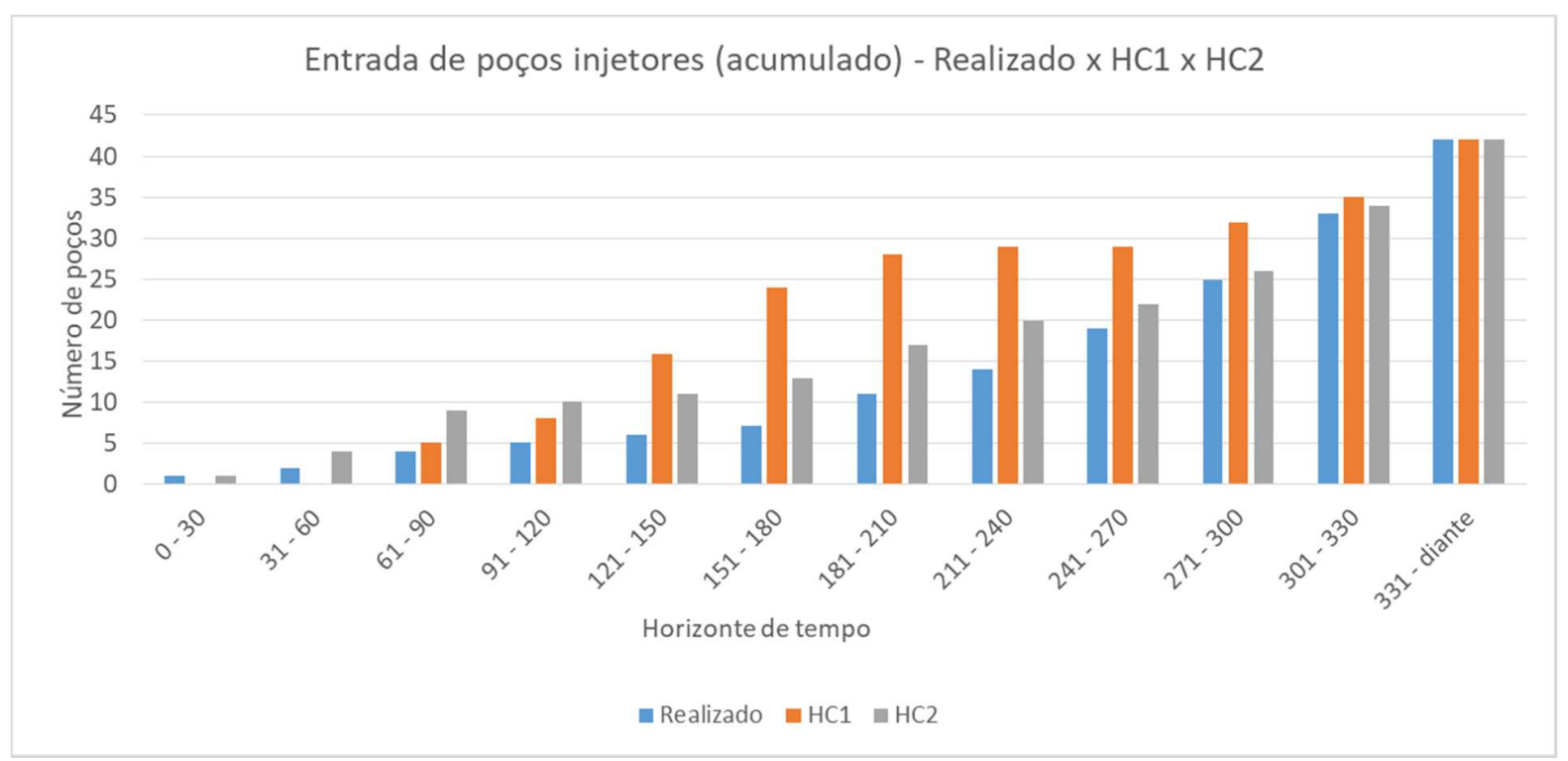

A Figura 20 expõe que a $\mathrm{HC} 2$ promoveu um aumento do número de poços produtores que foram interligados precocemente, enquanto a $\mathrm{HC} 1$ promovia um período de interligação mais forte nos meses do $2^{\circ}$ e $3^{\circ}$ trimestre do período analisado. $\mathrm{O}$ conceito de interligar atividades mais curtas, de fim de interligação mais cedo, é o principal fator para a obtenção deste resultado. Outro fator que ajuda a explicar, em um segundo plano, é a inserção da rotina prévia que analisa se a antecipação da segunda atividade contribui mais para a curva de produção de óleo que a primeira da listagem.

Pode-se verificar na Figura 21 que, enquanto a $\mathrm{HC} 1$ antecipou bastante as atividades de poços injetores, a $\mathrm{HC} 2$ as antecipou de um modo mais sutil. A mudança de lógica da heurística sugere que esta alteração é consequência das atividades injetoras não contribuírem em grande valor com a função objetivo. Por mais que sejam atividades que possam ter sua liberação mais cedo, elas são atividades que possuem uma duração da interligação maior o que, nesta nova lógica da heurística, lhe dá uma prioridade menor para antecipação da interligação. $\mathrm{Na} \mathrm{HC1}$ a lógica principal era a data de prontidão, o que explica o comportamento diferenciado. 
Outra visão interessante de ser avaliada é a evolução da curva de produção de óleo no decorrer do tempo analisado, nos casos realizado, HC1 e HC2. Estes dados são apresentados na Figura 22, que versa sobre a produção acumulada a cada período considerado.

Figura 22 - Perfil acumulado de curva de produção, por período avaliado (Realizado x HC1 x HC2)

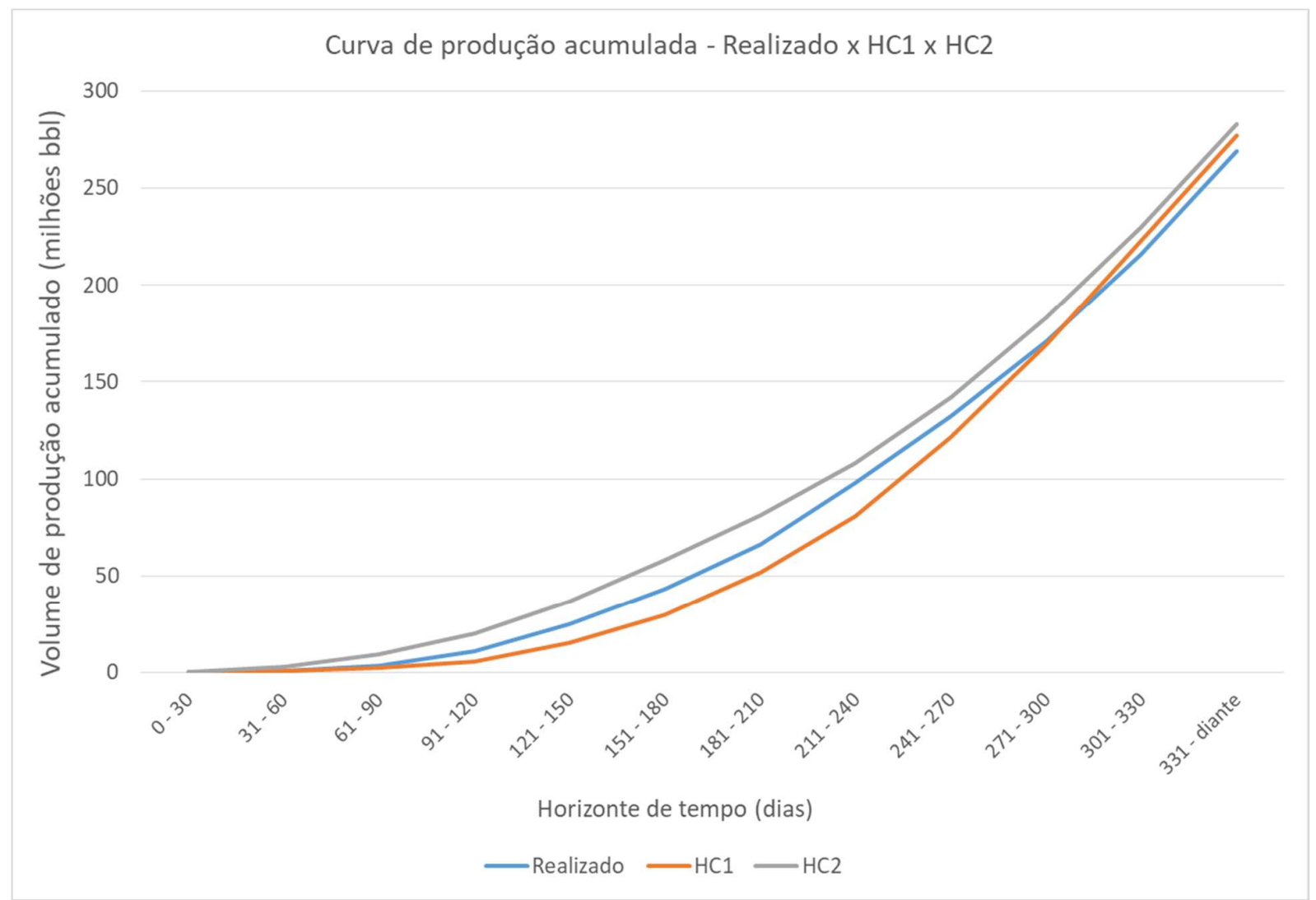

Interessante avaliar, na Figura 22, que o comportamento da produção está associado, fortemente, com o perfil de entrada dos poços produtores. Enquanto a $\mathrm{HC} 2$ possui entrada de poços produtores antecipada desde o começo do período de avaliação - o que leva a curva de produção acumulada estar todo o tempo acima da curva de realização -, a $\mathrm{HC} 1$, nesta visão acumulada, apresenta-se abaixo da linha de realização durante grande parte do tempo avaliado. A HC1 apresenta-se melhor que a visão realizada nos últimos períodos, resultado do maior número de poços produtores entrando em operação, em especial no $3^{\circ}$ trimestre do período avaliado, como apresenta a Figura 18. A partir deste período, pode-se notar que a inclinação do gráfico da HC1 fica mais acentuado do que a inclinação da curva de realização, ressaltando o incremento mais 
avançado neste horizonte de tempo. Esta curva de produção da Figura 22 também conversa diretamente com os resultados apresentados na Figura 20, com a entrada acumulada de poços produtores no decorrer do tempo.

Importante salientar que estes resultados são uma referência da eficácia das heurísticas. Porém, há que se ter em mente que há uma série de fatores que podem contribuir para alterações do resultado, tais como: as durações das tarefas entre o planejado e a realização pois, na prática, elas podem ter uma variação de duração a maior ou a menor a depender de condições de mar; na prática, podem ocorrer problemas relacionados à disponibilidade dos materiais para interligação ou, ainda, nas etapas de construção do poço, impactando na data final de sua completação; podem ocorrer problemas operacionais nas plataformas e poços, o que reduziriam sua produção e, por se estar trabalhando com volumes de potencial de produção, isto foi desconsiderado - ou seja, está se trabalhando com um cenário ideal; os valores de declínio e de acréscimo por poço injetor são valores estimados e que, na vida prática, podem variar quando verifica-se a real condição de operação do poço. O declínio constante de produção apresenta uma boa aproximação com a realidade, porém podem ocorrer flutuações não tão lineares na taxa de produção, efetivamente. Sendo assim, é de suma importância trabalhar com premissas niveladas e consistentes entre os casos que se está comparando para apurar com acurácia os resultados obtidos.

Um resultado de acréscimo de até 5,3\% no potencial de produção destes novos poços durante o período analisado apresenta-se de grande relevância ainda mais quando se retoma a justificativa deste projeto, que aborda os montantes com os quais se lida na indústria de petróleo. Vale ressaltar também que isto não implica em um aumento de mesma proporção na curva de óleo da companhia, dado que se está falando apenas deste conjunto de poços que necessitaram de interligação no período de referência, sem considerar os poços que já estavam em produção. 


\section{Conclusões e futuras pesquisas}

Este trabalho abordou o processo de interligação de poços de petróleo a unidades produtoras offshore, ou seja, em pleno alto-mar. Dado o crescimento da produção de petróleo brasileiro em ambiente marítimo e, em especial, à contribuição de poços da camada pré-sal neste resultado, é bastante relevante que sejam realizados estudos com vistas à caracterização e busca de melhorias para o processo.

Através da apresentação de características e fases de um projeto de petróleo típico bem como as áreas técnicas que o compõem, foi possível compreender a complexidade existente desde os estudos geológicos até a entrada em produção dos poços de petróleo após a interligação de cada duto com as embarcações do tipo $P L S V$. É necessária uma estratégia bem fundamentada para que o capital investido seja o melhor possível empregado.

Dado que este é um problema de alta combinatoriedade e que possui uma série de restrições práticas em uma situação a qual se deseja otimizar, fica caracterizada a relevância da aplicação de métodos de otimização para sua resolução. E, para tal, quanto melhor o problema for estudado com base na literatura existente, mais avanços podem ser trazidos não apenas em termos de auxílio na resolução, mas também no desenvolvimento de formulações apropriadas para características inovadoras. Este problema diferencia-se dos demais já apresentados na literatura por trazer a questão do declínio dos poços produtores e a contribuição dos poços injetores a partir do momento que estes também são interligados.

No decorrer do trabalho, foi percorrido um caminho de gradativo desenvolvimento, iniciando com a formulação matemática, que levou aos resultados ótimos para os testes de pequenas instâncias, que demonstraram a pertinência da formulação à situação descrita. Após isto, para resolver instâncias maiores, valeu-se da elaboração de duas heurísticas construtivas chamadas de $\mathrm{HC} 1$ e $\mathrm{HC} 2$-, que se aproveitaram das características e restrições gerais do problema para estabelecer um procedimento de ordenação que resultaram em uma melhoria expressiva de, respectivamente, $3,0 \%$ e 5,3\% no potencial de produção adicionado por estes poços no decorrer deste período analisado quando comparado à situação real. Lembrando que houve também uma fase de testes das heurísticas construtivas com dados de casos reais, mas em problemas de pequenas instâncias para que o comportamento de cada heurística fosse validado. 
Sendo assim, pôde-se comprovar que a aplicação de técnicas de Pesquisa Operacional são de fundamental importância para retratar de maneira fidedigna as restrições e peculiaridades do problema abordado. Também foi possível apresentar e modelar de maneira mais realista uma formulação matemática que engloba novas características técnicas da situação-problema, embora de forma aproximada, com um expressivo resultado.

Como futuras pesquisas deste trabalho, sugere-se que o estudo seja evoluído para uma estratégia de busca em vizinhança que seja capaz de investigar permutas de atividades após a alocação inicial que é sugerida pelas heurísticas construtivas. Por ser um problema que conta com um grande número de restrições, elaborar um procedimento avançado representa um grande desafio pois a solução pode perder suas características de factibilidade facilmente. Outra sugestão é realizar análises de cenários com alterações de quantidades de projetos e PLSVs, indicando também um tratamento probabilístico para a questão, tendo em vista que incertezas na duração das atividades tais quais causadas por condições marítimas, nem situações de quebras de embarcações ou indisponibilidades operacionais não foram contempladas neste trabalho. Outro fator que pode ser considerado é a restrição de número máximo de $P L S V s$ simultâneos sendo carregados na base, o que pode levar a um tempo de ociosidade do PLSV enquanto espera a operação de carregamento das linhas do próximo roteiro a ser executado.

Portanto, vê-se que a indústria petrolífera - na qual os montantes de investimento são elevados devido à extremidade tecnológica na qual se trabalha - pode ser auxiliada por técnicas e estudos aprofundados de otimização, dado que existem uma série de recursos trabalhando concomitantemente e essa gama de atividades deve ser sincronizada de modo sinérgico, ou seja, visando à maximização da utilização dos recursos envolvidos. 


\section{Referências Bibliográficas}

ANP. Anuário Estatístico Brasileiro do Petróleo, Gás Natural e Biocombustíveis 2017. Disponível em:

$<$ http://www.anp.gov.br/wwwanp/publicacoes/anuario-estatistico/3819-anuario-estatistico-2017 $>$. Acesso em 14/06/2017.

ANP. Contrato de concessão para exploração, desenvolvimento e produção de petróleo e gás natural. Disponível em: <www.anp.gov.br/?dw=44956>. Acesso em: 11/10/2014.

ARENALES, M.; ARMENTANO, V.; MORABITO, R.; YANASSE, H. Pesquisa Operacional. Editoria Elsevier. Rio de Janeiro, 2007.

ASSIS, L. S.; CAMPONOGARA, E. A MILP model for planning the trips of dynamic positioned tankers with variable travel time. Transportation Research, Part E, v. 93, p. 372-388, 2016.

AZI, N.; GENDREAU, M.; POTVIN, J. An exact algorithm for a single-vehicle routing problem with time windows and multiple routes. European Journal of Operational Research, v. 178, p. 755-766, 2007.

AZI, N.; GENDREAU, M.; POTVIN, J. An adaptive large neighborhood search for a vehicle routing problem with multiple trips. European Journal of Operational Research, 202, p.756-76, 2010.

BALLOU, R. H. Gerenciamento da Cadeia de Suprimentos / Logística Empresarial. $5^{\text {a }}$ ed. Bookman. Porto Alegre, 2004.

BELFIORE, P. P. Scatter Search para Problemas de Roteirização de Veículos com Frota Heterogênea, Janelas de Tempo e Entregas Fracionadas. Tese de Doutorado - Escola Politécnica, Universidade de São Paulo. São Paulo, 2006.

BIANCO, B. P.; GOMES, C. F. S.; CHAVES, M. C. C. Simulação e otimização de logística de embarcações para conexão de poços do Pré-Sal. XLVI Simpósio Brasileiro de Pesquisa Operacional, 2014.

BNDES. BNDES 60 anos: perspectivas setoriais. BNDES, 2012.

BREJON, S. R. C.; BELFIORE, P. P. A importância do enfoque sistêmico para problemas de roteirização de veículos. Revista Pesquisa e Desenvolvimento Engenharia de Produção, n. 5, p. 64-86, 2006.

BREMENKAMP, L. H.; CUNHA, V. A. C.; HAMACHER, S.; PESSÔA, L. S.; RIBAS, P. C. Modelo de Programação Matemática para apoio à decisão da programação de embarcações PLSV. XLVIII Simpósio Brasileiro de Pesquisa Operacional, 2016.

CATTARUZZA, D.; ABSI, N.; FEILLET, D.; VIDAL, T. A memetic algorithm for the Multi Trip Vehicle Routing Problem. European Journal of Operational Research, 236, p. 833-848, 2014. 
CHRISTIANSEN, M.; FAGERHOLT, K.; NYGREEN, B.; RONEN, D. Ship routing and scheduling in the new millennium. European Journal of Operational Research, v. 228, p. 467$483,2013$.

CHRISTOFIDES, N.; EILON, S. An algorithm for the vehicle-dispatching problem. Operational Research Quaterly, 20, n. 3, p. 309-318, 1969.

CLARKE, G.; WRIGHT, J.W. Scheduling of vehicles from a central depot to a number of delivery points. Operations Research, v.12, p. 568-581, 1964.

DANTZIG G. B.; RAMSER J. H. The truck dispatching problem. Management Science, v. 6, n. 1, p. 80-91, 1959.

DREXL, M. Rich vehicle routing in theory and practice. Logistics Research, v. 5, issue 1, p. 4763, 2012.

DULLAERT, W., JANSSENS, G. K., SORENSEN, K.,VERNIMMEN, B. New heuristics for the fleet size and mix vehicle routing problem with time windows. Journal of Operational Research Society, v. 53, p. 1232-1238, 2002.

FISHER. M.; JAIKUMAR, R.; A Generalized Assignment Heuristics For Vehicle Routing. Networks, v.11, n.2, p. 109-124, 1981.

FLEISCHMANN, B. The vehicle routing problem with multiple use of vehicles. Working Paper, Fachbereich Wirtschaftswissenschaften, Universität Hamburg, Germany, 1990.

FLOOD, M. M. The Traveling-Salesman Problem. Operations Research, v. 4, n. 1, p. 61-75, 1956.

GIROUDEAU, R.; NAUD, O.; HERNANDEZ, F.; FEILLET D. A new exact algorithm to solve the multi-trip vehicle routing problem with time window and limited duration. Laboratiore d'informatique, de robotique et de microélectronique de Montpellier, 2011.

GOLDBARG, M.C.; LUNA, H.P.L. Otimização Combinatória e Programação Linear Modelos e Algoritmos. Rio de Janeiro: Editora Elsevier, 2005.

GOLDEN, B.L.; ASSAD, A.; LEVY, L.; GHEYSENS, F. The fleet size and mix vehicle routing problem. Computers \& Operations Research, v.11, n.1, p. 49-66, 1984.

HENNIG, F.; NYGREEN, B.; CHRISTIANSEN, M.; FAGERHOLT, K.; FURMAN, K.C.; SONG, J.; KOCIS, G. R.; WARRICK, P.H. Maritime crude oil transportation - a split pickup and split delivery problem. European Journal of Operational Research, v. 218, p. 764-774, 2012.

HENNIG, F.; NYGREEN, B.; FURMAN, K. C.; SONG, J. Alternative approaches to the crude oil tanker routing and scheduling problem with split pickup and split delivery. European Journal of Operational Research, v. 243, p. 41-51, 2015. 
LEE, J.; KIM, B. Industrial ship routing problem with split delivery and two types of vessel. Expert System with Applications, v. 42, p. 9012-9023, 2015.

MOURA, V. C. Programação de frota de embarcações de lançamento de dutos. Dissertação de Mestrado - Escola Politécnica, Universidade de São Paulo. São Paulo, 2012.

NEVES, M. L.; LAZZARINI, A. L.; BRANDÃO, A. L. S.; CASTRO, J. F. T. Alocação de equipamentos críticos em projetos de produção de petróleo offshore. Simpósio Brasileiro de Pesquisa Operacional, 2012.

NISHI, T.; IZUNO, T. Column generation heuristics for ship routing and scheduling problems in crude oil transportation with split deliveries. Computers and chemical engineering, v. 60, p. 329$338,2014$.

PEREIRA, R. A. Escalonamento de atividades de desenvolvimento de poços de petróleo: GRASP. Dissertação de Mestrado - Instituto de Computação, Universidade Estadual de Campinas. Campinas, 2005.

PEREIRA, R. A.; MOURA, A. V.; SOUZA, C. C. Comparative Experiments with GRASP and Constraint Programming for the Oil Well Drilling Problem. Nikoletseas S.E. Experimental and Efficient Algorithms. Lecture Notes in Computer Science, v. 3503, p. 328-340. Berlin, 2005b.

PEREIRA, R. A.; MOURA, A. V.; SOUZA, C. C. Grasp strategies for scheduling activities at oil wells with resource displacement. Relatório técnico Instituto de Computação da UNICAMP. Disponível em:< http://www.ic.unicamp.br/ reltech/2005/05-28.pdf>. Acesso em 19/06/2017. Campinas, 2005c.

RODRIGUES, V. P.; MORABITO, R.; YAMASHITA, D.; SILVA, B. J. V.; RIBAS, P. C. Abordagens de otimização para um problema de roteirização e programação de navios petroleiros. Gestão \& Produção, v. 24, n. 4, p. 790-805. São Carlos, 2017.

SILVA, B. N.; GOMES, L. L.; MEDEIROS, R. L. Análise de risco de projetos de desenvolvimento da produção marítima de petróleo: um estudo de caso. Brazilian Business Review, v.3, n.2, p. 229-244, 2006.

SILVA, T. S. A. Programação por restrições e escalonamento baseado em restrições: um estudo de caso na programação de recursos para o desenvolvimento de poços de petróleo. Dissertação de Mestrado - Instituto de Matemática e Estatística, Universidade de São Paulo. São Paulo, 2012.

SINAVAL. PLSV Skandi Açu é batizado na Noruega. Disponível em: < http://sinaval.org.br/2016/04/plsv-skandi-acu-e-batizado-na-noruega/> . Acesso em: 26/10/2017.

SOARES, J. B. C. O.; LEITE, L. S. B. S. Transporte marítimo de carga na Bacia de Campos: uma abordagem por clusterização capacitada e roteirização de embarcações. XLVI Simpósio Brasileiro de Pesquisa Operacional, 2014. 
SOLOMON, M. M. Algorithms for the vehicle routing and scheduling problems with the time window constraints. Operations Research 35, p. 254-265, 1987.

TAILLARD, E. D.; LAPORTE, G.; GENDREAU, M. Vehicle routing with multiple use of vehicles. Centre de recherché sur les transports. Université de Montréal, 1995.

TOTH, P., VIGO, D. The Vehicle Routing Problem. Society for Industrial and Applied Mathematics, Philadelphia, 2002. 